\title{
One and the Same? An Exploration into Two Common Ideological Motivations for Lone-Actor Terror Attacks in the West Between 2010-2017
}

By

Tylah Brooke Fitzgerald

A thesis submitted to Victoria University for fulfilment for the requirements for a degree in Master of Arts in Criminology

Institute of Criminology

Victoria University of Wellington 


\section{Abstract}

Islamic extremism (IE) and right-wing extremism (RWE) are the two most common ideological motivations for perpetrating lone-actor terrorism in the West. This study explored the similarities and differences of these ideologies by coding for specific attack and personal characteristics of attacks that occurred between 2010-2017 in Western Europe, Australia, and North America. Lone-actor terrorism included attacks perpetrated by individuals, as well as isolated dyads and triads. A codebook was developed to capture the attack and personal characteristics, and data was obtained from media and other open-source reporting. The dataset included a total of 99 cases perpetrated by 102 individual actors. The study found that lone-actor attacks perpetrated by IE and RWE had increased significantly over the time period studied. Some key significant differences were found: IE were more likely to be an immigrant to the country of attack they were born in, were more likely to target civilians, and their plots or extremist activity were more visible to law enforcement and intelligence agencies, while RWE were more likely to be single, more likely to target social minorities less likely to have experienced tertiary level education or higher, less likely to have children, and are significantly older than IEs. However, for the majority of variables there were no significant differences between IE and RWE, including variables that may indicate strain in a perpetrator's life (mental health, social isolation and experience of stressful events), indicating that overall the attacks perpetrated by individuals of the two ideologies share more commonalities than differences. 


\section{Acknowledgements}

Firstly, I would like to thank my supervisor Dr. Russil Durrant, for all the support provided to me throughout my research. Your advice was invaluable in shaping my research and undertaking the analysis, and your clear directions helped me to effectively plan out how my research would be undertaken. As a returning student after an absence of two years, and my decision to undertake this research part-time while staying employed, your support helped me to stay focused and motivated throughout the entire research and writing process. Your enduring patience and flexibility with meeting times and providing timely feedback was extremely appreciated, especially towards the end of my thesis. I know that this thesis would not have been possible without your support, and I am eternally grateful.

Secondly, I want to thank my employer for supporting and encouraging my decision to go back to study while retaining my job. This support allowed me to return to study without any financial impediments, and I was also extremely grateful for the paid leave given to me that allowed me to focus on my study. To those in my direct management chain, I am especially appreciative for the flexibility you provided to me with working hours, which allowed me to take more time off to focus on research when I was especially busy.

Finally, I want to say thank you to my friends, family and flatmates for the support given to me throughout the thesis period. From allowing me to talk about my thesis, to offers to proof-read my final copy, I am so grateful for all the ways you have showed your friendship to me during this time. 


\section{Table of Contents}

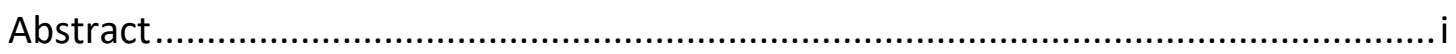

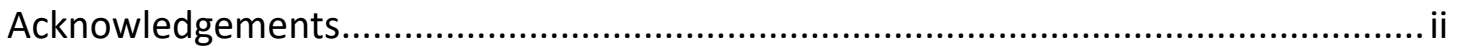

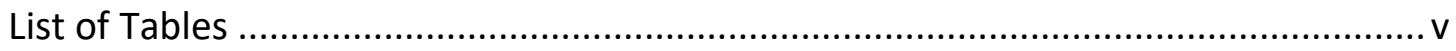

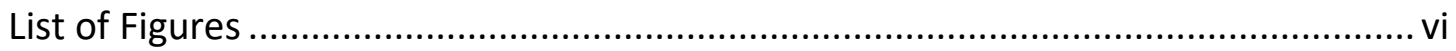

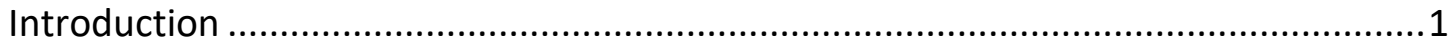

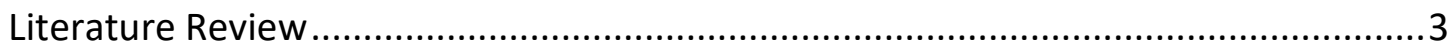

The Nature and Extent of Lone-Actor Terrorism .................................................

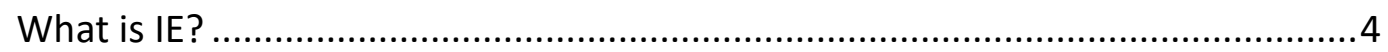

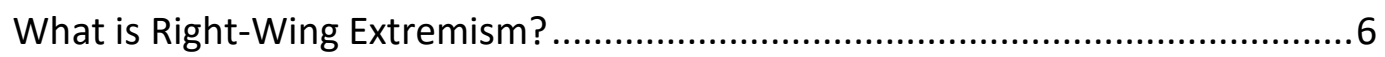

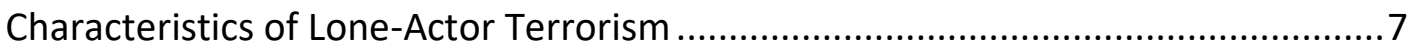

Biographical Variables .............................................................................

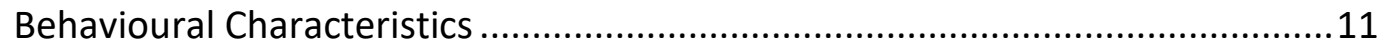

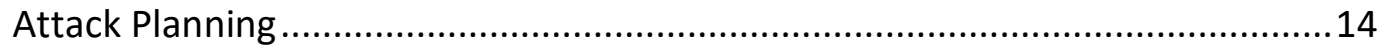

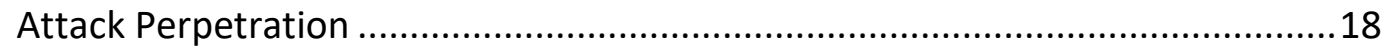

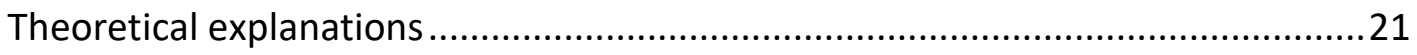

Theoretical Explanations for Lone-Actor Terrorism .......................................22

Theoretical Explanations and Ideological Motivations .......................................25

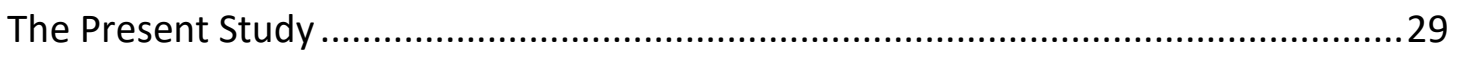

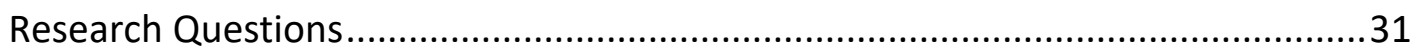

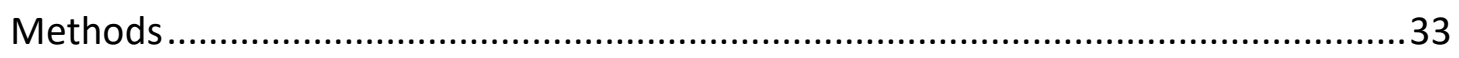

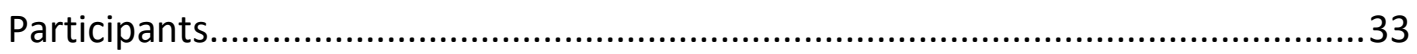

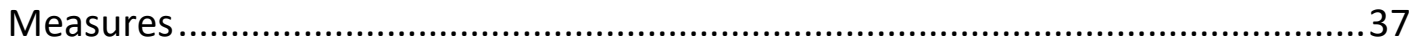

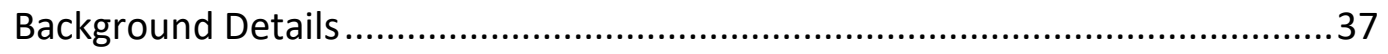

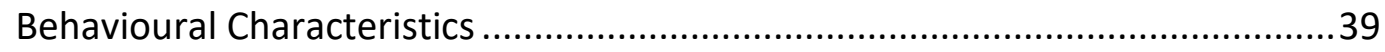

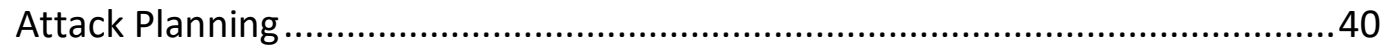




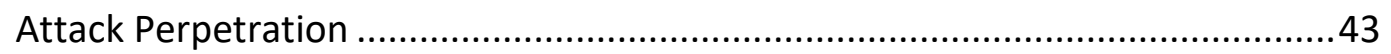

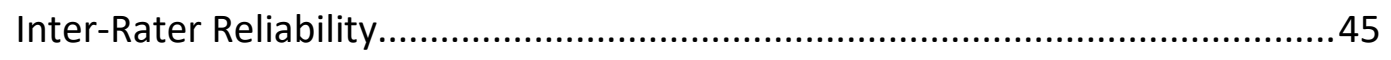

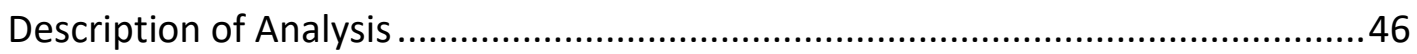

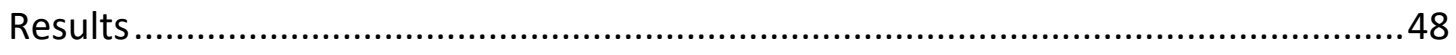

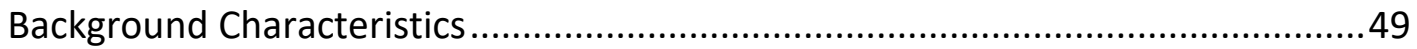

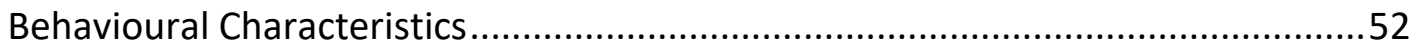

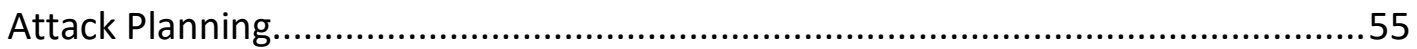

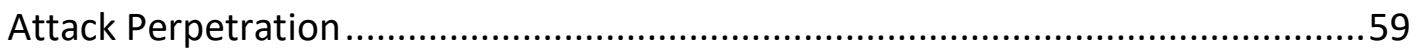

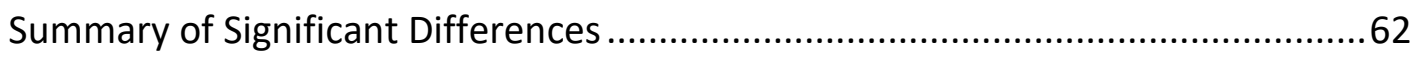

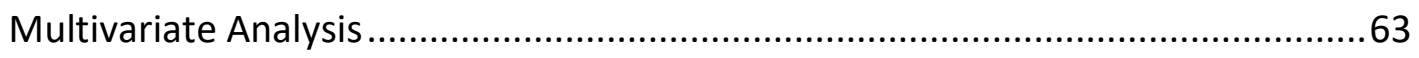

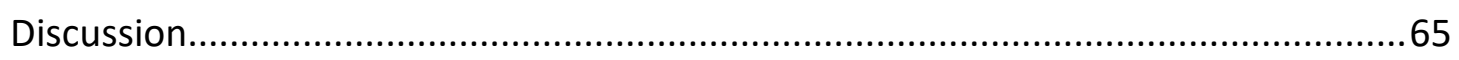

The Nature and Extent of Lone-Actor Terrorism, and Relation to Other Studies ...66

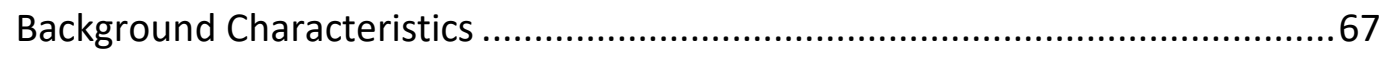

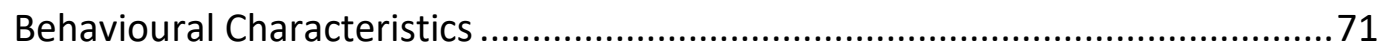

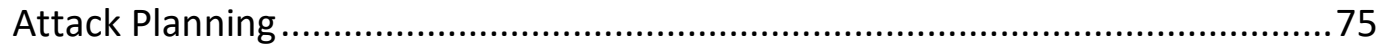

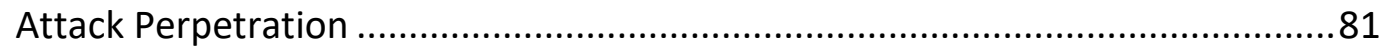

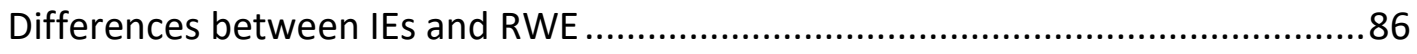

Attacks Perpetrated by Returning Foreign Fighters............................................89

Limitations, and Suggestions for Future Research..........................................91

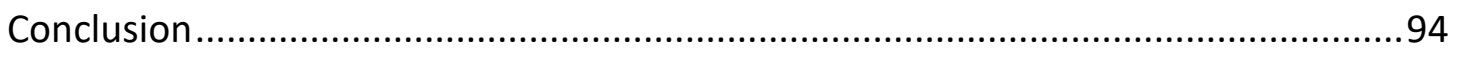

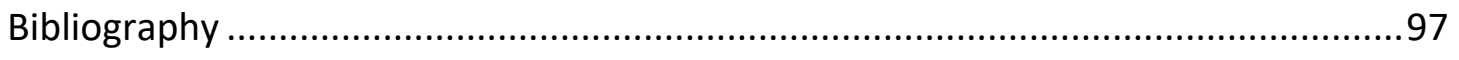

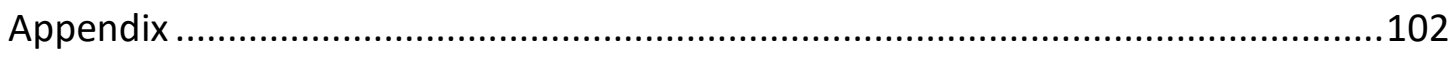




\section{List of Tables}

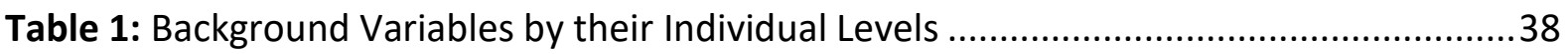

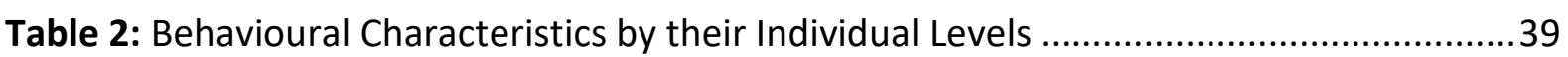

Table 3: Attack Planning Variables by their Individual Levels ............................................ 41

Table 4: Attack Perpetration Variables by their Individual Levels........................................44

Table 5: Counts and Percentages, or Ranges and Means for Background Characteristics ......50

Table 6: Count, Expected Count and Residuals for Marital Status and Ideology Cross Tabulation .52

Table 7: Counts and Percentages for Behavioural Characteristics.....................................53

Table 8: Counts and Percentages for Attack Planning Variables ........................................56

Table 9: Count, Expected Count and Residuals for Authorities Aware and Ideology Cross Tabulation .58

Table 10: Counts and Percentages, or Ranges and Means for Attack Perpetration Variables 60

Table 11: Count, Expected Count and Residuals for Collapsed Target Type and Ideology Cross Tabulation 62

Table 12: Significant Results for the Bivariate Analysis Comparing the Ideological Groups...63 Table 13: Logistic Regression Analysis Predicting Strain and Key Personal Characteristics for IEs Versus RWE. 64

Table 14: List of 99 Cases Included in the Current Study .102 


\section{List of Figures}

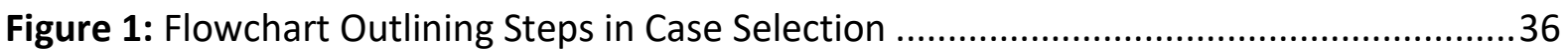

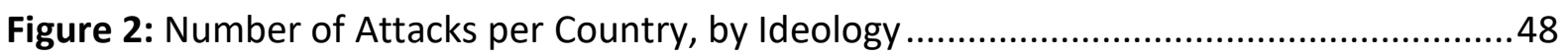

Figure 3: Number of Attacks Each Year, by Ideology ........................................................ 49

Figure 4: Attacks Undertaken by IEs Coded as Foreign Fighters, by Year .............................55 


\section{Introduction}

Terrorism comes in all shapes and sizes. It can be perpetrated by state or non-state actors, and can be conducted by lone-actors operating autonomously or by organised groups. However, over the last decade terror attacks undertaken by lone-actors have increased (Ellis et al., 2016) with some claiming that lone-actor attacks account for the majority of terror attacks occurring in Western Countries in recent times (Institute for Economics and Peace, 2015). This has resulted in attacks by lone-actors being perceived as a significant threat to national security in Western Countries (Europol, 2012; Kaplan, Lööw, \& Malkki, 2014).

Recent events have highlighted the threat from two different ideological motivations for conducting lone-actor terrorism. This first concerns lone actor terrorism perpetrated by Islamic extremist (IE) inspired individuals. At the start of the last decade, IE terror organisations such as al Qaeda started to shift the focus from large scale attacks to those perpetrated by individuals, which coincided with an increase in attacks perpetrated by IE inspired lone-actors (Nesser, 2012). In addition, since 2017 Islamic State of Iraq and the Levant (ISIL) have experienced significant territorial losses in Syria and Iraq, which have resulted in individuals who fought for this organisation returning to their country of origin (Institute for Economics and Peace, 2017). The second ideological motivation concerns lone-actors conducting attacks who are motivated by right-wing extremism (RWE). This ideology has a history of attacks committed by individuals, with leaders of white supremacist groups in the United States in the 1980's and 1990's encouraging the idea of leaderless resistance (Nesser, 2012). For example, Beam (1992) encouraged the concept of leaderless resistance in the struggle against the federal government and was inspired by Col. Ulius Louis Amoss who first wrote in 1962 about deploying leaderless resistance in the fight against communism. Attacks in the $21^{\text {st }}$ Century have emphasised the devastation that lone-actor terrorism can cause, such as the 22 July 2011 double attack in Norway, which killed 69 individuals and injured many more (Appleton, 2014).

Although the ideologies of IE and RWE could be viewed as two opposing types of fundamentalism, it is unclear at this stage to what extent the perpetrators who conduct loneactor terrorism and the features of the attacks are similar. Are the individual and attack characteristics extremely different between the two ideological groups, or are they the same, indicating that perpetrators of lone-actor terrorism only really differ in the ideology they 
adhere to? This research aims to explore the similarities and differences between IE and RWE inspired lone actor terror attacks in Europe, North America and Australia between 2010 2017. This will be accomplished by looking in depth at sociodemographic, behavioural, and attack planning and perpetration variables to explore the specific characteristics of attacks committed by individuals motivated by these two ideologies. Although other researchers have explored individual and attack characteristics of the two groups of lone-actors (e.g. Ellis et al., 2016; Gill \& Corner, 2016; Gill, Horgan, \& Deckert, 2014; Meloy \& Gill, 2016; Roy Van Zuijdewijn \& Bakker, 2016) they only included attacks up until 2015. The current study will be the first to undertake a comparative analysis between IE and RWE undertaking lone-actor attacks utilising a later timeframe. 


\section{Literature Review}

This thesis will start by reviewing the relevant literature on lone-actor terrorism. It will first start by exploring the nature and extent of lone-actor terrorism. Next, it will review prior research on the characteristics of lone-actor terrorism that are of interest to this study. Finally, it will discuss theoretical explanations for lone-actor terrorism and ideological motivations for conducting terrorism.

\section{The Nature and Extent of Lone-Actor Terrorism}

There are a myriad of ways that terrorism can be undertaken, which results in there being little consensus on a uniform definition of terrorism. However, there is some agreement on the foundation of terrorism as "attacks against non-combatants to cause fear and to advance a political aim" (Victoroff \& Kruglanski, 2009:1). This definition of terrorism will be expanded on in this research, to include acts that aim to inflict property damage, or impact on public health or safety (Gill et al., 2014) as long as the act resulted in the injury or death of someone other than the perpetrator(s). The lack of a consensus on an agreed definition is also found in the various sub-categories for terrorism. For lone-actor terrorism, some definitions include only attacks perpetrated by a single individual (Gruenewald, Chermak, \& Freilich, 2013b; Spaaij, 2010), while others broaden this to include attacks conducted by multiple perpetrators as long as there is no evidence of direction being given by a wider organisation (e.g. Corner \& Gill, 2015; Ellis et al., 2016; Gill \& Corner, 2016; Gill et al., 2014; Roy Van Zuijdewijn \& Bakker, 2016). While understanding the importance of studying attacks only perpetrated by one individual, this study will go further by utilizing a definition similar to what was used in the latter studies. As Pantucci, Ellis, and Chaplais (2015) argued, the majority of lone-actors cannot be considered as truly isolated, and investigations usually uncover connections with others during the attack planning or perpetration phases. Previous research has found that these connections play an important role in a perpetrator's belief in and ability to conduct a terror attack (Schuurman, Lindekilde, et al., 2018). Using a definition that includes attacks undertaken by two (dyad) or even three (triad) isolated actors will allow for those connections to be studied in greater detail. As such, lone-actor terrorism will be defined in this thesis as attacks perpetrated by one, two or three individuals only if there is no evidence of direction given from a wider group, or individuals linked to a group. 


\section{What is IE?}

Two types of ideological motivations for conducting lone-actor terrorism are the focus of this research. The first concerns lone-actor terrorists who adhere to an IE doctrine. This ideology believes in the establishment of one Islamic State, which stretches from North Africa to South East Asia, and proponents believe in undertaking a global jihad (struggle or fight) against global Western powers in order to establish this Islamic State (Sageman, 2004). IEs usually either belong to a known Jihadi terrorist group, notable examples of which include al Qaeda and ISIL, or they consume material or propaganda from these groups. The material from these groups will usually encourage violence towards Western countries and their occupants, and in recent times has been inspiring adherents in those countries to conduct an attack within their borders (Bjelopera, 2013).

IE is a common ideological motivation for conducting lone-actor attacks in Western countries. Previous research has found that IE accounts for more than one-third of attacks: Gill et al. (2014) found that $43 \%$ of their sample of successful and thwarted lone-actor attacks ${ }^{1}$ followed an IE ideology, while a later study by Gill found that $34 \%$ were motivated by IE (Meloy \& Gill, 2016) ${ }^{2}$. In their study on successful and foiled terror plots in Europe, Ellis and colleagues (2016) found that those who were inspired by IE accounted for $38 \%$ of all attacks 3 . IE terrorism in general has recently resulted in a large number of deaths in European countries. Approximately 10 attacks (including the eight co-ordinated attacks in Paris in November 2015, and the Nice attack in July 2016) accounted for a total of 137 deaths, contributing to the 600 percent increase in causalities from terrorism between 2014 and 2016 (Institute for Economics and Peace, 2017).

\section{Foreign Fighters}

This research will also be interested in exploring a sub-group that exists within IE, foreign fighters, which consist of individuals who travel to foreign countries to participate in conflict. The focus of this research will be on exploring the roles that returning foreign fighters (RFF) have on the prevalence of lone-actor terrorism in Western countries. The recent foreign fighter phenomenon started in 2012, which saw individuals travelling to Syria to fight as part

\footnotetext{
${ }^{1}$ This definition of lone-actors included only individual terrorists and isolated dyads

${ }^{2}$ This definition of lone-actors included only one terrorist

${ }^{3}$ This definition of lone-actors includes individuals, isolated dyads and isolated triads.
} 
of the uprising against the Syrian government, and since then people have also travelled to Iraq to participate in fighting there (van Ginkel et al., 2016). Estimates from 2015 state that there were approximately 25,000 to 30,000 individuals who have travelled to Iraq and Syria to take part in conflicts there (Institute for Economics and Peace, 2015; van Ginkel et al., 2016).

There has been increased concern from authorities and academics about the impact that RFF may have on the perpetration of terrorism in Western Countries. Van Ginkel and colleagues (2016) summarise the concern that European officials and researchers have about the threat to national security that RFF may cause, either through the application of weapons or combat training they received overseas in a domestic terror event, or the potential social and psychological upheaval that may be caused by a foreign fighter returning to the community. Pantucci and colleagues (2015) outline that RFF may not need assistance from a wider terrorist organisation in order to undertake a successful attack.

This concern from authorities seems to be supported by the research that has been undertaken on foreign fighters' involvement in terrorism in Western countries. Previous research has stated that only one in nine foreign fighters have returned to the West to participate in an attack (Hegghammer, 2013). In addition, researchers have found that RFF are involved in half the number of plots and attacks conducted in Western countries compared to those who believe in an IE ideology but have never participated in conflict overseas (Hegghammer \& Nesser, 2015; Pantucci et al., 2015). Although RFF are not as likely to undertake an attack as IE domestic terrorists, when they do participate their attacks are more deadly with a larger number of individuals being killed compared with attacks perpetrated by domestic terrorists (Hegghammer \& Nesser, 2015).

Previous research has found only a low number of foreign fighters will return to the West and participate in an attack. However, it is possible that this number may have increased since that research was conducted, due to the likely increase in RFF to western countries. The Institute for Economic Peace (2015) assessed that just over 21\% of foreign fighters come from Europe, with varying percentages of those fighters returning to their originating countries. Recent estimates had Belgium receiving $25 \%$ of the returning fighters from Syria, while France, the United States, and Germany receiving 18\%, 17\% and 12\% respectively (Institute for Economics and Peace, 2017). It is possible that since then the number of RFF to Western countries has risen, due to the significant territorial losses that ISIL has faced in Iraq and Syria 
("Islamic State and the crisis in Iraq and Syria in maps," 2018). As Hegghammer and Nesser (2015) outlined, in issue 9 of it's English language magazine Dabiq, ISIL advised supporters that if they were unable to participate in conflict in Iraq or Syria, then they should undertake an attack in their country of residence. If fighters have returned home, but still maintain their belief in and commitment to IE ideology, then participation in a terror attack in their home country could be viewed by some as a means of continuing their involvement in the Salafi Jihad movement (Pantucci et al., 2015). This involvement may be directed by or as part of a terrorist group, or the foreign fighter may decide to undertake an attack by themselves or as part of a small isolated group (e.g. dyad or triad). This research will be interested in exploring this through determining the prevalence of RFF in undertaking lone-actor terror attacks.

\section{What is Right-Wing Extremism?}

The main focus of this research will be on attacks perpetrated by IEs and will do so by comparing the similarities and differences between that and another ideology: right-wing extremism (RWE). Individuals belonging to the latter category are those who believe in a farright ideology, and who seek to advance that ideology through the use of violence. This is a nationalistic ideology, which believes that national sovereignty or personal liberty is (or is soon to be) under attack by some external threat (usually a specific ethnic or cultural group) and support for or participation in paramilitary actions is vital in order to counter any attack from the external threat (Gruenewald, Chermak, \& Freilich, 2013a). RWE is a broad category, and contains sub-groups that span various topics, such as ethno-nationalism, Christian religious identity, and anti-establishment views, although it is not uncommon to find a RWE ideology that consists of ideas taken from different sub-groups (Heitmeyer, 2005). In order to be included in this research, the perpetrators of a right-wing terror attack had to have an ideology that stemmed from at least one of the following five sub-groups: white supremacy, anti-immigration, anti-government, anti-Muslim and anti-Semitism. Some of these subgroups have clear crossovers; for example, those who adhere to a white supremacist ideology are likely to hold views that are against minorities (e.g. immigrants, Muslims and Jews). Another common thread between the various sub-groups is the belief in conspiracy theories, which according to Heitmeyer (2005) play an important role in RWE as a whole. 
Lone-actor attacks and plots motivated by RWE are generally found to have a steady prevalence compared to plots undertaken by other ideological groups in Western Countries. In their study of attacks undertaken by isolated actors, dyads, and triads in Europe, Ellis and colleagues (2016) found that terrorism perpetrated by RWE accounted for $33 \%$ of attacks, compared to those who were religiously inspired at $38 \%$. In their study on attacks perpetrated by individual terrorists and dyads in the United States and Europe, Gill and colleagues (2014) found that attacks undertaken by Al Qaeda inspired extremists were the largest group at 43\%, with attacks undertaken by RWE being the next group at 34\%. Overall, RWE is on average found to be the second most common motivation for conducting a lone-actor attack, after Islamic extremism.

\section{Characteristics of Lone-Actor Terrorism}

This study will be interested in comparing cases of lone-actor terrorism conducted by two types of ideological motivations: IE and RWE. Comparisons will be made across a number of background variables for each case of lone-actor terrorism. These background characteristics are split into four categories: biographical variables, behavioural characteristics, attack planning and attack perpetration. The literature review has been organised and reviewed by outlining the most relevant literature for each of the categories of variables.

\section{Biographical Variables}

This category of variables will be interested in exploring background information on the perpetrator. The seven variables of interest in this category are age, gender, education, marital and family status, nationality, and employment. Below, the relevant literature is reviewed in respect of these seven variables of interest.

The success of large scale attacks like 9/11 has focused academic and officials on the study of terrorism, trying to make sense of why it is undertaken by certain groups and individuals. In his study on perpetrated and attempted lone-actor terrorism in the United States since 9/11, Eby (2012) explored the characteristics of 'lone-wolves'" who conducted

\footnotetext{
${ }^{4}$ Eby's definition of lone wolves is limited to individuals who have operated alone. The term 'lone wolf' is contentious, as it is used by a number of researchers but rejected by others (e.g. (Schuurman, Lindekilde, et al.,
} 
attacks by themselves. Eby concluded that there is no single profile of 'lone-wolves', but many of the subjects share similar characteristics which he analysed for further information. For example, Eby's findings on gender were significant, with 48 out of 53 of the subjects being male and the remainder of the subjects having an unknown gender. Some of the other variables had more variance across the sample, such as age which ranged from 15 to 88 , with a mean age of 35.44. With respect to education and employment, Eby found that in those cases where there was sufficient open-source information to make a determination, $54 \%$ of the sample had completed high-school, $35 \%$ had a university-level education, and $41 \%$ were employed at the time of undertaking the attack.

Eby's study focused on terrorism perpetrated by one individual, but other studies have widened the scope to also include acts committed by autonomous groups. An example is a study undertaken by Meloy, Roshdi, Glaz-Ocik and Hoffman (2015) who investigated characteristics of 22 individuals who undertook a terror attack either as an individual or as part of an autonomous cell in Europe between 1985 and 2015. They coded characteristics of each case using the variables outlined in the Terrorist Radicalization Assessment Protocol (TRAP-18), which is used to determine an individual's risk of undertaking terrorism. Of the variables that are of interest to the background variables of the present study, Meloy and colleagues did not find any statistical differences between the two groups. However, when looking at the entire sample they did find some common characteristics. This sample was younger and less varied than Eby's (2012) sample, with a mean age of 31 years and the ages ranging from 21 to 50 . Similar to Eby they found that the majority of the sample was male, with only one perpetrator being noted as female. Of the 16 cases in which employment information was known, 12 were unemployed, 1 was underemployed given the level of education that they had experienced and 3 were employed full-time when the attack was undertaken. This study also looked into the family status of the terrorists on which there was background information on all minus one of the perpetrators. They found that the majority were single (61.9\%), with a third of the sample being married at the time of the attack $(33.3 \%)$ and one perpetrator was divorced (4.8\%). Family status also included the presence of

2018). This research will use the term lone-wolf when describing the results from researchers that have employed the term to describe their sample. 
children, and the study found that only five perpetrators had children (23.8\%) while the majority of the sample did not have children (76\%).

Some studies have limited their scope to focus on types of terrorism committed by certain ideological groups, or committed in certain geographical areas. This is true of a study undertaken by Bakker (2006), which looked into the network characteristics, individual characteristics and circumstances for joining for those involved in Jihadi plots or attacks in Europe since 9/11. These plots were conducted by 28 terror networks and resulted in 242 perpetrators. Of the variables of interest to the background group, Bakker found some findings similar to previous research. For example, his sample was overwhelmingly male (97.9\% of the sample were male). Although educational achievement could only be determined in a small number of cases (48 individuals), Bakker found that of those a significant portion had completed high school (87.5\%) and just under a third $(31.3 \%)$ had completed tertiary level education. When looking at occupation, (there was sufficient information to make a determination in 103 of the cases). Bakker found that the majority of the sample was employed at the time of undertaking the attack, with $33 \%$ classed as unskilled workers, $18.4 \%$ classed as semi-skilled, $13.6 \%$ classed as skilled and $11.7 \%$ Bakker categorized as being entrepreneurs, which usually involved owning their own business. In regards to age, Bakker's sample had a wider age range than Meloy and associates' but narrower than Eby's (2012), with the youngest being 16 and the oldest 59, with age measured at time of arrest. However, the average age was 27.3 which was similar to Meloy and colleague's sample, but was significantly younger than Eby's.

Yet, some results were surprising considering prior research. For example, in the cases in which there was enough information, Bakker found that the majority of the sample was married or in a committed relationship (59.1\%) at the time of the attack, with $33.3 \%$ single and $12.1 \%$ had experienced a divorce. Bakker also found that $37.9 \%$ of the sample had children. This is the opposite of what was found by Meloy and colleagues (2015) which found that the majority of the sample was single at the time of the attack and a smaller number of individuals having had children. This difference could be explained by the differences in scope of the studies: Meloy's smaller study was limited to lone-actor attacks in Europe, whereas Bakker's significantly larger study looked at attacks undertaken by all Jihadi's in Europe. Bakker also looked at variables that the other authors had not examined, and found one which is also of interest to this study. When accounting for nationality/ethnicity, Bakker found 
that only $7 \%$ of individuals had families that originated from Europe, with the rest being immigrants, or the children/grandchildren of immigrants.

Although it can be of value to understand lone-actor violence in the wider context of group-based violence, it is important to note that there have been some significant differences found between individuals who participate in both types of attacks. This was true of a study undertaken by Gruenewald and colleagues (2013a), who explored differences in RWE in the United States through comparing fatal attacks conducted by 'loners' 5 and attacks conducted by other RWE (e.g. those perpetrating group-based violence). They coded 139 attacks that occurred across a 20 year period, using variables spread across five categories: participation in RWE, social relationships, criminogenic factors, attack style, and personal characteristics. Four of these variables are of particular interest to the current study. In regards to age, the authors found the average age for 'loners' was 35 years old, which was significantly older than the average age for other extremists (27). The average age is similar to what was found by Eby (2012), but older than the ages found by Bakker (2006) and Meloy et al. (2015). The authors also found another significant difference between the two groups, with 'loners' less likely to be married than other domestic extremists. For the other variables that are of interest to the current study, Gruenewald and colleagues did not find any significant differences between 'loners' and other RWE. They found that both groups consisted mainly of males, which is in line with prior research examined in this section. They also found that both groups were mainly made up of white individuals. Bakker was the only other piece of research that looked at a similar variable, but he was mainly concerned with nationality of the perpetrators, which does not always line up with ethnicity. Gruenewald and colleagues found similar rates for employment, with $40 \%$ of single actors being coded as unemployed and $43 \%$ of other extremists coded as unemployed. These rates are much lower than what was found by Meloy and associates, whose sample had an unemployment rate of $75 \%$.

For the majority of the variables discussed in this section there is no uniform profile of those that perpetrate terrorism. The only exception is gender, with terror acts perpetrated

\footnotetext{
5 Gruenewald and colleagues used the term 'loners' to describe individuals who have no ties to other organisations and commit violence on their own.
} 
by males, regardless of the number of actors, the location of the attacks or the ideology of the offender(s).

\section{Behavioural Characteristics}

The second group of variables of interest to this research is the behavioural characteristics of the perpetrators. These include mental health, social isolation, presence of stressors, criminal history and history of violence.

One of the first studies to look in-depth at the behavioural patterns of lone-actor terrorists in Western countries was undertaken by Spaaij (2010), who studied behavioural and other characteristics in order to determine the main patterns of lone wolf ${ }^{6}$ terrorism in 15 Western countries. He coded 78 cases of terrorism over the span of 40 years analysing three main features of lone-actor terrorism: prevalence and patterns of lone wolves, influences across the social and political spheres, and how attacks are conducted. Spaaij also explored in-depth five case studies of terrorism in these countries in order to better understand the behaviours of the perpetrators, and his findings from this exploration are of particular interest to this study. Spaaij (2010) found support for prior assertions that the presence of mental health issues are higher in the lone wolf population than other terrorist groups, with four out of the five individuals in the case studies being diagnosed with either obsessive-compulsive disorder or a personality disorder. However, this case study has a very small sample size and so any inferences should be made with caution. Spaaij also explored the role that social isolation played in the perpetration of lone wolf terrorism, and found that all five individuals experienced some form of isolation. For example, all of the sample could be classed as 'loners', individuals who preferred to operate independently and only had a few friends, and two of the five individuals lived in seclusion from others. Spaaij concluded that the majority of the sample seemed happy to isolate themselves from others, instead of working alongside others who share their extremist beliefs.

Gill and colleagues (2014) coded network characteristics and behaviours of 119 loneactor terrorists leading up to their planned or attempted terrorist attack. Their sample included both individuals and dyads who committed an attack without any evidence of direction from a wider terrorist organisation, and compared results across four categories of

\footnotetext{
${ }^{6}$ Spaaij's definition of lone wolf terrorism is limited to individuals who have operated alone
} 
ideological beliefs, which included IE and RWE. Like Spaaij (2010), one of the variables of interest was social isolation, with Gill and associates concluding that over half (52.9\%) of the sample were coded as socially isolated. Mental health of the individuals was also coded for, and just under a third (31.9\%) had a diagnosis associated with a mental health or a personality disorder. This proportion is less than what was found by Spaaij, but as this sample was larger any inferences made to the population of lone-actor terrorists would be more reliable. Gill and colleagues also studied additional variables that were not studied by Spaaij. Firstly, Gill and colleagues found evidence that nearly a third (32.5\%) of their sample had experienced a high level of stress at the time the event took place. Of this subset, the majority $(74.3 \%)$ of the stressful events occurred within 1 year of the attack. There were many reasons that these individuals had experienced stress, including (but not limited to) employment or financial issues. Another variable that Gill and colleagues coded for was criminal history, and they found that $41.2 \%$ of the sample had a prior conviction, of which $63 \%$ of the sample had been incarcerated. They also found evidence that just under a third (32.3\%) had been radicalised while incarcerated. Gill and colleagues also coded for history of violence and found that more than a third (37.8\%) had a history of violence prior to undertaking the attack.

Weenink (2015) undertook a study that explored behavioural characteristics of Jihadi's in the Netherlands. His sample consisted of 140 individuals who had either travelled to Syria or Iraq and were known or suspected of participating in the fighting there, or were known to have aspirations to do so but had not yet left the Netherlands. The first variable of interest studied was mental health, and he identified that in the majority of cases (60\%) there existed a psychosocial problem of some nature. When examined more closely, he found that $6 \%$ of his sample were diagnosed with a mental illness or personality disorder. This was much less than what was found by Spaaij (2010) and Gill and associates (2014); however, it is likely that this number is underreported in Weenink's study as he only coded for a diagnosis of mental health or personality disorder if it was listed in Police files or databases. His study did not have access to psychiatric reports, and in the Netherlands there are restrictions on the ability of mental health professionals to share information on patients with law enforcement. Weenink did not explore the presence of stressors in the sample overall, but he did account for the presence of some variables that would fit the definition of a stressor. For example, his study found that some in the sample had experience with homelessness, with six (4\%) of the individuals recorded as homeless at the time of registration in one of the Police databases. 
Another variable that Weenink explored was criminal history. He found that just under half of the sample (47\%) had at least one report outlining criminality in the Police database, which was a slightly higher proportion than found by Gill and colleagues. However, Weenink advised that his data on criminality had some limitations, and should be interpreted with caution. Weenink found the convictions to be a larger proportion of the sample (53\%) than Police reports. As not all entries into the Police system would result in a conviction, Weenink concluded that the Police database that held reports must be incomplete.

Schuurman, Bakker, Gill, and Bouhana (2018) explored terrorist behaviour across 198 variables by basing the codebook on that developed by Gill and associates (2014), and expanding it to focus on specific variables of interest, based on what was found in the wider literature. In addition to the codebook, they took their sample from Gill and colleague's (2014) study, and chose the 55 cases in which there was substantial information to incorporate the new variables ${ }^{7}$. Their research found support for prior findings on mental health, in that the presence of mental health concerns is higher in lone-actor terrorists when compared to both the general population and group-based terrorists. This finding is in line with what was found by other researchers discussed above. Similar to Weenink (2015), Schuurman and colleagues did not explore the presence of stressors by themselves; however, they did look at 'trigger' events which included, amongst other variables, the presence of stressors. They found that in $44 \%$ of cases, the decision to undertake the attack followed a 'trigger' event, which could have been the presence of a stressor in an individual's life or a cognitive opening (e.g. witnessing another individual undertake an attack successfully). This finding was higher than what Gill and colleagues found with social isolation; however, this is not surprising as Schuurman and associates did not look at stressors in isolation. Finally, this study also explored the prevalence of violence in the attackers' history and found that this was present in just under half of the sample (46\%), which is higher than what was found by Gill and colleagues in their earlier sample. This difference is likely attributed by Schuurman and colleagues focusing on a subset of those studied by Gill and colleagues.

Overall, prior research has strong findings for a number of variables in the behavioural characteristics section, with mental health difficulties, social isolation, criminal history and

\footnotetext{
${ }^{7}$ They utilised a definition of lone-actors that included only single actors
} 
history of violence all occurring at higher rates in the sample of lone-actor terrorists than what is found in the general population.

\section{Attack Planning}

The third category of variables that are of interest to this study are attack planning variables. Prior research on lone-actor attacks in Western countries has found that most are not spontaneous, with the perpetrators having participated in some type of attack planning or preparation prior to the attack (Gill et al., 2014; Meloy \& Gill, 2016; Spaaij, 2010). Studying attack planning variables could discover shared behaviours across different types of loneactor terrorists. The variables within this category are: prior relationship with a terrorist group, contact with other extremists or terrorists, participation in training, target reconnaissance, leakage (to family/friends, authorities/target, to internet) third party assistance, and the extent to which the authorities were aware of radicalisation or extremist beliefs. These variables are explored in the relevant literature below.

Meloy and Gill (2016) investigated differences between ideological types of lone-actor terrorists and successful and thwarted attacks by coding for the TRAP-18 indicators using open-source material. Their sample consisted of 111 lone-actors ${ }^{8}$ who carried out an attack, or who planned to carry out an attack in Europe and the United States. The first indicator of the TRAP-18 that is of interest to the attack planning variables is 'failure to affiliate with a terrorist group'. This indicator is made up of two variables, and Meloy and Gill found that $22 \%$ of the sample had failed to form a terrorist group of their own, and that $14 \%$ of the sample had faced rejection when applying to join a terrorist or extremist group. The next indicator of interest to this study was the indicator for 'leakage' which is made up of six variables. Two of the variables were concerned with leakage of their ideology, and they found that $59 \%$ of their sample had produced a written document or made public statements about their ideology, and $68 \%$ had advised close associates of their ideology. Two of the variables included leakage of intent, and they found that just under half (49\%) of the sample had communicated verbally of their intent or belief to a number of people outside of their close family and friends, and just over half (51\%) had told close associates of their intent. The last two variables showed that the majority of the sample had in some way provided a warning to

\footnotetext{
${ }^{8}$ This definition of lone-actors included only single actors
} 
their close associates, with $74 \%$ of the sample showing evidence of leaking their grievance and $65 \%$ leaking their intent to hurt others. Another indicator of interest is dependence on the virtual community, and Meloy and Gill coded for two variables that made up this indicator. They found that just under a third (30\%) interacted online with others who share their extremist views, and that under half (42\%) had used the internet to undertake research to assist with planning the attack. Although an aspect of training was evident in the last indicator, Meloy and Gill also had a separate indicator that focused on training, which they labelled 'pathway warning behaviour'. This indicator was made up of five different variables, of which three were of interest to the current study: they found that $24 \%$ of the sample engaged in behaviours to help prepare for the attack, $30 \%$ engaged in a dummy run prior to undertaking the attack, and $23 \%$ had engaged in practical training for the attack. Meloy and Gill argued that any individual who showed evidence of having at least one of the variables for the 'pathway warning behaviour' indicator means that they planned at least some of their attack. They found that the majority (80\%) of their sample had evidence of at least one of the pathway warning behaviour variables and suggested that this disproves arguments that loneactor terror attacks were impulsive and unplanned.

Ellis and colleagues (2016) undertook a study as part of the Countering Lone-Actor Terrorism (CLAT) Project, which investigated the processes of lone-actor terrorism by studying both attacks and plots undertaken by individuals or small cells (dyads and triads) in Europe between 2000-2014. Their sample consisted of 120 individuals, and they utilized a database that included over 70 variables. In addition, they also compared their findings for two ideological groups: religiously motivated individuals (or those who adhere to an IE ideology) and RWE. Similar to Meloy and Gill (2016) they investigated the presence of leakage behaviours in the sample, and they found that just under half (46\%) of their sample had stated to others either their intent to act or extremist beliefs. A similar result was found in Meloy and Gill's study, who determined that $49 \%$ of their sample had told others of their beliefs or intent to act, which was one of six variables in total they studied for leakage. There was no significant difference between religiously inspired actors or RWE. In addition, they found that in one-fifth (21\%) of the cases the perpetrator shared aspects of the attack plan with a third party. When determining the audience for this leakage behaviour, they found religiously inspired individuals were more likely (45\%) to leak their intent to close associates than RWE (18\%), the majority of who leaked their intent on the internet (41\%). Unlike Meloy and Gill, 
Ellis and colleagues did not study training as a variable in itself. However, they did study using the internet to prepare for the attack, and found that this occurred in just under a third (33\%) of their sample, which is less than what was found by Meloy and Gill (42\%).

As part of an assessment on the threat of terrorism from lone actors, Jasparro (2010) analysed case studies of attacks (either successful or foiled) that were undertaken in the US. His sample consisted of 14 plots from Jihadi 'lone-wolves' ${ }^{9}$, eight of which were successful. The first variable he studied that was of interest to the attack planning category was leakage. Jasparro found that five of the eight successful attackers (62.5\%) had discussed their beliefs or their intention to hurt others with close associates. This number was similar to what was found by Meloy and Gill (2016) for three of their variables for leakage: telling close associates of their ideology (68\%), their plans (51\%), or their intention to hurt others (65\%). However, this was a higher proportion than what was found by Meloy and Gill for one of the other variables for leakage (49\%) and higher than what was found by Ellis and colleagues (2016), which both measured those who had told others of their extremist beliefs or intent to undertake an attack. The other variable of interest counted if the perpetrator was known to the authorities for extremist sentiments. Interestingly, Jasparro found that the perpetrators of two of the eight (25\%) successful attacks were known to authorities prior to the attack for their association with other radicals. However, as always with studies that have a small sample size, any findings from Jasparro's study should be interpreted with caution.

Lindekilde, O'connor, and Schuurman (2019) explored the impact of radicalisation type on the attack planning and preparation behaviours in a sample of 33 lone-actors who undertook attacks in the US and Europe during 1986-2015. They selected the lone-actors ${ }^{10}$ who had sufficient background information from the dataset developed by Gill et al. (2014), and included some additional cases that they had found in open-source material. Lindekilde and colleagues determined radicalisation type by two of the most common pathways: Autonomous, which accounts for 23 actors from the sample and, Volatile which consists of 10 individuals. The authors define Volatile actors as individuals who radicalise quickly and have short periods of extremist behaviour which are interspersed with periods of pleasure-seeking behaviour (including criminal activity and substance use). Based on this frequent change in

\footnotetext{
${ }^{9}$ This definition of 'lone-wolf' was limited to individuals acting alone.

${ }^{10}$ This definition of lone-actors included only single actors
} 
behaviour, they struggle to fully embed into a radicalised group as they are viewed as unreliable. Autonomous lone-actors, on the other hand, are usually well embedded in the extremist community, which echoes their extremist beliefs and provides justifications for undertaking violence. When they do act, they usually utilise the concept of leaderless resistance by operating individually or in small autonomous groups. The first variable of interest was contact with a terrorist group. They found that the majority of Autonomous (78\%) and Volatile (70\%) lone-actors were likely to have some contact with a terrorist group or individual. However, they found that a smaller proportion of Autonomous (30\%) and Volatile (57\%) lone-actors were likely to be accepted as members of terrorist groups or communities and when coding for failure to join a terrorist group they found that this number was higher for Volatiles (30\%) versus Autonomous (13\%) actors. This was similar to prior research by Meloy and Gill (2016), who found that $14 \%$ of individuals had failed to join a terrorist group. The next variable of interest to the current study is target reconnaissance, with Lindekilde and colleagues finding similar rates for Autonomous (44\%) and Volatiles (40\%) for undertaking target reconnaissance, which was similar to rates found by both Meloy and Gill (42\%) and slightly higher than what was found by Ellis et al. (2016) at just under a third of their sample (33\%). Lindekilde and associates studied some aspects of leakage behaviour, and they found that Autonomous actors were less likely (4\%) to leak their desire to die for their extremist beliefs compared to Volatile actors (40\%). It is difficult to compare this with what was found by prior research as leakage about desire to die for beliefs is a subset of other variables, such as leakage of intent to undertake a terrorist attack. Lindekilde and associates also coded for the authorities' awareness of the perpetrator during the attack planning stage, and they found that while this number was $48 \%$ for Autonomous actors, a larger proportion (80\%) was found for Volatile lone-actors. This was higher than that found in the study undertaken by Jasparro (2010), who found that a quarter of his sample was known to the authorities. However, Jasparro's study specified those who were known for their extremist beliefs or intended terrorist activity, whereas this limitation was not placed on Lindekilde and colleagues' coding which may explain why their proportion was higher. Finally, Lindekilde and associates coded for one variable that had not been studied in the other three studies: assistance during attack planning stage. They found that $26 \%$ of Autonomous actors had received assistance from a third party whereas no Volatiles had. Assistance by third parties is a variable that will be coded in the present study. 
Prior studies have confirmed that most lone-actors participate in some type of planning or preparation for their attacks with leakage of beliefs or intent to act and training being two variables that are consistently found in the majority of lone-actor attacks.

\section{Attack Perpetration}

The final category of variables is attack perpetration, which is concerned with coding behaviours of the attackers during the attack, or certain characteristics of the attack. This group of variables includes the number of attackers, number of casualties, target type, weapon type, end of attack and assistance by a third party to undertake the attack.

Gruenewald et al. (2013a) compared attacks undertaken by right-wing 'loners' ${ }^{11}$ and other far-right perpetrators of homicide (small cells or groups) in the US, and was reviewed in greater detail in the biographical variables section of this thesis. They found that for both categories of perpetrators, it was more likely that only one victim was killed in the attack. However, when looking at attacks which had multiple victims, 'loners' (25.5\%) were significantly more likely to have more than one victim than attacks undertaken by other RWE (9.7\%). The next variable Gruenewald and colleagues studied was victim type, which they coded for five different types of victims: abortion providers, social minority, civilians, government/military, and sex offenders. They did not find any significant differences in the choice of victim between the two groups. However, they did find that the majority of both 'loners' (53.2\%) and other right-wing perpetrators (71.0\%) targeted social minorities. Another variable that the researchers coded for was the choice of primary weapon. They found that 'Ioners' were significantly more likely $(84.8 \%)$ to use a firearm as the primary weapon, compared to attacks committed by other far-rightists (40.2\%), who were more likely to use knives, blunt objects and other weapons. The final variable that Gruenewald and associates studied was how the attack ended, and two of the variables they coded for are of interest to this study: perpetrator(s) killed by law enforcement while undertaking the attack, and perpetrator(s) committing suicide. They found that $10.6 \%$ of 'loners' were killed by law enforcement during the attack and $4.3 \%$ committed suicide during or directly after the attack, compared to other far-right perpetrators of homicide, where $3.3 \%$ were killed by law

\footnotetext{
${ }^{11}$ This definition of 'loners' includes attacks perpetrated by a single individual.
} 
enforcement and $6.5 \%$ committed suicide. However, these results should be interpreted with caution as they found no significant differences between the two groups for these measures.

Ellis et al. (2016), investigated processes of terror attacks undertaken by lone-actors in Europe. Similar to this thesis, they utilised a definition on lone-actors that includes individuals, dyads and triads. This study was described in more detail earlier on in the literature review. The first variable of interest they studied was casualties, and unlike Gruenewald and colleagues (2013a) they looked at both fatalities and injuries. Ellis and associates found that on average lone-actor attacks accounted for 1.99 fatalities and 4.58 injuries, but advised that this data was skewed by the two extremely fatal attacks undertaken in Norway on 22 July 2011. Also, they found that the majority of attacks did not cause any fatalities (76\%) or even injuries (58\%), and concluded that although most lone-actor attacks fail to cause any fatalities, those that do can be extremely devastating. They also looked at the proportion of casualties they found from each ideological group, and found that both fatalities and injuries were more common in RWE attacks when compared to IEs. The second variable that Ellis and associates studied was target type. They found that the most targeted group were civilians (35\%) with over one-third (37\%) of the perpetrators targeting civilians following an IE doctrine, and one-quarter (25\%) having a right-wing ideology. This is different to what was found by Gruenewald and associates, who found that social minorities were the group most targeted. However, comparisons between the two studies should be made with caution as Ellis and colleagues included some social minorities within the civilian group, instead of counting it within its own category. The next variables studied by Ellis et al. (2016) was weapon type, and they found that firearms were the most common choice (31\%), followed by a mixture of weapons (21\%), explosives (17\%) and weapons with a blade, such as a knife or axe (12\%). They found no significant difference on weapon choice for the different ideological groups. Gruenewald and colleagues also found that firearms were the most used, but they had a higher prevalence in their sample for both 'loners' and other RWE. There are two possible explanations for this difference in prevalence: firstly, Gruenewald and associates' sample were entirely from the US where firearms are more widely available (through both legal and illegal channels); secondly, they coded for primary use of firearm whereas Ellis and colleagues coded for use of firearm by itself. It should be noted that a mixture of weapons was the second most common variable for weapon type in their study, and it is possible that a majority of those combinations included a firearm. The final variable 
that Ellis and associates accounted for which is of interest to this thesis was the number of attackers. They calculated the number of attackers for both disrupted plots and successful attacks, and of the 72 successful attacks the majority (83.3\%) were undertaken by a single perpetrator, with dyads and triads accounting for $8.3 \%$ each.

The Institute for Economics and Peace produces an annual summary titled the Global Terrorism Index, which investigates terror attacks undertaken in countries that belong to the Organisation for Economic Co-operation and Development (OECD). This study looks at a number of variables associated with both group and lone-actor terrorism in OECD countries, and each year the report highlights different aspects of terrorism that are relevant at the time. The 2017 report focused on two items that are of interest to the current study: lone-actor terrorism ${ }^{12}$ and the impact of ISIL (Institute for Economics and Peace, 2017). Firstly, the report found that attacks undertaken by lone actors between January 2014 - June 2017 had a casualty rate of one person per attack, whereas attacks undertaken by all other terrorists during the same timeframe was under 0.3 persons for every attack. This number is less than what was found by Ellis and colleagues, who found just under two fatalities per attack for lone-actors. This difference is likely explained by Ellis and colleagues' results including, and therefore being skewed by, the highly fatal 22 July 2011 double attack in Norway. The second variable that is of interest to this study is weapon type. When looking into attacks involving ISIL committed by both lone-actors and groups, the Institute for Economics and Peace found that just over half $(51.1 \%)$ of the attacks utilised a firearm, just under a quarter utilised explosives (24.2\%), with the remainder of the attacks not having a specified weapon type. That firearms are the most common weapon follows what was found by previous research, but the proportion in this case is in the middle of prior research, being lower than what was found by Gruenewald et al. (2013a) but higher than what was found by Ellis and colleagues (2016).

Schuurman, Bakker and colleagues (2018) explored the prevalence of attack planning and perpetration variables in a sample of lone-actor terrorists ${ }^{13}$ (a more comprehensive review can be found in the behavioural characteristics section above). Schuurman and colleagues coded for target selection during the planning phase and found that for a number

\footnotetext{
12 This definition of lone-actors includes only single actors

${ }^{13}$ This definition of lone-actors included only single actors
} 
of terrorists there were a lot of considerations and constraints when selecting a target. In over a third (36\%) of the cases, the lone-actors had earmarked multiple locations or entities that could be potential targets for their attacks ( $33 \%$ unknown), and in $60 \%$ of cases the target selection was influenced by various limitations (such as possibility of family or friends being targeted in that location, security at location etc). Another variable that was coded for by Schuurman and associates was weapon type. They found that firearms were the most common weapon type (62\%), with explosive devices in second place (44\%). Each attack was able to have more than one weapon type. The popularity of firearms was expected based on prior research, and the use of firearms was at a similar level to what was found by the Institute for Economics and Peace (2017) at 51.1\% and between the numbers found by Gruenewald and colleagues (2013a) for right-wing loners (84.8\%) and other RWE (40.2\%); however, this was double the number found by Ellis et al. (2016). Both Schuurman and colleagues, and Ellis and colleagues coded for presence of weapon, rather than other studies who coded for primary weapon, so this difference in prevalence rate is interesting. The final variable of interest is concerned with accounting for third party assistance, and Schuurman and colleagues found that $29 \%$ of the sample had some assistance during the attack preparation phase. This thesis is interested in counting assistance while undertaking the attack, such as assistance with transport or weapons, but Schuurman and colleagues did not count this. However, as weapon type is a shared variable between Schuurman's attack preparation phase and this thesis's attack perpetration phase, there may be some crossover with what Schuurman coded for and what this thesis coded for.

Of all the attack perpetration variables found by other studies, weapon choice was by far the most consistent result with firearms being used the most in lone-actor attacks occurring in Europe and North America. Other variables, such as target type and number of perpetrators had strong findings within the individual studies but did not have the same consistency across studies as weapon choice.

\section{Theoretical explanations}

There are a range of different theoretical approaches to understanding terrorist behaviour which view terrorism through different lenses. This has resulted in several different theoretical perspectives to understanding terrorism, with little agreement between the 
perspectives. Most of the prior theories on terrorism have been developed with group actors in mind, although this does not preclude them being applied to lone-actors. Relevant theories have been explored in two sections below; the first which involve theories which help explain why individuals choose to undertake attacks as lone-actors, and the second which includes theories that explain the role that ideologies play in the perpetration of terror attacks.

\section{Theoretical Explanations for Lone-Actor Terrorism}

Individual explanations. Some theoretical explanations determine that the motivations and causes for undertaking terrorism lie within aspects of the individual. For example, some involve understanding the cognitive methods that individuals utilize which allow them to undertake a terror attack, such as Ribeaud and Eisner (2010) who argue that moral self-sanctions are cognitive techniques that stop individuals conducting violence towards others. In order to conduct an act of violence, like a terror attack, individuals will employ moral neutralizations to overcome the self-sanctions. Ribeuad and Eisner outlined four mechanisms of moral neutralizations: cognitive reconstruction, minimizing own agency, disregarding or distorting negative impact, and blaming or dehumanizing the victim. The authors argue that as these mechanisms are likely to occur before the action, they therefore contribute to the action taking place. Moral neutralizations theory combined elements of other similar theories of techniques that individuals use to overcome moral self-sanctions such as neutralization techniques (Sykes \& Matza, 1957), moral disengagement (Bandura, Barbaranelli, Caprara, \& Pastorelli, 1996) and secondary self-serving cognitive distortions (Barriga \& Gibbs, 1996).

Some theories focus on the perpetrator's motivations for conducting terrorism, rather than the cognitive methods they may employ to undertake terrorism. For example, Rational Choice Theory for suicide terrorism (Perry, Hasisi, \& Violence, 2015) argues that individuals will only involve themselves in suicide terrorism after determining that the anticipated social, religious or personal rewards for undertaking suicide terrorism will be greater than any costs from undertaking the attack. They argue that all individuals who undertake suicide terrorism will do so only after making a rational choice, even if their verbal or written statements portray their motivations as altruistic in nature. Perpetrators of lone-actor terrorism would 
make a rational choice, only following through if the personal cost (i.e. incarceration or death) of undertaking terrorism is worth the anticipated rewards.

Some theories will explain terrorism as an individual's reaction to external stimuli. For example, the situational action theory of crime (Wikström, 2014) argues that crime is the result of an individual's response to a situation, and that crime occurs when the individual undergoes a moral change to view the crime as a morally acceptable action given the circumstances that the individual finds themselves in. Wikström and Bouhana (2017) applied situational action theory to terrorism, and argued that radicalization occurs when an individual is predisposed to moral change, and they are in a radicalizing setting (which is defined as a situation where there is an insufficient level of social control, includes material that supports terrorism and the individual has the opportunity to form a bond with the sources of the material). The requirement for the existence of the moral change as well as the radicalizing setting explains why some lone-actors will undertake terrorism while others, who are exposed to the same situation, may not.

Strain theories. Strain theories attempt to understand terrorism as a response to the strains that one may encounter, either at a personal or a group level. The General Strain Theory of Terrorism (Agnew, 2010) posits that terrorism is more likely in situations where a group an individual belongs to has experienced collective strains, that must adhere to the following three conditions. The first is that the strains must be perceived to have a high degree of harm, be persistent, and unlikely to cease in the future. They must also be widespread and impact on civilians, and can either be experienced by the perpetrator themselves or a group that the perpetrator identifies with. The second condition is that the strain must be perceived to be inflicted on the group unjustly, which may include being undeserved, not being experienced for the greater good, contravening robust social or cultural norms, or being different to how the group was treated previously, or different to how other similar groups are being treated. The third condition is that the strain must be placed on the group by those who occupy a more powerful position, and can include infliction by complicit civilians. Those who impose the strain must have a weak relationship with the group that is experiencing the strain. As it argues that if the three conditions are met then terrorism is more likely, General Strain Theory of Terrorism provides an understanding of why some individuals may choose to undertake terrorism whereas others do not. Prior research has shown support for strain theory of terrorism, showing that lone-actors have experienced a number of strains, including 
presence of mental health issues (Gill et al., 2014; Gruenewald et al., 2013a; Meloy \& Gill, 2016; Roy Van Zuijdewijn \& Bakker, 2016) social isolation (Gill et al., 2014; Jasparro, 2010; Roy Van Zuijdewijn \& Bakker, 2016; Spaaij, 2010) and stressful events prior to the attack occurring (Gill et al., 2014; Jasparro, 2010) ${ }^{14}$.

In his work studying members of Jihadi networks Sageman (2004) theorised that as the majority of Jihadis were young westernised Muslim males, they were detached from their cultural origins at the time of radicalisation, and sought companionship with a "Bunch of Guys" who also experiencing the same levels of isolation as they were. This Bunch of Guys resented the Western society they lived in, and developed extremist views within their social circle. Thus social affiliation amplified their radicalisation, which occurred prior to joining a terror group. Cottee (2011) applied subcultural theory to Sageman's work and identified that for those Jihadis the subculture of IE was a collective solution to the strains they were experiencing by straddling two cultures: the traditional Islamic culture of their (or their parent's) origin with the Western secular culture that they were embedded within.

Radicalisation pathways. Although most other theories have been developed with group actors in mind, some have been developed to determine an individual's inability or unwillingness to undertake a terror attack as a member of a group. This was true of one purported by Malthaner and Lindekilde (2017) who explored the roles that relational pathways have on understanding lone-actor radicalisation, and argued that analysing the various relations that lone-actors have with others (including their evolutions over time) can help to understand why an individual has radicalised toward violent action. Based on prior research and theories, the authors identified potential patterns and mechanisms of loneactor terrorism. These mechanisms include those that focus on withdrawal from personal relationships (either due to conflict, eventual attrition, or mental health concerns), isolation (either through experiences such as incarceration, or facing rejection from a terrorist group), or increased integration in the virtual community, which results in a withdrawal from other relationships. They then applied this theory by conducting an in-depth analysis of one case study and found that the mechanisms they developed were able to assist in identifying the

\footnotetext{
${ }^{14}$ Spaaij's definition of lone wolf terrorism and Gruenewald et al's definition of 'loners' were limited to individuals who had operated alone. Meloy and Gill's definition of lone-actors included only individual actors, while Gill et al.'s definition of lone-actors expanded this to include isolated dyads. Roy Van Zuijdewijn \& Bakker's definition includes individuals, isolated dyads and isolated triads. Jasparro's definition of 'lone-wolves' was limited to individuals acting alone.
} 
distinct pathway of radicalisation for that individual. Although this analysis was promising, they concluded that analysis was required on a larger sample of radicalised lone-actors before any inferences could be made with confidence.

The authors then followed this with a more detailed analysis of mechanisms that lead to different radicalisation pathways for lone-actor terrorists (Lindekilde, Malthaner, \& O'connor, 2019). They analysed a sample of 33 lone-actor ${ }^{15}$ cases, and identified two types of radicalisation pathways, peripheral and embedded lone-actor terrorists. They then conducted an in-depth analysis on five of these cases, which classified some sub-types of the two main radicalisation pathways. They concluded by stating that lone-actor radicalisation patterns do not exist in isolation, and in some cases they found similar patterns of radicalisation in their sample of lone-actors than what has been found in group terrorism. However, they confirm that there are three types of causal mechanisms which are specific to lone-actor radicalisation: those that limit further integration into an extremist group; those that result in a separation with or a disconnect from a terrorist group; and those that result in radicalisation while the individual is secluded. They concluded by arguing that relational configurations of individuals undergoing radicalisation are key to understanding lone-actor radicalisation.

\section{Theoretical Explanations and Ideological Motivations}

This section will discuss theoretical explanations for why individuals adhere to an ideology to the extent that they are willing to commit acts of violence in order to further that ideology.

Individuals' responses to ideology. An analysis of the wider social psychological explanations of terrorism has concluded that there were three factors that were critical for an individual to undergo radicalisation towards violence (Webber \& Kruglanski, 2018). The first is that an individual must have an initial need that propels them to undertaking violence. This need may be a hardship or strain that an individual has felt, or something that has caused humiliation and motivates the individual to undertake action in order to negate the humiliation. The second is that the individual must adhere to an ideology which identifies a target for their action, and provides a framework that justifies violence as legitimate. The

\footnotetext{
15 This definition of lone-actors included only single actors
} 
authors argue that as long as the ideology has these two components it does not matter what the ideology is, or where it sits on the political spectrum. Thirdly, a strong social network must be present that shares the ideological beliefs of the perpetrator and provides a collective identity which help the individual take the final steps to undertaking terrorism. Webber and Kruglanski (2018) conclude by saying that although a number of individuals may feel one or two of these factors, it is only the combination of all three that separate out the small number of individuals who will conduct terrorism, with the wider population of those who are dissatisfied or who hold extreme beliefs, but do not take action. Thus, although IE and RWE exist on opposite ends of the political spectrum, those who have undertaken violence in the name of either of the ideologies are likely to have similar backgrounds, involving some past humiliation and contact with a social network that shares the same ideological beliefs.

Support for ideological motivations for committing terrorism can also be understood in terms of an individual's perceived control over various aspects of their life. For example, compensatory control theory (Kay, Gaucher, Napier, Callan, \& Laurin, 2008) outlines that when an individual feels like they have lost control in one area of their life (personal control), they are likely to increase their trust in control in another area of their life (social or ideological control). The increase in social or ideological control offers the individual security and allows them to compensate for their perceived failure in personal control. Further, Kay and Eibach (2013) found that individuals are more likely to embrace extreme ideologies, especially those that believe in external sources of control, when they are faced with seemingly random or threatening events. Prior research has found indicators of a loss of control in the lives of loneactors who commit ideological terrorism, including the inability for both IEs and RWEs to find or keep gainful employment (Gill et al., 2014; Gruenewald et al., 2013a; Weenink, 2015), and the inability for RWEs to find an intimate partner (Gruenewald et al., 2013a) or to gain higher levels of education (Gill et al., 2014) ${ }^{16}$.

Some theoretical explanations explore ideological motivations for conducting terrorism within the wider cultural paradigm, such as through the lens of subcultural theory. For example, Colvin and Pisoiu (2018) used neutralisation theory to explore how perpetrators of ideological violence utilise moral neutralisations techniques when recounting their past

\footnotetext{
${ }^{16}$ Gruenewald et al's definition of 'loners' includes individuals operating alone. Gill et al.'s definition of loneactors included only individual terrorists and isolated dyads. Weenink's sample consisted of Jihadis who had travelled to Syria/Iraq to join ISIL or had aspirations to do so
} 
violent actions as a mechanism to justify those actions. They utilised the five original moral neutralisation techniques from Sykes and Matza (1957) and argued that there are different ways that the moral neutralisation techniques can be employed, two of which can be viewed as opposite to each other. The first is via an encultured mode which is one that frames the narrative within the mainstream culture, and the second is via a subcultural mode which frames the narrative in a culture that exists alternatively to the mainstream. Moral neutralisation techniques have a different function depending on the mode in which they were employed. Colvin and Pisoiu (2018) then analysed accounts of violence from men incarcerated for undertaking right-wing violent acts in Germany using the different modes of moralisation techniques, and found that both subcultural and encultured modes were utilised by the perpetrators when recounting acts of violence, sometimes even in the same sentence. This led them to tentatively conclude that perpetrators adhere to a set of norms and values that are alternative to those believed by the mainstream while at the same time they also reference mainstream ideals, which lends support to some narrative criminology understandings that those who conduct violence within an ideological subculture can have a fluctuating relationship with the mainstream (e.g. existing as both an alternative to the mainstream while at the same time incorporating ideals of the mainstream). The ultimate goal for the sub-culture is to replace the mainstream ideals with the ideals championed by the sub-culture. Attacks undertaken in the name of a specific ideology, such as attacks perpetrated by IEs and RWEs, can be viewed as a mechanism for gaining awareness of the existence of an ideology, and attempting to spread the ideals that ideology holds.

Conflict between the ideologies. Some theories discuss psychological explanations for how individuals act in group circumstances. For example, ingroup bias is where individuals view members of their own group in a better light than members of an external group, and can result in choices being made to favour members of their ingroup. Tajfel, Billig, Bundy, and Flament (1971) found support for this theory, finding that participants would systematically choose scenarios that favoured their (arbitrarily assigned) ingroup, over the outgroup. This finding was so strong that participants would even continue to demonstrate ingroup bias by choosing strategies that favoured their group at the expense of other groups even when presented with an alternative strategy that would provide maximum utilitarian advantages to all groups. In certain circumstances, such as intergroup conflict, ingroup bias can result in 
strategies being chosen that can lead to violence towards the outgroup, which may result in retaliatory violence from the outgroup.

IE and RWE are two ideologies that are at times opposed to each other, and therefore may be viewed as being a part of inter-group conflict. However, theoretical explanations can show the ways in which they can influence each other. Contagion refers to the spread of violence as individuals imitate forms of other violence that they admire, and this spread is intensified by technological advancements in media such as the internet (Nacos, 2009). Contagion may spread amongst terrorists who have the same ideological beliefs (or are from the same in-group), but may also spread across the ideological divide: for example, Anders Breivik confirmed that he was inspired by Al Qaeda's tactics when planning his attacks in Norway (Nesser, 2012). Therefore, ideological framing can result in higher levels of terrorism, providing individuals with a framework that quickly identifies an out-group, and social processes that may result in violence spreading through retaliation and/or imitation.

Although they all provide different mechanisms for perpetrating terrorism, the theoretical explanations on ideological motivations for conducting terrorism detailed here are all similar in that they argue that belief in an ideology is a crucial factor in undertaking terrorism, rather than emphasising the requirement to follow one ideology over another. It follows then that those who undertake terrorism for a specific ideology may share some personal traits, and they may plan and conduct an attack in a similar way. 


\section{The Present Study}

This study is interested in comparing lone-actor terrorism committed by those who believe in an IE ideology with those who believe in a RWE ideology for a variety of reasons. Firstly, previous studies have found that these two types of ideologies are the most common motivations for conducting lone-actor attacks in Western countries. Gill et al. (2014) found that $43 \%$ of their sample of successful and thwarted lone-actor attacks followed an IE ideology while $34 \%$ held right-wing beliefs, and a later study by Gill found that $34 \%$ pertained to an IE ideology while 38\% were aligned with RWE (Meloy \& Gill, 2016) ${ }^{17}$. In their study on successful and foiled terror plots in Europe, Ellis and colleagues (2016) found that those who held IE or RWE beliefs accounted for nearly three quarters of the entire sample, with IE perpetrators accounting for $38 \%$ and right-wing accounting for $33 \% 18$.

Secondly, studies on both ideological motivations have found evidence that certain characteristics are more likely to be present in individuals conducting lone-actor attacks and who belong to the same ideological sub-group. In his study on Jihadi terrorists in Europe, Bakker (2006) found that there was no uniform profile for a Jihadi terrorist; rather there are a number of shared traits that exist across a number of Jihadis. This conclusion was also reached by other research; Gill and colleagues (2014) found some similarities between individuals who believe in the same ideology, but concluded that there is no standard profile for all perpetrators of lone-actor attacks. They found that those who believe in IE ideology were more likely to be younger, be students at the time of offending, have sought approval from an authority figure, and had used online sources for training and research than compared to right-wing and single-issue perpetrators. In addition, they found that RWE were more likely to be unemployed, less educated, broadcast their beliefs to family and friends and have made physical preparations for their attack than IE or single-issue perpetrators.

Thirdly, although they have separate ideological motivations for conducting terrorism, IEs and RWEs can be influenced by each other. Heitmeyer (2005) argued that there are certain circumstances in which cooperation can occur between the two groups, due to shared beliefs. An example is both groups' negative views on Jews, which results in both ideologies espousing anti-Semitic beliefs. This influence can also have a negative association. Since 9-11 and the

\footnotetext{
${ }^{17}$ Meloy and Gill's definition of lone-actors included only while individual actors, while Gill et al.'s definition of lone-actors expanded this to include isolated dyads.

18 This definition of lone-actors includes individuals, isolated dyads and isolated triads
} 
number of deadly attacks in Europe and North America, attacks conducted by IEs have been the main focus of public perception of terrorism (Ellis et al., 2016). This has resulted in a rise of an anti-Islamic movement in these countries, an ideology that is supported and promoted by legitimate actors such as politicians and powerful public figures, to fringe actors such as extremist groups. The anti-Islamic movement has also had an impact on the perpetration of right-wing terror attacks, with Berntzen and Sandberg (2014) arguing that the actions of Andres Breivik, the perpetrator of the 2011 bombing and subsequent mass shooting in Norway, originated from and was influenced by the rhetoric of the anti-Islamic movement.

Therefore, it could be argued that an increase in attacks perpetrated by IEs in Western countries may result in a rise of anti-Islamic sentiment, which in turn may influence the perpetration of attacks conducted by RWEs who subscribe to this sentiment. Prior research has found that lone-actor attacks conducted by RWEs increased after 9/11, which was a highly-publicised attack conducted by a Jihadi terror group (Gruenewald et al., 2013a). The Institute for Economics and Peace (2017) found that terror attacks conducted by IEs have significantly increased since 22 September 2014, when an ISIL spokesman called on supporters to undertake attacks on targets in Western countries. The theory of contagion, as outlined above, may result in violence being imitated by individuals who subscribe to IE, as well as other ideological motivations: for example, Anders Breivik's attack planning was influenced by the tactics of Al Qaeda (Nesser, 2012). Thus, the increase in one motivation for conducting terrorism could influence the likelihood of attacks by the other motivation. It is possible that the perpetrators in this sample have been inspired by attacks undertaken by others, both those who share their ideological beliefs and those who oppose it.

Lastly, although IEs and RWEs attempt terror attacks at similar rates, there is a marked difference in how successful these attacks are. Ellis and colleagues (2016) found that only 55\% of plots from RWEs lead to an attack, whereas $75 \%$ of plots from IEs lead to an attack. They concluded that IEs showed more of an ability to undertake a successful terror attack. Understanding why the disparity occurs may provide insight into behaviours that successful perpetrators undertake, which could assist law enforcement and intelligence agencies in identifying and apprehending lone-actors. 


\section{Research Questions}

This thesis intends to be an exploratory investigation into two ideological motivations for perpetrating lone-actor terrorism. Although there have been several studies that have examined the ideological motivations for undertaking terrorism overall, they have not looked specifically at populations of lone-actors (Chermak \& Gruenewald, 2015; Sageman, 2004). There have been some studies that have looked at lone-actor terrorism, but have either studied it overall (Eby, 2012; Meloy et al., 2015; Spaaij, 2010) ${ }^{19}$, only explored one of the ideological motivations (Gruenewald et al., 2013a, 2013b; Jasparro, 2010), or undertook a comparative analysis with one of the ideological motivations and the population of LAT overall (Bouhana, Corner, Gill, \& Schuurman, 2018). Of the few studies that have examined IE and RWE populations of lone-actor terrorist, some have not undertaken a statistical comparative analysis between the two groups (Ellis et al., 2016; Roy Van Zuijdewijn \& Bakker, 2016) , while those who have undertaken a statistical comparative analysis have taken their sample from the same dataset, and only included attacks up to 2014 (Gill et al., 2014; Meloy $\&$ Gill, 2016). Therefore this is the only piece of research (so far) to undertake a comparative analysis on IE and RWE lone-actor terrorism, examining attacks that have been perpetrated up until the end of 2017.

The first research question is interested in exploring and identifying trends in the sample of lone-actor terrorists, and evaluating how this compares with prior research.

1. What is the nature and extent of lone-actor terrorism in North America, Western Europe and Australia between 2010-2017 and how does this relate to the results of other studies?

This thesis's main focus is on exploring the most common ideological reason for committing terrorism in Western countries: IE. Comparison with another type of ideological motivation will allow for similarities and differences between the two groups to be highlighted, which could help in the overall understanding of IE and RWE perpetrated loneactor attacks.

${ }^{19}$ Eby's and Spaaij's definition of lone wolves is limited to individuals who have operated alone 
2. How do IE and RWE lone-actor terrorists differ in terms of the characteristics coded for in this study?

A subset of IE is the foreign fighter phenomenon. During the last decade, the conflict in Iraq and Syria has resulted in a flow of individuals to those regions who intend on fighting for IE groups such as ISIL, many of them from Western Countries. As mentioned above, ISIL has recently had significant territorial losses which has resulted in a number of foreign fighters returning to their home countries. It is possible that these individuals would still adhere to an IE ideology, and may support that ideology by committing an act of terrorism, which this thesis is interested in determining.

3. How many attacks have been perpetrated by RFF and have these attacks increased over time? 


\section{Methods}

\section{Participants}

The database of perpetrators was developed by first finding relevant cases from the Global Terrorism Database (GTD; National Consortium for the Study of Terrorism and Responses to Terrorism, 2018). The GTD is developed and maintained by the National Consortium for the Study of Terrorism and Responses to Terrorism (START), and consists of over 190, 000 global terror attacks that have occurred since 1970.

All terror attacks that occurred between $1^{\text {st }}$ January $2010-31^{\text {st }}$ December 2017 in North America, Western Europe and Australia were downloaded from the GTD. These countries were chosen due to the likelihood that cases were readily available to code utilising information found in open source media. Although attacks from 2018 were available later during the research, at the time of compiling the database the GTD only included attacks up to $31^{\text {st }}$ of December 2017.

The download of the GTD includes two columns that list the deaths and injuries caused by each attack. Terror attacks that had no injuries or deaths were excluded at this stage, as this study was only interested in attacks which caused an injury or fatality to someone other than the perpetrator.

The GTD download includes a perpetrator type column, where the cases are classified by the type of ideology that the perpetrator adheres to. All types that were clearly not linked to either IE or right-wing extremism were filtered out. Cases where the perpetrator type was known but it was not clear if it could be categorised as either IE or right-wing extremism were kept in, as determination on the ideology could be made later when looking more closely at each individual case. Cases where the perpetrator type was 'unknown' were excluded as for most of those cases it was unlikely that additional information would be uncovered to determine if the case fits within IE or right-wing extremism.

The next stage of filtering the GTD dataset involved viewing the facts of each case to determine if they met the following inclusion criteria:

1. Can the attack be considered under the definitions of IE or RWE?

2. Does the attack have three or less perpetrators?

3. Did the attack happen without instruction from a wider terrorist organisation or extremist movement (including from individuals linked to either of those)? 
4. Did the attack cause a fatality or injury to someone other than the perpetrator?

Each attack was examined to determine if it could fit the ideology of IE or RWE. The definition for RWE included attacks which fall under at least one of the five-subcategories of RWE that is of interest to this study: white supremacist, anti-immigration, anti-government, anti-Muslim and anti-Semitic. Determining if cases fit into one of the two ideologies of this research may rely on the authorities investigating those attacks determining the motive of the perpetrator(s). If the motive is ambiguous, or there has been no clear motive found then it may be more difficult to assess if the individual could meet the first inclusion criteria. Additionally, as right-wing extremism includes a broad range of sub-ideologies that generally overlap with each other, determining if a case fits one of the five sub-categories was at times difficult. To overcome this, cases where the primary motive could not be classified under one of the five sub-categories were not included. The most notable examples were attacks perpetrated by incels, such as the attack undertaken by Elliot Rodger in 2014. Incels believe themselves to be 'involuntarily celibate', as they are denied sexual experiences by women who instead choose sexual experiences with alpha males (Young, 2019). Incels are part of a wider movement of right-wing hate-groups that interlace misogyny and elements of white supremacy (Anti-Defamation League, 2018). However, as the primary driver is misogyny, attacks undertaken by incels were excluded from this research.

Cases where more than three perpetrators, or there was evidence of direction being given from a wider terror organisation were excluded. This research employs a definition of lone actor attacks which include attacks perpetrated by one, two (dyad) or three (triad) individuals if there is no direction given from an organisation. Perpetrators may have had prior contact or minor interaction with a terrorist organisation, or may have publicly shown support for the terrorist organisation; however, to be included the perpetrators had to operate independently of the wider organisation and not receive direction from the organisation in planning or undertaking the attack. Cases where direction has been given from another individual have been included only if the total number of perpetrators and individuals giving direction does not exceed three, and individuals giving direction did not have ties to a wider terrorist organisation or extremist movement.

Cases where the only injury or death was the perpetrator were also excluded at this stage as this research was only interested in those attacks that had caused a physical injury 
or death to someone other than the perpetrators. Instances where the only injury or death was to police officers or other authorities responding to the terrorist incident were included.

As this study is interested in examining the background characteristics of the perpetrators, cases where the perpetrator was unknown, or the identity was not released to the public were excluded due to minimal information available on the perpetrators. Where the identity of the perpetrator was only partially released, as is the case with most perpetrators in Germany, the attack was included as enough information on the perpetrators can usually be found in open-source media.

Research was undertaken to find other cases of lone-actor terrorism that were either not included in the GTD, or were removed from the initial filtering that was undertaken (e.g. from deciding to exclude cases where the perpetrator type was 'unknown'). Cases were found by undertaking searches using search engines or databases and by looking at cases that were studied by other researchers. Search terms utilised a combination of terrorism related words and the countries of interest, such as 'terror attacks Europe', 'Ione-actor terrorism United States' and 'terrorism Australia' and were entered into Google, Google Scholar, LexisNexis and Te Waharoa (the Victoria University of Wellington search engine). After applying the inclusion criteria, a total of six cases of lone-actor terrorism were added to dataset.

Figure 1 shows the steps taken to obtain the sample, and how many cases were excluded at each step. The eventual sample consisted of 102 individuals who perpetrated 99 terror attacks between $1^{\text {st }}$ January 2010 and $31^{\text {st }}$ December 2017 in North America, Western Europe and Australia. Initially 19 countries were included in the study, but after applying all of the inclusion criteria to all cases, only 12 countries remained: Canada, United States of America, Australia, Belgium, Denmark, Finland, France, Germany, Italy, Norway, Sweden and the United Kingdom. Demographics of the perpetrators such as age, gender and education background are described in the results section.

The next stage of the research involved reviewing each case and making an observation for each variable in the codebook from open-source material. The open-source material included news articles about the attack, government reports written about the attacks, academic research on the perpetrators, interviews with the perpetrators or their family and friends, and where possible court documents or evidence from the trial. The GTD entry or source where the attack came from usually contains some information about the 


\section{Figure 1}

Flowchart Outlining steps in Case Selection

Initial download of GTD included terror attacks meeting the following criteria:

$>$ Occurred between 01/01/2010 and 31/12/2017

$>$ Occurred in North America, Europe and Australia Total of 1756 attacks

First stage of filtering excluded irrelevant attacks, including those:

$>$ Which caused no injuries or deaths (including unknown casualty numbers) (1392)

$>$ Where perpetrator type was clearly not Islamic Extremism or RWE, or was unknown (181)

Total 183 Cases

Second stage of filtering included examining each case, to exclude:

$>$ Perpetrators where motive was unclear or not linked to the definitions of IE and RWE used in this research (including maybe not being terrorism) 35

$>$ Those that had more than three perpetrators or unknown 16

$>$ Those that had direction from a wider organisation or individual linked to organisation 22

$>$ Those where the only injury and/or death were that of the perpetrator(s) 6

$>$ Those where the identity of the perpetrator(s) was unknown or not made public 11

Total removed 90

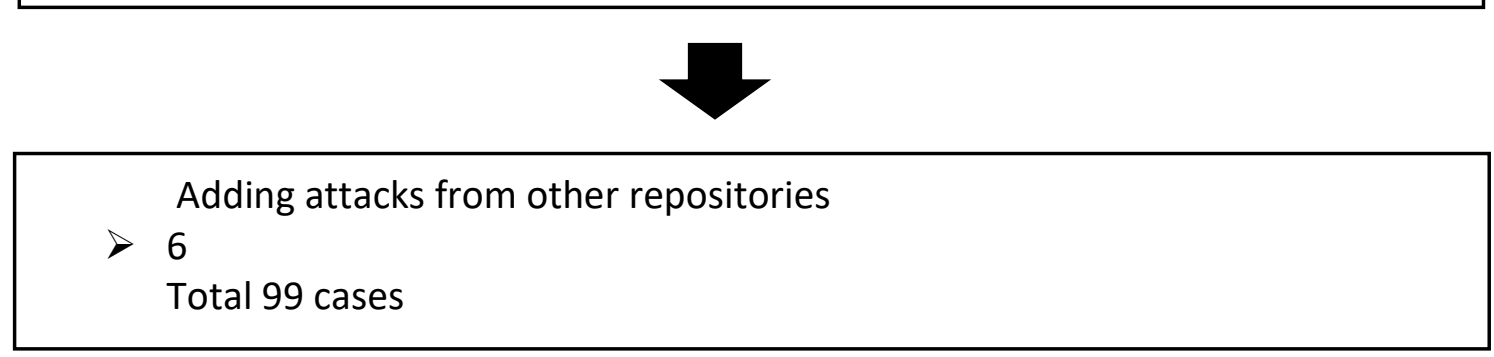

attack, including the perpetrators' names. Then search terms were entered into specific search engines (Google and Lexis Nexis) to find relevant material. Search terms involved an attack-specific characteristic (such as perpetrator name(s), attack type or victim name) or the location of the attack, or a combination of both. Examples include 'Roshonara Choudhry stabbing', 'Anders Breivik school' and 'Pulse nightclub shooting'. The search terms varied 
depending on the search engine being used, the amount of information available on the case, and the uniqueness of attack characteristics (such as perpetrators name, or number of attacks that had happened in a certain country or location).

\section{Measures}

A codebook was developed for this research, which examined the background and attack characteristics for each perpetrator. This codebook was developed from a review of prior research into the perpetration of terror attacks, mostly including those studies cited in the literature review of this thesis. The codebook contains 28 variables across four different categories: background characteristics, behavioural characteristics, attack planning and attack perpetration.

There are two types of variables that are present in the codebook below. The first are called Type 1 variables, and are coding aspects of the attack overall. These variables would be the same for all perpetrators of an attack. The second are called Type 2, and are looking at characteristics at the individual level, and are likely to differ across the perpetrators of an attack. The type of variable has been indicated for each variable in Table 1, Table 2, Table 3, and Table 4.

\section{Background Details}

The first category consists of seven demographic and background characteristics of the perpetrator. Table 1 outlines the levels for each variable, with a brief explanation of each variable underneath.

Age. This measures the age of the perpetrator at the time of the attack, in the numerical number.

Gender. This categorises if the individual is male or a female.

Education. This variable has a total of five levels, which rank education from primary school, high school, tertiary education (undergraduate) or equivalent, and postgraduate study or equivalent. There is no requirement that the participant has completed or graduated from a level, rather a perpetrator can be coded if they have participated at that level.

Marital status. This measures relationship status at the time of the attack. The first level is when the perpetrator has never had a serious relationship or has been single for a 
Table 1

Background Variables by their Individual Levels

\begin{tabular}{|c|c|c|}
\hline Variable & Levels & Type \\
\hline Age & Numerical number & 2 \\
\hline Gender & $\begin{array}{c}0=\text { Male } \\
1=\text { Female }\end{array}$ & 2 \\
\hline Education & $\begin{array}{c}1=\text { Primary School } \\
2=\text { High School } \\
3=\text { Tertiary education (undergrad) or } \\
\text { relevant } \\
4=\text { Post graduate study or relevant } \\
5=\text { information not available }\end{array}$ & 2 \\
\hline Marital Status & $\begin{array}{c}1=\text { Single } \\
2=\ln \text { a relationship } / \text { married } \\
3=\text { Divorced } / \text { separated } / \text { widowed } \\
4=\text { Unknown }\end{array}$ & 2 \\
\hline Family Status & $\begin{array}{c}0=\text { No children or unknown } \\
1=\text { Have children }\end{array}$ & 2 \\
\hline $\begin{array}{l}\text { Nationality/ } \\
\text { Immigration? }\end{array}$ & $\begin{array}{c}1=\text { Immigrant } \\
2=\text { born in country of attack } \\
3=\text { unknown }\end{array}$ & 2 \\
\hline Employment & $\begin{array}{c}1=\text { Unemployed } / \text { retired } \\
2=\text { Student } \\
3=\text { Employed } \\
4=\text { information not available }\end{array}$ & 2 \\
\hline
\end{tabular}

long time, the second is when the perpetrator is in a relationship (including being married) and the third is when the perpetrator has been separated or widowed.

Family status. This variable counts the presence of children for a perpetrator. It can include step or fostered children as long as the perpetrator had a role in their upbringing.

Nationality/Immigration Status. This variable determines the relationship the perpetrator has with the country that the attack took place in. The first level is to capture those individuals who were not born in the country of the attack, while the second is to capture instances where they are born in the country of attack. Instances where the 
perpetrator was born in another country, but it was because their parents were temporarily there (e.g. on holiday or member of the diplomatic core) are counted as born in country of attack.

Employment. This variable has four levels, the first is to count instances where the perpetrator is unemployed or retired. The second is where they are a student, and the third is where they are employed. It is possible for a perpetrator to be both a student and employed at the same time, but this variable is categorising what their primary role is.

\section{Behavioural Characteristics}

The second category of variables consists of six behavioural characteristics of the perpetrator. Table 2 outlines the levels for each variable, with a brief explanation of each variable underneath.

\section{Table 2}

Behavioural Characteristics by their Individual Levels

\begin{tabular}{|c|c|c|}
\hline Variable & Levels & Type \\
\hline Mental Health & $\begin{array}{c}1=\text { Formal Diagnosis } \\
2=\text { Mention of Mental health difficulties } \\
3=\text { No evidence } / \text { mention of mental health } \\
\text { issues }\end{array}$ & 2 \\
\hline Social Isolation & $\begin{array}{c}0=\text { Mention of Social Isolation } \\
1=\text { No mention of social isolation }\end{array}$ & 2 \\
\hline Stressors & $\begin{array}{c}1 \text { = Presence of one stressor } \\
2=\text { Presence of multiple stressors } \\
3=\text { No presence/mention of stressors }\end{array}$ & 2 \\
\hline Criminal History & $\begin{array}{c}0=\text { Presence of criminal history } \\
1=\text { No criminal history/no mention }\end{array}$ & 2 \\
\hline History of Violence & $\begin{array}{c}1=\text { Formal record of violence } \\
2=\text { Mention of violence } \\
3=\text { No mention of violence }\end{array}$ & 2 \\
\hline Foreign Fighter & $\begin{array}{c}0=\text { Foreign Fighter } \\
1=\text { No evidence of being a foreign fighter }\end{array}$ & 1 \\
\hline
\end{tabular}


Mental health. This variable has three levels: mention of formal diagnoses of mental health or personality disorders made by a mental health professional who had access to the perpetrator (either before the attack or afterwards); instances where mental health difficulties were mentioned by sources, but not enough to be coded as a formal diagnosis; no mental health issues were mentioned.

Social Isolation. This variable measures mention of the perpetrator experiencing social isolation prior the attack taking place. Social isolation counts where sources mention that the perpetrator was isolated, being alone socially or an outcast.

Stressors. Stressors can be several stressful events that occur in the perpetrators life which may cause significant stress or emotional turmoil. These can include financial stressors (e.g. loss of job/income), relationship stressors (e.g. breakdown of personal relationship), physical or personal stressors (e.g. injury or illness) but must have occurred in the 12 months prior to the attack taking place. This variable is counted over three levels: the first counting where one stressor has occurred, the second where more than one stressor has occurred, the third where no stressors have occurred.

Criminal history. This variable counts if this perpetrator has been convicted of a crime prior to the attack occurring. Instances where the perpetrator has been arrested but no conviction was made are not counted as a criminal history.

History of violence. This variable counts the perpetrator conducting violence prior to the attack taking place. The first level is counting instances where there is a formal record of violence, and includes a conviction for a violent crime, or mention of violence in court cases which were not dismissed or lost. The second level is for instances where there was mention of violence in the perpetrator's background, but this was not a formal record.

Foreign Fighter. This variable is defined as an individual having participated in noncombat roles or moving to an area where there is sustained conflict. This can not be counted if the perpetrator participated in the conflict as part of the military of their home country or the country in which the attack happened.

\section{Attack Planning}

The third category consists of eight variables that evaluate instances of a perpetrator's life, or actions that a perpetrator takes when they were planning the attack. These variables 
Table 3

Attack Planning Variables by their Individual Levels

\begin{tabular}{|c|c|c|}
\hline Variable & Levels & Type \\
\hline $\begin{array}{l}\text { Relationship with terrorist } \\
\text { group }\end{array}$ & $\begin{array}{c}0=\text { Previous member } / \text { failed to join or ties to } \\
\text { terrorist group } \\
1=\text { No evidence of link to terrorist group }\end{array}$ & 2 \\
\hline $\begin{array}{l}\text { Contact with other } \\
\text { extremists }\end{array}$ & $\begin{array}{c}1=\text { Face to face contact } \\
2=\text { Virtual contact } \\
3=\text { No mention of contact }\end{array}$ & 2 \\
\hline Training & $\begin{array}{c}1=\text { Formal } / \text { hands on training } \\
2=\text { Consumption of training material } \\
3=\text { No evidence of training }\end{array}$ & 2 \\
\hline Target reconnaissance & $\begin{array}{c}1=\text { Visiting target } \\
2=\text { Researching target } \\
3=\text { No evidence of target reconnaissance }\end{array}$ & 2 \\
\hline Leakage Behaviour & $\begin{array}{l}1 \text { = Leakage of plans } \\
2=\text { Leakage of extreme beliefs } \\
3=\text { No evidence of leakage }\end{array}$ & 2 \\
\hline Authorities Aware & $\begin{array}{c}1=\text { Authorities aware of plans/activity } \\
2=\text { Authorities aware of extreme beliefs } \\
3=\text { Authorities aware of other } \\
4=\text { No evidence authorities were aware or } \\
\text { authorities were not aware }\end{array}$ & 2 \\
\hline $\begin{array}{l}\text { Third party assistance } \\
\text { (attack planning) }\end{array}$ & $\begin{array}{c}0=\text { Assistance was given } \\
1=\text { No assistance was given }\end{array}$ & 1 \\
\hline Level of planning & $\begin{array}{l}1 \text { = High } \\
2=\text { Medium } \\
3=\text { Low }\end{array}$ & 2 \\
\hline
\end{tabular}

are explained in further detail below Table 3, which summarises each variable and their individual levels.

Relationship with terrorist group. This variable measures a perpetrator's connection to a wider terrorist group and can be positively coded for if the individual has previously been a member, or has any ties to a terror group (including a failed attempt to join). The terror group has to be designated as such by a country or international body (e.g. the sanctions 
placed on individuals and groups linked to ISIL and AI-Qaida by the United Nations, pursuant to Security Council resolutions 1267 and 2253 (United Nations Security Council, 2019).

Contact with other extremists. This variable is concerned with capturing instances where perpetrators have had contact with other individuals who did not conduct the attack, but who share their extreme beliefs within five years of the attack occurring. The first level measures face-to-face contact with other extremists, the second measures virtual contact. If sources mention contact but do not specify if it was virtual or face-to-face, this is coded under the second level.

Training. This variable measures the amount of attack or weapon planning that the perpetrator has undertaken. The first level counts instances of formal or hands on training, such as prior military services, going to a gun range or undertaking a weapons course. The second level captures instances where the perpetrator has consumed training material, which includes reading extremists guides that discuss attack perpetration or weapons preparation. The third level counts instances where no training was undertaken.

Target reconnaissance. This variable captures the amount of research that the perpetrator has undertaken on the target or location of the attack. Instances where the perpetrator has physically visited the location or target prior to the attack are coded in the first level. Instances where the perpetrator did not visit but did undertake some form of research (e.g. through the internet) are captured in the second level.

Leakage behaviour. Leakage is a concept well utilized in other studies of terrorism and is defined as conveying through actions or words an individual's desire or intent to cause harm (Meloy \& O' Toole, 2011) which is captured by the first level. Instances where the perpetrator had leaked their extreme beliefs without an intent to cause harm is captured by the second level. To be counted as leakage, the leakage had to occur with enough time for a response (e.g. leakage immediately before an attack took place would not count), and had to occur to someone other than a co-conspirator or third party who gave assistance and was aware of the individual's intent).

Authorities aware. The first level counts instances where the authorities were aware of the plans of the perpetrator, or that the perpetrator held the extreme beliefs and intended to act on them (e.g. attempts to move to Syria to join ISIS). For the second level, the authorities were aware that the perpetrator had extreme beliefs but had no indication of an intent to act. For the third level, the authorities were not aware of the perpetrators extreme 
beliefs but were aware of something that may have pointed to their likelihood of undertaking an attack (e.g. purchasing precursor materials for explosives).

Third party assistance (attack planning). This variable is capturing instances where the perpetrator had assistance planning the attack from a third party, and this assistance was vital for the attack occurring. This could include someone who helped purchase weapons or funded the attack, either with or without knowing the perpetrators intent.

Level of planning. This variable includes an assessment on the level of planning of the attack, and is determined by either the amount of time an individual spent planning the attack (or the length of time between radicalisation and undertaking the attack), or the number of planning variables that were positively coded for, or a mixture of both. The first level measures attacks that had a high level of planning, which can be counted where it was planned for more than six months or where many of the planning variables were positively coded for. The second level captures instances where a medium level of planning was involved, such that the attack was planned for 2-6 months, or if more than a few of the planning variables were positively coded for. The third level captures low level of planning, where the attack was planned for less than a few months, or only a few of the planning variables were positively coded for.

\section{Attack Perpetration}

The last category contains seven variables measuring those parameters related to undertaking the attack. The levels for each variable are captured in Table 4, and further down is an explanation for each individual variable.

Number of perpetrators. This variable measures the number of perpetrators that undertook the attack (e.g. solely, dyad or triad). To be counted as a perpetrator, an individual had to have physically undertaken the attack. If an individual wasn't present for the attack, but they helped with planning or preparing for the attack (e.g. being the get-away driver, or helping to purchase weapons) then they would need to be counted in one of the third party assistance categories.

Number of deaths and number of injuries. These variables count the number of deaths and injuries caused by the terror attack but does not include the death or injury of the 
Table 4

Attack Perpetration Variables by their Individual Levels

\begin{tabular}{|c|c|c|}
\hline Variable & Levels & Type \\
\hline Number of perpetrators & Numerical number (1-3) & 1 \\
\hline Number of deaths & Numerical number & 1 \\
\hline Number of injuries & Numerical number & 1 \\
\hline Target Type & $\begin{array}{c}1=\text { Civilians } \\
2=\text { Social minorities } \\
3=\text { Government institutions/figures } \\
4=\text { Political figures/events } \\
5=\text { Other }\end{array}$ & 1 \\
\hline Weapon Type & $\begin{array}{c}1=\text { Explosive } \\
2=\text { Firearm } \\
3=\text { Incendiary device } \\
4=\text { Vehicle (not VBIED) } \\
5=\text { Knives or other sharp objects } \\
6=\text { Hands or blunt objects } \\
7=\text { other }\end{array}$ & 1 \\
\hline End of attack & $\begin{array}{c}1=\text { Perpetrator death by their own hand } \\
2=\text { Perpetrator death by authorities } \\
3=\text { Perpetrator in custody } \\
4=\text { Perpetrator escaped }\end{array}$ & 1 \\
\hline $\begin{array}{l}\text { Third party assistance } \\
\text { (attack perpetration) }\end{array}$ & $\begin{array}{c}0=\text { Third party assistance } \\
1=\text { No third party assistance }\end{array}$ & 1 \\
\hline
\end{tabular}

perpetrators. It does include deaths or injuries of third parties caused by authorities responding to the terror attack.

Target type. This variable is categorising the primary target of the attack across five levels. The first level is civilian, which counts attacks on the public which were not targeting a specific ethnic, social, or religious group. The second level counts attacks that are aimed at a specific social minority group. The third level counts attacks that were aimed at government institutions or figures, while the fourth captures those that are aimed at political figures or events. 
Weapon type. This variable measures the type of weapon used by the perpetrator and has seven levels measuring a variety of different types of levels. The first six levels measure different categories of weapons, while the seventh is for weapons that do not easily fit into one of the other six. In some cases, a weapon may fit into multiple categories or a perpetrator may use multiple weapons, so the primary weapon used will need to be counted for (e.g. weapon that caused the most injuries or casualties or was used the most).

End of attack. This variable is measuring how the attack ended. The first two levels are capturing instances where the perpetrator was killed, either by their own hand or by the authorities responding to the incident. This includes where they were injured but then later died of their wounds. The third variable is for when the perpetrator was detained and arrested within a kilometre of the attack occurring, and the fourth variable counts instances where the perpetrator escaped.

Third party assistance (attack perpetration). This variable is capturing instances where the perpetrator had assistance undertaking the attack from a third party, and this assistance happened immediately prior or after the attack. This could include someone who provided transport during the attack but did not participate in it, or someone who helped the perpetrator evade authorities after the attack.

\section{Inter-Rater Reliability}

All cases were reviewed by one researcher, with approximately one-tenth of the cases being reviewed by a research supervisor. Inter-rater reliability was measured using Cohen's Kappa to determine if there was agreement between the primary coder and the research supervisor and was interpreted using the scale of Kappa value developed by Landis and Koch (1977). For one case ( $3^{\text {rd }}$ party planning), Cohen's Kappa was unable to be calculated because one of the variables was a constant. For the other 27 variables, the lowest level of agreement was found for leakage, $K=.00, p=1.00$, and the highest level of agreement was found for seven variables which all had perfect agreement, $K=1.00, p<.001$ : number of attackers, number of deaths, number of injuries, weapon type, gender, family status, and history of violence, which all had perfect agreement. Overall, there was a high level of agreement between the two researchers, with social isolation, $\mathrm{K}=.72, \mathrm{p}=.005$ and employment, $\mathrm{K}=.78$ $p<.001$, being the median scores. 
According to the scale by Landis and Koch (1977), 11 variables (39.29\%) had perfect or almost perfect agreement between the researcher and supervisor, 6 (21.43\%) had substantial agreement, 8 (28.57\%) had moderate agreement, 1 (3.57\%) had fair agreement, and $1(3.57 \%)$ had slight agreement. For the two variables that had slight or fair agreement (leakage and level of planning respectively), the discrepancies were discussed and resolved between the two researchers. Overall, inter-rater reliability was an acceptable level considering the challenges that can be met with when utilising open-source research and indicated that other researches would obtain similar results if they undertook research utilising the same codebook.

\section{Description of Analysis}

This research employs a definition of lone-actor terrorism that includes attacks undertaken by one, two or three individuals if there is no direction from a wider group or individuals linked to a group. Of the 99 attacks that were studied in this research, approximately $10 \%$ had more than one perpetrator. The data was collected by looking at the characteristics of individual perpetrators across all variables; however, some variables in the codebook were coding aspects of the attack overall, and would therefore be the same for every individual conducting an attack. To avoid duplicating results, data from Type 1 variables were excluded from the analysis for the second and third perpetrator of an attack.

Of the 102 individuals who have conducted an attack, seven (approximately 7\%) have undertaken more than one attack. There was no exclusion of some of the attacks undertaken by perpetrators more than once, as although some of the variables may be exactly the same and therefore counted twice, many of the variables would differ enough between each instance of undertaking an attack.

The data was entered into an excel spreadsheet, and statistical analysis was undertaken using IBM's SPSS Statistics Version 26 for Windows. SPSS was chosen due to the researchers' familiarity, and its ability to undertake analysis on both categorical and numerical data while also being able to exclude results (e.g. for Type 1 data).

In order to answer the second research question, "how do IEs and RWE differ in terms of characteristics coded for in this study', bivariate analyses were undertaken to compare if there were any similarities or differences between the two ideological groups. The majority 
of the variables were categorical, so Pearson's chi square tests were performed. Significant chi square results were interpreted using standardized residuals (Agresti, 2007), whereby a residual score is interpreted as significant if two or more for a table that has only a few cells or lower degrees of freedom, and if three or more for a table that has many cells or higher degrees of freedom. A small number of the variables were numerical, and so independent samples t-tests were undertaken to make comparisons in those cases. Multivariate analysis was undertaken to further explore the relationship between the ideological groups, utilising a selection of key variables. A binary logistic regression model was utilised to examine the extent to which the two ideologies were similar or different. The variables that were selected have been outlined in the results section.

For variables where the unknown category was counted separately, cases where data was missing for that variable were excluded from the bivariate and multivariate analysis. The majority of categorical variables were counting more than two levels. In some cases the variables were collapsed to be dichotomous, mainly in situations where bivariate analysis could not be computed as the cell sizes were too small, or for all variables used in the multivariate analysis. The results section is explicit for those variables where the analysis was undertaken after excluding unknown cases or utilising collapsed variables. Results of all statistical analysis tests were deemed significant if the alpha level was less than $5 \%(p<.05)$. 


\section{Results}

The sample consisted of 102 individuals who perpetrated 99 terror attacks between $1^{\text {st }}$ January 2010 and 31 ${ }^{\text {st }}$ December 2017 in twelve countries across North America, Western Europe and Australia. The counts and proportions for each variable, and the comparisons between the two ideological groups have been described in the sections of four categories of variables below. Statistics on attacks perpetrated by country and year have been described in this section.

Country. There were twelve countries that attacks were conducted in, shown in Figure 2. The United States had the most attacks conducted for both RWE (21) and IE (20). Finland had the least number of attacks, with only one conducted by an IE. Many countries had only a small number of attacks overall, with only three (United States, United Kingdom and France) had more than ten attacks combined across both ideologies.

\section{Figure 2}

Number of Attacks per Country, by Ideology

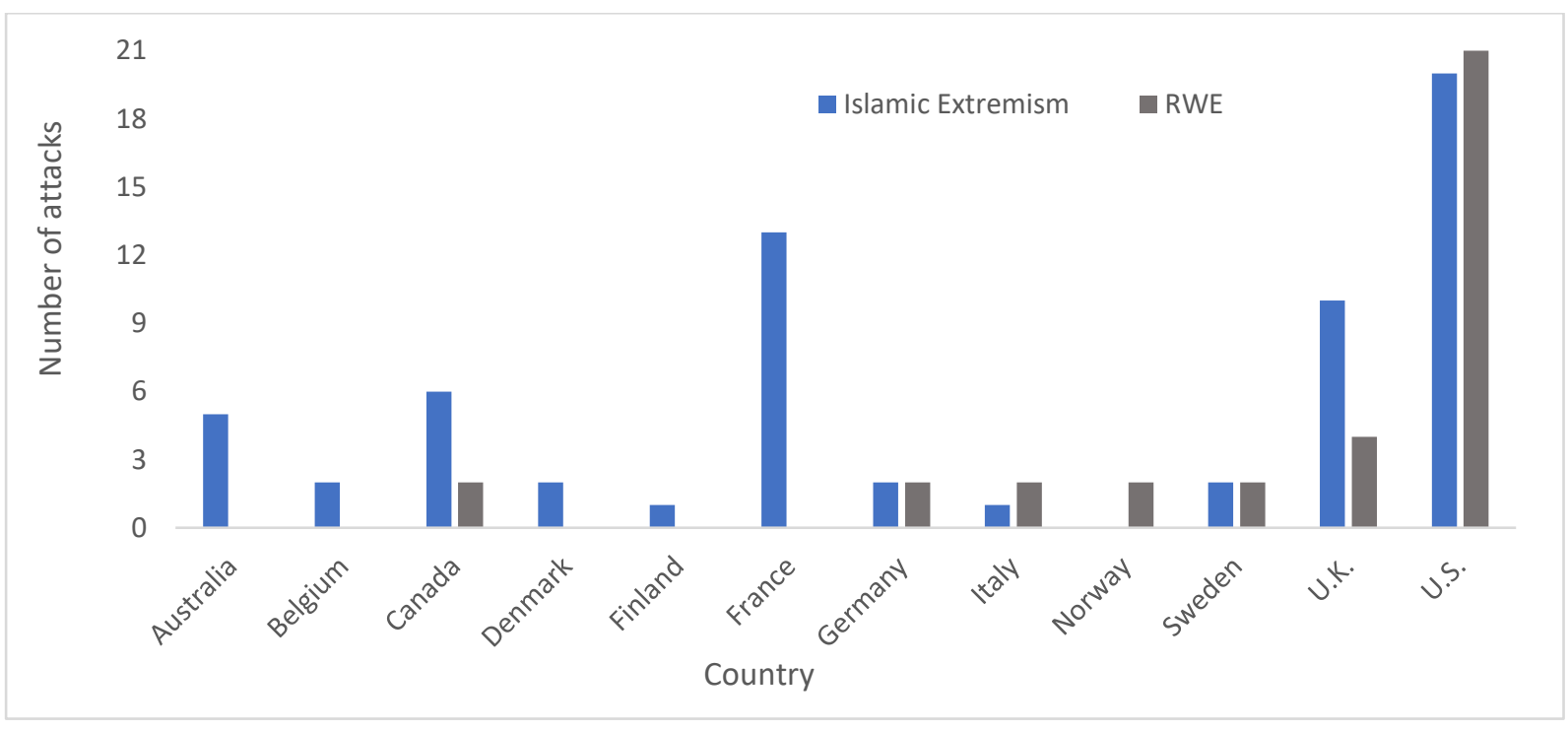

Year. The number of attacks by year have been outlined in Figure 3. The number of attacks has increased from 2010 - 2017 each year for both ideological types, with the maximum number of attacks occurring in 2017. For all years apart from 2011, the number of attacks perpetrated by IEs were equal to or greater than those conducted by RWE. Overall, Figure 3 shows that the trends for attacks conducted for both ideological groups are broadly similar, especially towards the end of the time period. 
Figure 3

Number of Attacks Each Year, by Ideology

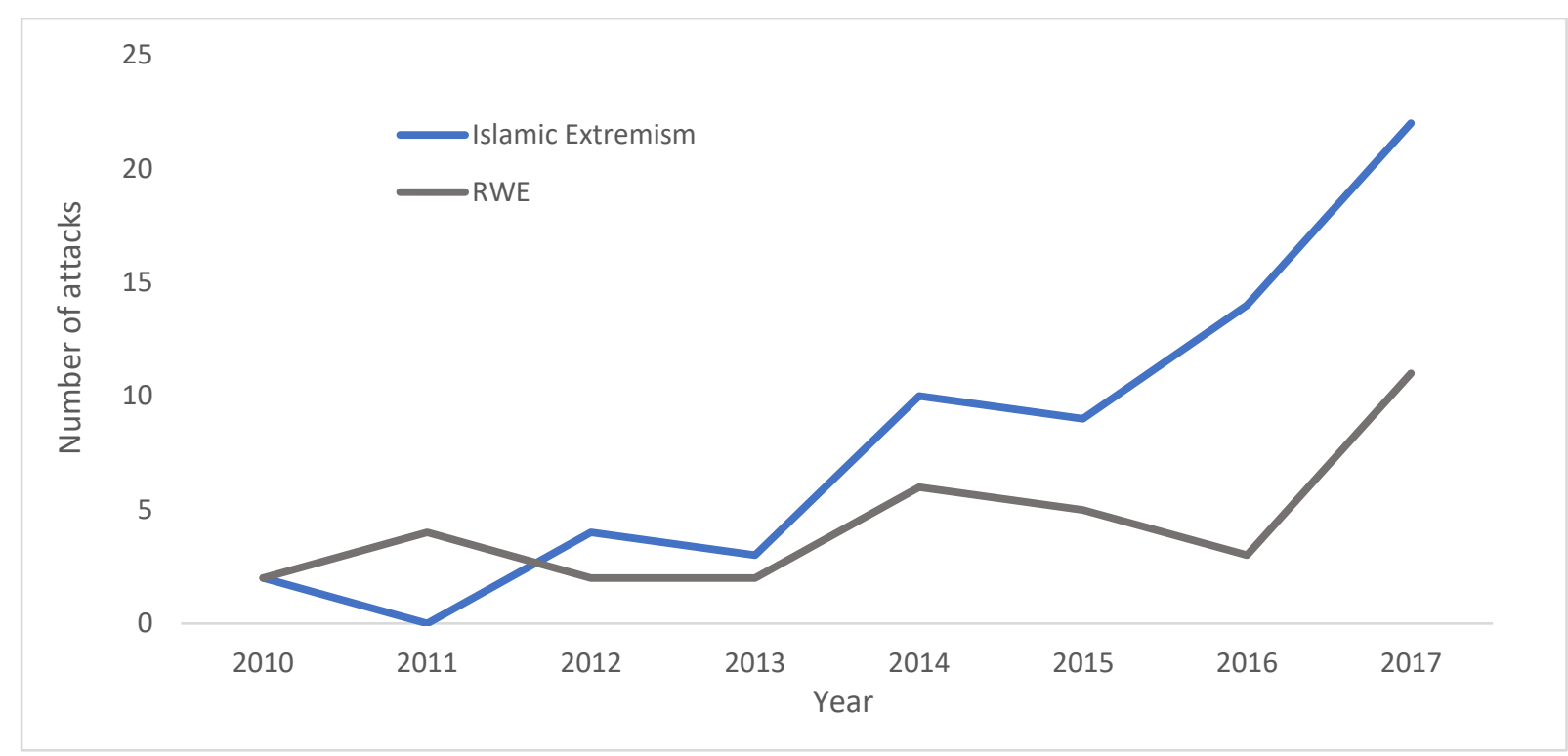

\section{Background Characteristics}

The results for background characteristics have been discussed for each variable in this section. All variables are Type 2 variables, so analysis has been undertaken on data from all perpetrators. The counts for each variable are displayed in Table 5, and comparisons have been made between the two ideological groups and discussed for each variable below.

Age. Although the youngest age of both groups was similar, RWE had a larger range than IEs. An independent samples t-test was undertaken to find a difference between the ages of perpetrators for the two ideological groups. A significant difference was found, $t(45.04)=-3.69, p=.001$, with the IEs being younger on average $(M=27.58, S D=7.38)$ than individuals adhering to a RWE ideology $(M=37.16, S D=14.90)$.

Gender. The whole sample was disproportionately male, with only 3 women in the IE group, and one woman in the RWE group. A chi square test of independence was undertaken to discover a link between gender and ideology of the perpetrator, but was unable to provide a result as the test assumptions were not met, as 2 of the cells (50\%) had an expected count of less than 5 .

Education. For a fair amount of IES and RWE, data could not be found on their education levels ( $24 \%$ and $35.1 \%$ respectively). Of those cases where data was available, the majority of IEs had the highest level of education as university (52.9\%), followed by high 
Table 5

Counts and Percentages, or Ranges and Means for Background Characteristics

\begin{tabular}{|c|c|c|c|c|}
\hline \multirow[b]{2}{*}{ Variable } & \multirow[b]{2}{*}{ Levels } & \multicolumn{2}{|c|}{ Ideology } & \multirow[b]{2}{*}{$\begin{array}{l}\text { Chi } \\
\text { Square or } \\
\text { t-test }\end{array}$} \\
\hline & & $\begin{array}{c}\text { IEs } \\
(n=74)\end{array}$ & $\begin{array}{c}\text { RWE } \\
(n=37)\end{array}$ & \\
\hline Age & Numerical number & $16-52(27.58)$ & $\begin{array}{l}19-73 \\
(37.16)\end{array}$ & $* *$ \\
\hline Gender & $\begin{array}{l}\text { Male } \\
\text { Female }\end{array}$ & $\begin{array}{l}71(95.9 \%) \\
3(4.1 \%)\end{array}$ & $\begin{array}{c}36(97.3 \%) \\
1(2.7 \%)\end{array}$ & NS \\
\hline Education & $\begin{array}{c}\text { Primary School } \\
\text { High School } \\
\text { Tertiary education } \\
\text { Post-graduate study } \\
\text { Unknown }\end{array}$ & $\begin{array}{c}3(4.1 \%) \\
20(27.0 \%) \\
27(36.5 \%) \\
1(1.4 \%) \\
23(24 \%)\end{array}$ & $\begin{array}{c}0(0 \%) \\
7(45.9 \%) \\
5(13.5 \%) \\
2(5.4 \%) \\
13(35.1 \%)\end{array}$ & $*$ \\
\hline $\begin{array}{l}\text { Marital } \\
\text { status }\end{array}$ & $\begin{array}{c}\text { Single } \\
\text { In a relationship/married } \\
\text { Divorced/separated/widowed } \\
\text { Unknown }\end{array}$ & $\begin{array}{c}3(4.1 \%) \\
22(29.7 \%) \\
15(20.3 \%) \\
34(45.9 \%)\end{array}$ & $\begin{array}{l}11(29.7 \%) \\
8(21.6 \%) \\
3(8.1 \%) \\
15(40.5 \%)\end{array}$ & $* *$ \\
\hline $\begin{array}{l}\text { Family } \\
\text { status }\end{array}$ & $\begin{array}{c}\text { No children or unknown } \\
\text { Have children }\end{array}$ & $\begin{array}{l}47 \text { (63.5\%) } \\
27(36.5 \%)\end{array}$ & $\begin{array}{c}33 \text { (89.2\%) } \\
4 \text { (12.9\%) }\end{array}$ & $* *$ \\
\hline Nationality & $\begin{array}{c}\text { Immigrant } \\
\text { Born in country of attack } \\
\text { Unknown }\end{array}$ & $\begin{array}{c}36(48.6 \%) \\
32(43.2 \%) \\
6(8.1 \%)\end{array}$ & $\begin{array}{l}2(5.4 \%) \\
15(40.5 \%) \\
20(54.1 \%)\end{array}$ & $* *$ \\
\hline Employment & $\begin{array}{c}\text { Unemployed/ retired } \\
\text { Student } \\
\text { Employed } \\
\text { Information not available }\end{array}$ & $\begin{array}{l}25(33.8 \%) \\
8(10.8 \%) \\
18(24.3 \%) \\
23(31.1 \%)\end{array}$ & $\begin{array}{l}15(40.5 \%) \\
2(5.4 \%) \\
11(29.7 \%) \\
9(24.3 \%)\end{array}$ & NS \\
\hline
\end{tabular}

school (39.2\%), primary school (5.9\%) and post-graduate study (2.0\%). For RWE, the majority of those had high school as their highest level (70.8\%), followed by tertiary education (20.8\%) and post-graduate study (8.3\%). To investigate a link between education level and ideology, a chi square test was undertaken for a $4 \times 2$ table (with the cases with unknown results excluded), but the test assumptions were not met as more than $20 \%$ of the cells had an 
expected value of less than five. To meet the assumptions, primary and high school levels were collapsed together, and the tertiary and postgraduate (or equivalent) levels were collapsed together. Another chi square test was undertaken, and this time the assumptions were met, and a significant association between education level and ideology of the perpetrator was found, $\chi 2(1)=4.34, p=.037$. IEs were more likely to have a higher education, with over half (54.9\%) having experienced higher one compared to just over one-quarter (29.2\%) of RWEs.

Marital status. For both IEs and RWE, the marital status of the perpetrators was unknown for more than two-fifths of the cases. When excluding unknown cases, over half of the IEs were married or in a relationship (55.0\%), and over a third were previously in a relationship but now single (37.5\%) with a small number being single (7.5\%). However, the opposite was true for RWE, with half being single (50\%), over a third being married or in a relationship (36.4\%) and the rest being previously in a relationship but now single (13.6\%). A chi square test of independence was undertaken to examine the relationship between marital status and ideology of the perpetrator (excluding unknown cases) and there was a significant association found, $\chi 2(2)=15.16, p=.001$. Standardized residuals were calculated for each level to explore the association between each level and the ideological types, and are displayed in Table 6. For one level there was a significant residual score, with RWE more likely to be single than IEs.

Family status. For both IEs and RWEs, over half of the perpetrators did not have children/no information was available (63.5\% and $89.2 \%$ respectively). To test the strength of association between family status and ideology, a chi square test for independence was performed. A significant association was found between family status and ideology of the perpetrator, $\chi 2(1)=8.08, p=.004$, with IEs being more likely to have children than RWE.

Nationality. Table 5 shows that while the nationality status of only a small proportion of IEs are unknown (8.1\%), over half of the nationality status of RWEs are unknown. When discounting the unknown cases, over half (52.9\%) of the IEs are immigrants to the country of attack, while the vast majority (88.2\%) of RWEs were born in the country of attack. To test if there is an association between nationality and ideology for the entire sample, a chi square square test was undertaken (excluding unknown cases). It found a significant association between the nationality and ideology of the perpetrator, $\chi 2(1)=9.33, p=.002$. 
Table 6

Count, Expected Count and Residuals for Marital Status and Ideology Cross Tabulation

\begin{tabular}{cccc}
\hline \multicolumn{2}{c}{ Marital status } & \multicolumn{1}{c}{ Ideology } \\
& & IE & RWE \\
& & $(\mathrm{n}=74)$ & $(\mathrm{n}=37)$ \\
\hline \multirow{2}{*}{ Single } & Count & 3 & \\
& Expected Count & 9.0 & 11 \\
& Standardized Residual & -3.8 & 5.0 \\
In a relationship/ & Count & 3.8 \\
married & Expected Count & 19.4 & \\
& Standardized Residual & 1.4 & 10.6 \\
Divorced/separated/ & Count & 15 & -1.4 \\
widowed & Expected Count & 11.6 & 3 \\
& Standardized Residual & 2.0 & 6.4 \\
& &
\end{tabular}

Employment. For a relatively large proportion of the sample, there was no information to be found on their employment status; just under a third for IEs (31.1\%) and just under a quarter for right wing extremists (24.3\%). When discounting the unknown cases, the majority of individuals were unemployed or retired for those who adhered to an IE belief (49.0\%) and those who adhered to a RWE belief (53.6\%). The next variable was employed, with $35.3 \%$ of the IEs and $29.3 \%$ of RWE being employed. Finally, students were not as common in the sample, with them accounting for $15.7 \%$ of the IEs and only $7.1 \%$ of RWE. A chi square test was undertaken to test the association between employment and ideology. There was no significant association between employment status and ideology, $\chi 2(2)=1.20$, $p=.550$.

\section{Behavioural Characteristics}

The results for behavioural characteristics have been discussed for each variable in this section. All variables are Type 2 variables, so analysis has been undertaken on data from all perpetrators. The counts for each variable are displayed in Table 7, and comparisons have been made between the two ideological groups and discussed for each variable below.

Mental health. Just under half of IEs (48.6\%) were coded for no evidence of mental health issues, with just under two-fifths (18.9\%) having a formal diagnosis of a mental health 
Table 7

Counts and Percentages for Behavioural Characteristics

\begin{tabular}{|c|c|c|c|c|}
\hline \multirow[b]{2}{*}{ Variable } & \multirow[b]{2}{*}{ Levels } & \multicolumn{2}{|c|}{ Ideology } & \multirow[b]{2}{*}{$\begin{array}{c}\text { Chi Square } \\
\text { or t-test }\end{array}$} \\
\hline & & $\begin{array}{c}\text { IEs } \\
(n=74)\end{array}$ & $\begin{array}{c}\text { RWE } \\
(n=37)\end{array}$ & \\
\hline \multirow{3}{*}{$\begin{array}{l}\text { Mental } \\
\text { Health }\end{array}$} & Formal Diagnoses & 14 (18.9\%) & $14(37.8 \%)$ & \multirow[t]{3}{*}{ NS } \\
\hline & $\begin{array}{c}\text { Mention of mental health } \\
\text { issues }\end{array}$ & 24 (32.4\%) & $8(21.6 \%)$ & \\
\hline & No evidence of issues & 36 (48.6\%) & 15 (29.4\%) & \\
\hline \multirow[t]{2}{*}{$\begin{array}{l}\text { Social } \\
\text { Isolation }\end{array}$} & $\begin{array}{l}\text { Mention of social } \\
\text { isolation }\end{array}$ & $23(31.1 \%)$ & $14(37.8 \%)$ & \multirow[t]{2}{*}{ NS } \\
\hline & $\begin{array}{l}\text { No mention of social } \\
\text { isolation }\end{array}$ & 51 (68.9\%) & $23(62.2 \%)$ & \\
\hline \multirow[t]{3}{*}{ Stressors } & Presence of one stressor & $28(37.8 \%)$ & $11(29.7 \%)$ & \multirow[t]{3}{*}{ NS } \\
\hline & $\begin{array}{c}\text { Presence of multiple } \\
\text { stressors }\end{array}$ & 14 (18.9\%) & $5(13.5 \%)$ & \\
\hline & $\begin{array}{c}\text { No presence/mention of } \\
\text { stressors }\end{array}$ & 32 (43.2\%) & $21(56.8 \%)$ & \\
\hline \multirow{2}{*}{$\begin{array}{l}\text { Criminal } \\
\text { history }\end{array}$} & Has a criminal history & 32 (43.2\%) & 17 (45.9\%) & \multirow[t]{2}{*}{ NS } \\
\hline & $\begin{array}{l}\text { No criminal history or no } \\
\text { mention }\end{array}$ & $42(56.8 \%)$ & $20(54.1 \%)$ & \\
\hline \multirow{4}{*}{$\begin{array}{l}\text { History of } \\
\text { violence }\end{array}$} & Formal record of violence & $23(31.1 \%)$ & $6(16.2 \%)$ & \multirow[t]{3}{*}{ NS } \\
\hline & Mention of violence & 11 (14.9\%) & $7(18.9 \%)$ & \\
\hline & No mention of violence & $40(62.5 \%)$ & $24(64.9 \%)$ & \\
\hline & & & & \multirow[t]{3}{*}{ N/A } \\
\hline Foreign & Foreign fighter & $7(10.9 \%) \dagger$ & $0(0.0 \%)+$ & \\
\hline Fighter & $\begin{array}{c}\text { No evidence of foreign } \\
\text { fighter }\end{array}$ & $57(89.1 \%) \dagger$ & $35(100.0 \%)+$ & \\
\hline \multicolumn{5}{|c|}{ tAnalysis on third party assistance (planning) excluded data related to Type 1 variables, and therefore had a sample size os. } \\
\hline \multicolumn{5}{|c|}{64 for IEs and 35 for RWE. } \\
\hline \multicolumn{5}{|c|}{$N S=$ not significant; ${ }^{*}=p<.05 ;{ }^{* *}=p<.01 ; * * * p<.001$ (two-tailed). } \\
\hline & not equal 100 due to rounding. & & & \\
\hline
\end{tabular}

issue, and just under one-third (32.4\%) having mention of mental health difficulties but no formal diagnosis. Opposite results were found for RWE, with the largest group being those with a formal diagnosis (37.8\%), followed by those with no evidence of mental health issues (29.4\%) and those who have mention of mental health difficulties but no formal diagnosis (21.6\%). To explore the relationship between ideology and mental health, a chi square test 
for independence was undertaken. There was no significant association between mental health and ideology, $\chi 2(2)=4.85, p=.088$.

Social isolation. For both IEs and RWE, the majority had no mention of social isolation (68.9\% and $62.2 \%$ respectively). To test if there was an association between the two variables, a chi square test for independence was conducted. There was no significant association between social isolation and ideology, $\chi 2(1)=.51, p=.477$.

Stressors. Both ideologies had the most representation in the no presence or mention of stressors group, with $43.2 \%$ of IEs and over half ( $56.8 \%$ of RWE) falling within it. The next largest group was the presence of one stressor, with over a third of IEs (37.8\%) and over a quarter of RWE (29.7\%) experiencing one stressful event in the last 12 months. Both groups had low numbers of those experiencing multiple stressful events in the last 12 months, with $18.9 \%$ for IEs and $13.5 \%$ of RWE. A chi squared test of independence was conducted to examine the relationship between stressors and ideology, but no significant association was found, $\chi 2(2)=1.83, p=.401$

Criminal history. Although most of the sample did not have a criminal history, a significant proportion of both IEs and RWE had a criminal history $(43.2 \%$ and $45.9 \%$ respectively). Although these proportions were similar for both ideological groups, a chi square test was undertaken to explore if a relationship existed between these two variables. However, as expected, no significant association was found between criminal history and ideology, $\chi 2(1)=.07, p=.787$.

History of violence. Similar to criminal history, over half of those in both ideological groups had no mention of violence in their past. IEs had a higher proportion (31.1\%) of those who had a formal record of violence than RWEs (16.2\%), but RWEs had a higher proportion (18.9\%) of those who had a mention of violence but no formal record than IEs (14.9\%). To explore the existence of a relationship between history of violence and ideology, a chi square test of independence was undertaken but no significant association was found, $\chi 2(2)=2.84$, $p=.242$.

Foreign fighter. Just under one-ninth (10.9\%) of the attacks perpetrated by IEs were undertaken by a RFF, while none of the attacks perpetrated by RWEs involved a RFF. This is not surprising, considering that this variable was included in this study to explore if the proportion of IE foreign fighters has increased over time, and due to this finding, a multivariate analysis was not undertaken as it was not required. Figure 4 shows the 
prevalence of attacks undertaken by foreign fighters in the IE group by year. There has been no increase in attacks conducted by foreign fighters over time, with the highest peak being the three attacks conducted by one individual in 2012 .

\section{Figure 4}

Attacks Undertaken by IEs Coded as Foreign Fighters, by Year

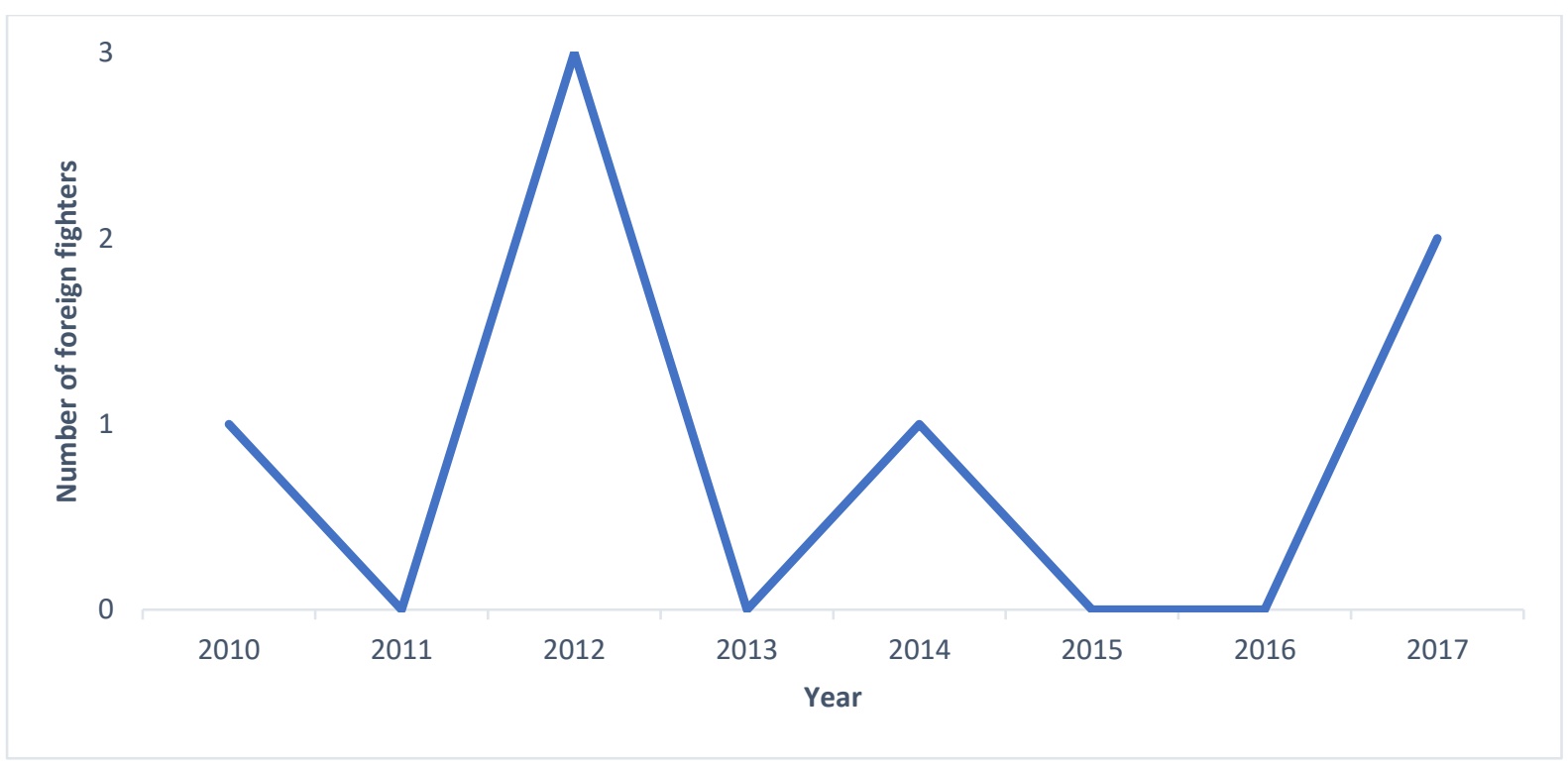

\section{Attack Planning}

The results for behavioural characteristics have been discussed for each variable in this section. All variables but one (third party assistance (planning)) are Type 2 variables, so results for the second and third perpetrators in attacks with more than one perpetrator have been included in the analyses described below. For third party assistance (planning), which is a Type 1 variable, data on the second and third perpetrators in attacks with multiple perpetrators have been excluded in the analysis for that variable.

Relationship with group. Most IEs had no previous ties or links to a terror group $(68.9 \%)$ while the entire sample of RWEs $(100 \%)$ had no previous ties or links to a terror group. To test the relationship between these variables, a chi square test of independence was undertaken. A significant association was found between the relationship with a terror group and ideology, $\chi 2(1)=14.51, p>.001$, with IEs more likely to be a previous member of a terror group than RWE.

Contact with other extremists. Just under half (48.6\%) of IEs had face to face contact with another extremist, and $14.9 \%$ had virtual contact only, while the rest had no mention of 
Table 8

Counts and Percentages for Attack Planning Variables

\begin{tabular}{|c|c|c|c|c|}
\hline \multirow[b]{2}{*}{ Variable } & \multirow[b]{2}{*}{ Levels } & \multicolumn{2}{|c|}{ Ideology } & \multirow[b]{2}{*}{$\begin{array}{c}\text { Chi Square } \\
\text { or t-test }\end{array}$} \\
\hline & & $\begin{array}{c}\text { IEs } \\
(n=74) \dagger\end{array}$ & $\begin{array}{c}\text { RWE } \\
(n=37) \dagger\end{array}$ & \\
\hline \multirow[t]{2}{*}{$\begin{array}{l}\text { Relationship } \\
\text { with group }\end{array}$} & $\begin{array}{l}\text { Previous member/failed } \\
\text { to join }\end{array}$ & $23(31.1 \%)$ & $0(0.0 \%)$ & $* * *$ \\
\hline & $\begin{array}{l}\text { No evidence of link to } \\
\text { terror group }\end{array}$ & 51 (68.9\%) & 37 (100\%) & \\
\hline \multirow{3}{*}{$\begin{array}{l}\text { Contact } \\
\text { with } \\
\text { extremists }\end{array}$} & Face to face contact & 36 (48.6\%) & 12 (32.4\%) & NS \\
\hline & Virtual contact & $11(14.9 \%)$ & $6(16.2 \%)$ & \\
\hline & No mention of contact & $27(36.5 \%)$ & $19(51.4 \%)$ & \\
\hline \multirow[t]{3}{*}{ Training } & Formal/hands-on training & $23(31.1 \%)$ & $18(48.6 \%)$ & NS \\
\hline & $\begin{array}{c}\text { Consumption of training } \\
\text { material }\end{array}$ & $10(13.5 \%)$ & $3(8.1 \%)$ & \\
\hline & No evidence of training & $41(55.4 \%)$ & $16(43.2 \%)$ & \\
\hline \multirow{3}{*}{$\begin{array}{c}\text { Target } \\
\text { recon- } \\
\text { naissance }\end{array}$} & Visiting target & $17(23.0 \%)$ & $9(24.3 \%)$ & NS \\
\hline & Researching target & $10(13.5 \%)$ & $11(29.7 \%)$ & \\
\hline & No evidence & $47(63.5 \%)$ & 17 (45.9\%) & \\
\hline \multirow{3}{*}{$\begin{array}{l}\text { Leakage } \\
\text { behaviour }\end{array}$} & Leakage of plans & $19(25.7 \%)$ & $6(16.2 \%)$ & NS \\
\hline & $\begin{array}{c}\text { Leakage of extreme } \\
\text { beliefs }\end{array}$ & 25 (33.8\%) & $18(48.6 \%)$ & \\
\hline & No evidence of leakage & 30 (40.5\%) & 13 (35.1\%) & \\
\hline \multirow{4}{*}{$\begin{array}{l}\text { Authorities } \\
\text { aware }\end{array}$} & Aware of plans/activity & $24(32.4 \%)$ & $1(2.7 \%)$ & $* * *$ \\
\hline & Aware of extreme beliefs & $16(21.6 \%)$ & $3(8.1 \%)$ & \\
\hline & Aware of other & $8(10.8 \%)$ & $9(24.3 \%)$ & \\
\hline & $\begin{array}{l}\text { No evidence of being } \\
\text { aware }\end{array}$ & $26(35.1 \%)$ & 24 (64.9\%) & \\
\hline \multirow{2}{*}{$\begin{array}{l}\text { Third party } \\
\text { assistance }\end{array}$} & Assistance was given & $14(21.9 \%) \dagger$ & $4(11.4 \%) \dagger$ & NS \\
\hline & No assistance was given & $50(78.1 \%) \dagger$ & $(88.6 \%)+$ & \\
\hline \multirow{3}{*}{$\begin{array}{l}\text { Level of } \\
\text { planning }\end{array}$} & High & $30(40.5 \%)$ & $11(29.7 \%)$ & NS \\
\hline & Medium & $25(33.8 \%)$ & $10(27.0 \%)$ & \\
\hline & Low & $19(25.7 \%)$ & $16(43.2 \%)$ & \\
\hline \multirow{2}{*}{\multicolumn{5}{|c|}{$\begin{array}{l}\text { TAnalysis on third party assistance (planning) excluded data related to Type } 1 \text { variables, therefore had a sample size of } 64 \text { fo } \\
\text { IEs and } 35 \text { for RWE. }\end{array}$}} \\
\hline & & & & \\
\hline NS $=$ not significant & $=p<.05 ; * *=p<.01 ; * * * p<.00$. & tailed). & & \\
\hline
\end{tabular}


contact (36.5\%). A smaller proportion of RWEs had face to face contact with other extremists $(32.4 \%)$, while $16.2 \%$ had virtual contact only and the majority $(51.4 \%)$ had no mention of contact. A chi square test was undertaken to explore the association between contact with extremists and ideology, but no significant association was found, $\chi 2(2)=2.85, p=.241$.

Training. The majority (55.4\%) of IEs had not undertaken training for the attack, with $31.1 \%$ only undertaking formal or hands-on training while $13.5 \%$ had consumed training material. Conversely, the majority of RWEs had undertaken training prior to the attack, with $48.6 \%$ participating in formal or hands-on training and $8.1 \%$ consuming terrorist propaganda. However, the proportion of those who had not undertaken training was still substantial at 43.2\%. To investigate an association between these variables, a chi square test was performed. No significant association was found between level of training and ideology $\chi 2(2)$ $=3.39, p=.184$.

Target reconnaissance. Just under two-thirds of IEs had no evidence of target reconnaissance $(63.5 \%)$, with $23.0 \%$ visiting target and only $13.5 \%$ researching target. However, the majority of RWEs had undertaken some form of target reconnaissance, with just under a quarter (24.3\%) visiting the target, and just under a third researching the target (29.7\%). To explore the relationship between target reconnaissance and the ideology of the perpetrator, a chi square test of independence was undertaken but no significant association was found, $\chi 2(2)=4.77, p=.092$.

Leakage behaviour. Although they had similar numbers, slightly more IEs (40.5\%) were more likely to have no evidence of leakage than RWEs. IEs also had a higher proportion of individuals who had leaked plans (25.7\%) compared to RWEs (16.2\%). However, RWEs had a larger proportion of people who leaked their extreme beliefs but not plans, with nearly half (48.6\%) compared to one-third (33.8\%) of IEs. A chi square test of independence was undertaken to determine if there was a relationship between these variables. However, there was no significant association found between leakage behaviour and ideology, $\chi 2(2)=2.57, p$ $=.276$.

Authorities aware. IEs had higher proportions of authorities being aware of plans or activity $(32.4 \%)$ or extreme beliefs without plans $(21.6 \%)$ than RWEs $(2.7 \%$ and $8.1 \%$ respectively). However, RWEs had a higher proportion of authorities being aware of other at nearly one quarter (24.3\%) than IEs (10.8\%), and for nearly two-thirds (64.9\%) of RWEs there was no evidence that authorities were aware compared to just over one-third (35.1\%) of IEs. 
Table 9

Count, Expected Count and Residuals for Authorities Aware and Ideology Cross Tabulation

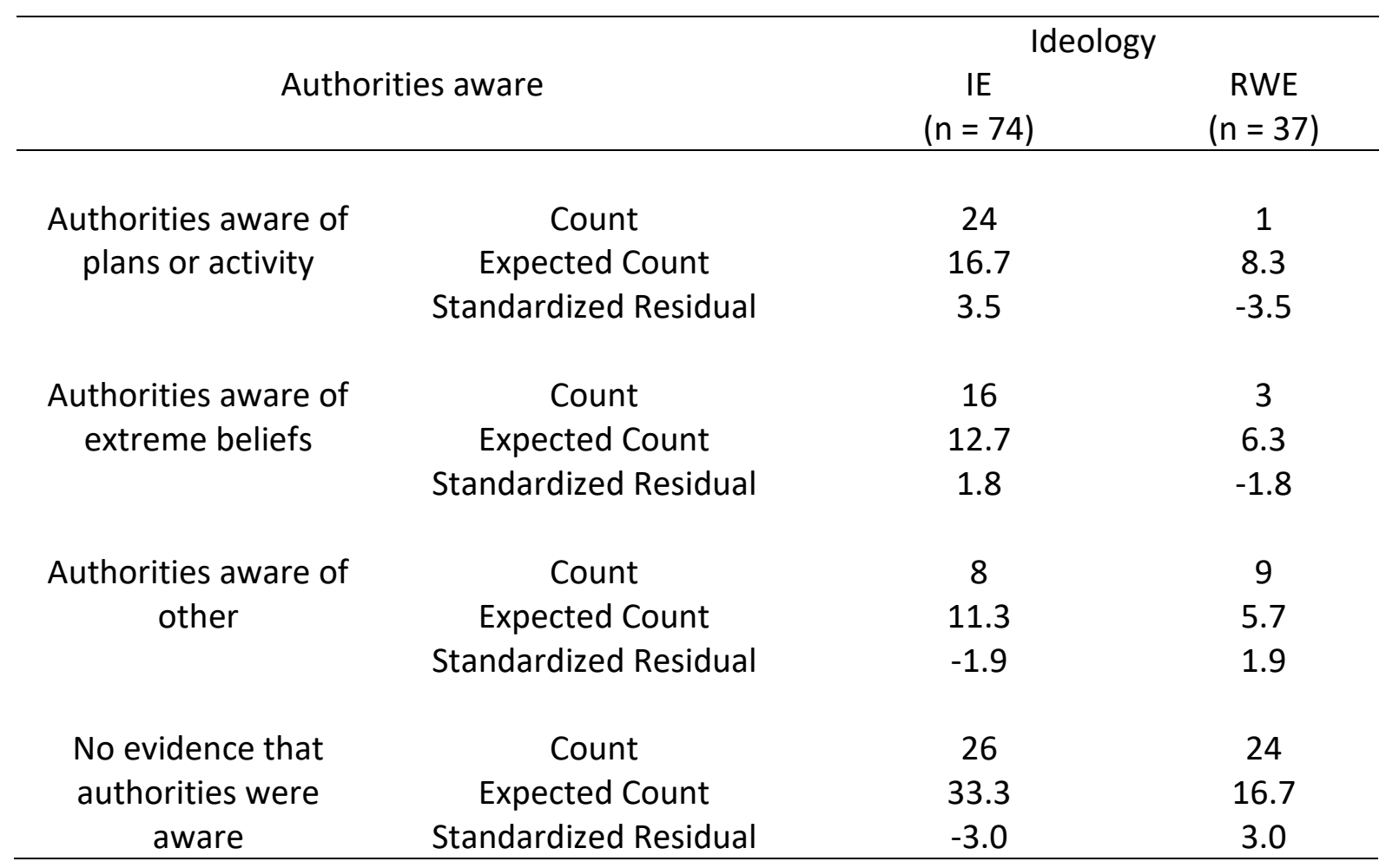

To test the relationship between authorities aware and ideology a chi square test of independence was undertaken, which found a significant association, $\chi 2(3)=20.09, p<.001$. Residuals were calculated to explore the association between the individual levels and ideology. Table 9 shows all results, but two levels had significant results: authorities were more likely to be aware of the plans or activity of IEs than RWEs, and attacks undertaken by RWEs were more likely to have no evidence that authorities were aware compared to IEs.

Third party assistance (planning). Most of the sample had no assistance from a third party during planning the attack, with $21.9 \%$ of IEs and only $11.4 \%$ of RWEs having had assistance. To explore a relationship between these two variables a chi square test was performed but found no significant association between ideology of the perpetrator and the third-party planning variable, $\chi 2(1)=1.66, p=.198$.

Level of planning. Opposite results were obtained for level of planning for the two ideological groups. IEs had the most individuals at high levels of planning (40.5\%), followed by medium level of planning at one-third (33.8\%) and low level of planning at one-quarter (25.7\%). Conversely, the highest proportion of RWEs fell into the low level of planning group (43.2\%), followed by high level of planning at $29.7 \%$ and finally medium level of planning at 
27.0\%. A chi square test of independence was conducted to explore the association between these two variables but found no significant association between level of planning and ideology, $\chi 2(2)=3.55, p=.169$.

\section{Attack Perpetration}

The results for behavioural characteristics are displayed in Table 10 and have been discussed for each variable below. All variables are Type 1 variables, so results for the second and third perpetrators in attacks with more than one perpetrator have been excluded in the analyses described below.

Number of perpetrators. The vast majority of attacks were undertaken by a single perpetrator for both IE (87.5\%) and RWE (94.3\%). Attacks undertaken by two perpetrators was the second most common for both IE (9.4\%) and RWE (5.7\%), and attacks undertaken by three people were only undertaken by IEs (3.1\%). A chi square test of independence was undertaken to explore the relationship between number of perpetrators and ideology, but the test assumptions were not met as two cells (33\%) had an expected count less than five. To counter this, the second and third levels were collapsed into one level called multiple attackers. A chi square test was taken with these new levels but the assumptions were still not met as one cell (25\%) had an expected count of less than five. Overall, as the number of multiple perpetrators was low in both groups, it is clear there was no significant difference between ideology types.

Number of deaths. IEs had a wider range of deaths than RWEs, but RWEs had a slightly larger mean. To test if the differences were significant an independent samples t-test for significance was undertaken. It found no significant difference in the number of deaths between the two ideological groups, $\mathrm{t}(97)=-.02 \mathrm{p}=.982$, with $\operatorname{RWE}(\mathrm{M}=3.54, \mathrm{SD}=11.62)$ killing the same amount of victims than IEs $(M=3.48, S D=12.28)$.

Number of injuries. IEs had both a wider range and higher mean number of injuries than RWEs. To test to see if there are any significant differences between the number of injuries of the two ideologies, an independent samples t-test was performed. Although IEs injured more individuals $(M=17.36, S D=63.19)$ than RWE $(M=10.00, S D=34.45)$ there was no significant difference between these two groups, $\mathrm{t}(97)=.635, \mathrm{p}=.527$. 
Table 10

Counts and Percentages, or Ranges and Means for Attack Perpetration Variables

\begin{tabular}{|c|c|c|c|c|}
\hline \multirow[b]{2}{*}{ Variable } & \multirow[b]{2}{*}{ Levels } & \multicolumn{2}{|c|}{ Ideology } & \multirow[b]{2}{*}{$\begin{array}{c}\text { Chi Square } \\
\text { or t-test }\end{array}$} \\
\hline & & $\begin{array}{c}\text { IEs } \\
(n=64)\end{array}$ & $\begin{array}{c}\text { RWE } \\
(n=35)\end{array}$ & \\
\hline \multirow{3}{*}{$\begin{array}{l}\text { Number of } \\
\text { perpetrators }\end{array}$} & 1 & $56(87.5 \%)$ & $33(94.3 \%)$ & NS \\
\hline & 2 & $6(9.4 \%)$ & $2(5.7 \%)$ & \\
\hline & 3 & $2(3.1 \%)$ & $0(0.0 \%)$ & \\
\hline Deaths & Numerical number & $0-86(3.48)$ & $0-69(3.54)$ & NS \\
\hline Injuries & Numerical number & $0-434(17.36)$ & $\begin{array}{l}0-209 \\
(10.00)\end{array}$ & NS \\
\hline \multirow[t]{5}{*}{ Target type } & Civilians & $26(40.6 \%)$ & $0(0.0 \%)$ & $* * *$ \\
\hline & Social minorities & $10(15.6 \%)$ & 22 (62.9\%) & \\
\hline & $\begin{array}{c}\text { Government } \\
\text { places/figures }\end{array}$ & $21(32.8 \%)$ & $8(22.9 \%)$ & \\
\hline & Political figures/events & $3(4.7 \%)$ & 5 (14.3\%) & \\
\hline & Other & $4(6.3 \%)$ & $0(0.0 \%)$ & \\
\hline Weapon & Explosive & 7 (10.9\%) & $2(5.7 \%)$ & NS \\
\hline \multirow[t]{6}{*}{ Type } & Firearm & $21(32.8 \%)$ & $16(45.7 \%)$ & \\
\hline & Incendiary Device & $1(1.6 \%)$ & $1(2.9 \%)$ & \\
\hline & Vehicle (not VBIED) & $11(17.2 \%)$ & $4(11.4 \%)$ & \\
\hline & Knives/sharp objects & $20(31.3 \%)$ & $9(25.7 \%)$ & \\
\hline & Hands/blunt objects & $3(4.7 \%)$ & $2(5.7 \%)$ & \\
\hline & Other & $1(1.6 \%)$ & $1(2.9 \%)$ & \\
\hline \multirow[t]{4}{*}{$\begin{array}{l}\text { End of } \\
\text { attack }\end{array}$} & $\begin{array}{c}\text { Perpetrator killed } \\
\text { themself }\end{array}$ & $2(3.1 \%)$ & $3(8.6 \%)$ & NS \\
\hline & $\begin{array}{c}\text { Perpetrator killed by } \\
\text { authorities }\end{array}$ & $20(31.3 \%)$ & $5(14.3 \%)$ & \\
\hline & Perpetrator in custody & $27(42.2 \%)$ & 11 (31.4\%) & \\
\hline & Perpetrator escaped & $15(23.4 \%)$ & $16(45.7 \%)$ & \\
\hline \multirow{2}{*}{$\begin{array}{l}\text { Third party } \\
\text { assistance }\end{array}$} & Assistance was given & 2 (3.1\%) & $1(2.9 \%)$ & NS \\
\hline & No assistance was given & $62(96.9 \%)$ & $34(97.1 \%)$ & \\
\hline
\end{tabular}

Target type. Civilians were the group most often targeted by IEs (40.6\%) followed by government places/figures (32.8\%), social minorities $(15.6 \%)$, other category $(6.3 \%)$ and 
political figures or events (4.7\%). For RWEs only three of the groups were targeted, with social minorities being the most common (62.9\%) followed by government places/figures (22.9\%) and political figures or events (14.3\%). To test the relationship between target type and ideology, a chi square test for independence was undertaken but the test assumptions were not met as 3 cells (30\%) had an expected count of less than five. To meet the assumption the 'civilian' and the 'other' levels were collapsed into one level, civilian or other. A second chi square was undertaken which found a significant association between the collapsed target type and the ideology of the perpetrators, $\chi 2(3)=35.37, p<.001$. To explore the levels of collapsed target type that had the significant results, the standardized residuals were calculated by ideology. Table 10 shows that two levels had a significant residual score: IEs were more likely to target civilians (or other) than RWEs, and RWEs were more likely to target social minorities than IEs.

Weapon type. Firearms were the most popular weapon choice for both IEs (32.8\%) and RWEs (45.7\%), followed by knives or other sharp objects ( $31.3 \%$ and $25.7 \%$ respectively), and vehicles (17.2\% and $11.4 \%$ respectively). The other four weapon choices were less popular, as they were used by only a small number of individuals. To explore a relationship between weapon type and ideology, a chi square test of independence was undertaken, but the test assumptions were not met as 7 cells (50\%) had an expected count of less than five. To counter this, some of the levels were collapsed together to create four levels: explosive and incendiary devices, firearms, vehicles, and other weapons. Another chi square test for independence was but there was no significant association between the collapsed weapon type and ideology of the perpetrator, $\chi 2(3)=1.88, p=.597$.

End of attack. For IEs, the most common end of an attack was that the perpetrator was in custody (42.2\%) followed by killed by authorities (31.3\%), perpetrator escaped (23.4\%) and finally perpetrator killed themselves (3.1\%). For RWEs, the most common ending was that the perpetrator escaped (45.7\%), followed by perpetrator in custody $(31.4 \%)$ perpetrator killed by authorities (14.3\%) and perpetrator killed themselves (8.6\%). It should be noted that all those who escaped custody did not remain at large, and they were either later killed or caught by the authorities. To test the relationship between end of attack and ideology, a chi square test was undertaken, but the test assumptions were violated as two cells (25\%) had an expected count of less than five. Perpetrator death by own hand and perpetrator death by authorities were collapsed into one level, and a Chi squared was 
Table 11

Count, Expected Count and Residuals for Collapsed Target Type and Ideology Cross Tabulation

\begin{tabular}{|c|c|c|c|}
\hline \multirow{2}{*}{\multicolumn{2}{|c|}{ Target Type }} & \multicolumn{2}{|c|}{ Ideology } \\
\hline & & IE & RWE \\
\hline \multirow[t]{3}{*}{ Civilian or other } & Count & 30 & 0 \\
\hline & Expected Count & 19.4 & 10.6 \\
\hline & Standardized Residual & 4.9 & -4.9 \\
\hline \multirow[t]{3}{*}{ Social minorities } & Count & 10 & 22 \\
\hline & Expected Count & 20.7 & 11.3 \\
\hline & Standardized Residual & -4.8 & 4.8 \\
\hline \multirow{3}{*}{$\begin{array}{l}\text { Government } \\
\text { institutions or figures }\end{array}$} & Count & 21 & 8 \\
\hline & Expected Count & 2.3 & 10.3 \\
\hline & Standardized Residual & 1.0 & -1.0 \\
\hline \multirow{3}{*}{$\begin{array}{l}\text { Political events or } \\
\text { figures }\end{array}$} & Count & 3 & 5 \\
\hline & Expected Count & 5.2 & 2.8 \\
\hline & Standardized Residual & -1.7 & 1.7 \\
\hline
\end{tabular}

calculated. No significant association was found between the ideology of the perpetrator and the collapsed end of the attack, $\chi 2(2)=5.26, p=.072$.

Third party assistance (attack perpetration). For both IEs (96.9\%) and RWEs (97.1\%), the vast majority of attacks did not have any assistance immediately before or after an attack occurred. A chi square test for independence was undertaken to explore the association between these two variables but the test assumptions were not met as two cells (50\%) had an expected count of less than five. Overall, as the number of attacks with assistance were low for both groups it is clear there is no significant association between ideology type and third party assistance in the perpetration phase.

\section{Summary of Significant Differences}

The current research found some significant associations between IEs and RWEs for eight of the variables of the codebook. As Table 12 shows, the majority of significant associations were found for the background characteristics, although a small number were found in the attack planning and attack perpetration characteristics. No significant differences 
Table 12

Significant Results for the Bivariate Analysis Comparing the Ideological Groups

\begin{tabular}{llll}
\hline $\begin{array}{l}\text { Background } \\
\text { Characteristics }\end{array}$ & $\begin{array}{l}\text { Behavioural } \\
\text { Characteristics }\end{array}$ & Attack Planning & Attack Perpetration \\
\hline Age** & N/A & $\begin{array}{l}\text { Relationship } \\
\text { group*** }\end{array}$ & with Target Type*** \\
Education* & Authorities aware*** & \\
Marital status $* *$ & \\
Family status** & \\
Nationality** & \\
\hline NS $=$ not significant $; *=p<.05 ; * *=p<.01 ; * * * 0<.001$ (two-tailed).
\end{tabular}

were found for the behavioural characteristics. However, for most of the variables there were no significant associations found meaning that IEs and RWEs had similar results for many of the variables.

\section{Multivariate Analysis}

A logistic regression model was undertaken using ideology as the dependent variable, and a selection of key perpetrator characteristics. At first a model was built using the variables that had significant results when undertaking the bivariate analysis comparing IEs and RWEs. However, once the unknown cases were removed the sample size was too small, resulting in an unstable model when comparing the number of dependent variables. Therefore, a model was built to explore if the two groups differ in terms of strain variables (mental health, social isolation and stressors) and some key personal characteristics (age, employment, marital status and education level).

Dichotomous variables were used for the logistic regression so once unknown cases were excluded, the categorical variables which had more than two levels were further collapsed. The following variables were used in the model, with collapsed variables indicated in parenthesis: mental health (collapsed to has mental health issue/no evidence), social isolation, stressors (collapsed to has stressors/no evidence), age, employment (collapsed to 
unemployed or retired/student or employed), marital status (collapsed to single or divorced or separated/in a relationship or married) and education (collapsed to primary or high school/tertiary or higher). The model did not significantly predict ideology $\chi 2(7, N=33)=$ 12.89, $\mathrm{p}=.075$, therefore confirming the bivariate analysis that there is no significant association between variables that indicate strain and the ideological reasons for perpetrating lone-actor terrorism. Table 13 outlines the interactions for each dependent variable, with only one variable (collapsed education) having a significant result, which indicates that IEs are significantly more likely to have experience of higher education compared to RWEs.

\section{Table 13}

Logistic Regression Analysis Predicting Strain and Key Personal Characteristics for IEs Versus RWES

\begin{tabular}{|c|c|c|c|c|c|c|c|c|}
\hline \multirow[t]{2}{*}{ Variable } & \multirow[t]{2}{*}{$B$} & \multirow[t]{2}{*}{ S.E. } & \multirow[t]{2}{*}{ Wald } & \multirow[t]{2}{*}{$d f$} & \multirow[t]{2}{*}{ Sig. } & \multirow[t]{2}{*}{$\operatorname{Exp}(B)$} & \multicolumn{2}{|c|}{$\begin{array}{c}95 \% \text { C.I. for } \\
\operatorname{Exp(B)}\end{array}$} \\
\hline & & & & & & & Lower & Upper \\
\hline Age & .03 & .04 & .60 & 1 & .44 & 1.03 & .95 & 1.13 \\
\hline \multirow[t]{2}{*}{ Social Isolation } & - & 1.62 & 2.27 & 1 & .13 & .09 & .00 & 2.09 \\
\hline & 2.44 & & & & & & & \\
\hline Mental Health & .01 & 1.13 & .00 & 1 & .99 & 1.01 & .11 & 9.34 \\
\hline \multirow[t]{2}{*}{ Stressors } & - & 1.12 & .80 & 1 & .37 & .37 & .04 & 3.28 \\
\hline & 1.00 & & & & & & & \\
\hline Marital Status & 2.02 & 1.42 & 2.03 & 1 & .15 & 7.55 & .47 & 121.62 \\
\hline Education & 2.62 & 1.16 & 5.11 & 1 & .02 & 13.68 & 1.42 & 132.27 \\
\hline Employment & .43 & 1.07 & .163 & 1 & .69 & 1.54 & .19 & 12.44 \\
\hline
\end{tabular}




\section{Discussion}

The primary aim of this research was to investigate if there were any similarities or differences between lone-actor terror attacks perpetrated by IEs and RWEs. This was an exploratory study focused on answering the following three research questions:

1. What is the nature and extent of lone-actor terrorism in North America, Western Europe and Australia between 2010-2017 and how does this relate to the results of other studies?

2. How do IE and right-wing lone actor terrorists differ in terms of the characteristics coded for in this study?

3. How many attacks have been perpetrated by returning foreign fighters (RFF) and have these attacks increased over time?

The discussion is organised around answering the research questions in chronological order. Firstly, the results of the current study are discussed in the context of the wider literature on relevant studies that have explored the prevalence of specific personal and attack characteristics of terror attacks, focusing on those that have explored either lone-actor terrorism overall or the ideological motivations for perpetrating terrorism. There is not an abundance of prior research that has undertaken a comparative analysis on IEs and RWEs. Chermak and Gruenewald (2015) studied the differences between individuals who had conducted extremist violence in the United States for three ideological sub-types: right-wing extremists, Al Qaeda related, and left-wing extremists. However, this study was not limited to lone-actors, and studied those that were part of a group or had received direction from a group. Gill and colleagues (2014) did undertake an analysis of a sample of 119 individuals undertook lone-actor terrorism ${ }^{20}$ (or planned to but were caught by authorities) in the United States and Europe, and did a comparative analysis on three ideological sub-groups: rightwing, single issue and Al-Qaeda related. The same dataset was utilised later by Meloy and Gill $(2016)^{21}$ who applied the TRAP-18 indicators to explore if there were any differences between the three ideological sub-groups. The studies mentioned above all investigated variables that are similar to some of the variables cited in the current study. However, not all variables

\footnotetext{
${ }^{20}$ Meloy and Gill's definition of lone-actors only included individuals, while Gill and al.'s sample expanded on this to include isolated dyads.

${ }^{21}$ This definition of lone-actors includes only single actors
} 
mentioned in this study have been previously studied by authors undertaking comparisons between the two ideological groups.

Next, the second research question will be investigated by summarising the key similarities and differences to build profiles of the two ideological groups and explored in the context of key theoretical explanations of lone-actor terrorism. Thirdly, the findings for attacks perpetrated by RFF will be discussed, and finally limitations of the current study will be outlined, including suggestions for further research.

\section{The Nature and Extent of Lone-Actor Terrorism, and Relation to Other Studies}

This research involved a total of 99 attacks perpetrated by 102 individuals between 2010-2017 in North America, Western Europe and Australia and resulted in a total of 347 deaths and 1461 injuries. The results of this study found that attacks for both ideologies have increased by $725 \%$ over the time period of this study, with only four attacks perpetrated in 2010 in comparison to 33 attacks perpetrated in 2017. Since 2012 the gap between attacks undertaken by IEs and RWEs has generally increased, with IEs conducting progressively more attacks than RWEs over time. This pattern fits in with prior research, as studies undertaken on attacks occurring prior to 2010 did not find an increase in attacks over time (Gruenewald et al., 2013b; Spaaij, 2010)22, whereas a study including attacks perpetrated after 2010 did find an increase (Ellis et al., 2016) ${ }^{23}$.

As argued by Nacos (2009), contagion involves perpetrators imitating violence that they see others conduct, and widespread availability of media on the internet can ensure that violence spreads more quickly than ever before. This may explain the increase in lone actor attacks that have been found in this study and other studies including more recent attacks, compared to those conducted before 2010. Attacks from both ideologies have increased overall from 2010 - 2017 and have followed a similar trend, which lends support to the idea of contagion; that violence breeds more violence. Media reporting has confirmed that some perpetrators were likely influenced by other terror attacks; for example, images and videos of other terror attacks were found on a laptop and removable media belonging to Farid Ikken (case 201717), who attacked policemen outside of Notre Dame in 2017. Of course it is

\footnotetext{
22 Definitions employed by Spajj and Gruenewald et al. were limited to individuals who have operated alone

${ }^{23}$ This definition of lone-actors includes individuals, isolated dyads and isolated triads
} 
important to recognise that variations in the frequency of lone-actor terror attacks are likely to be influenced by a range of factors and any analysis of attack frequency has to also recognise potential changes in the way that attacks are reported and recorded in open source media and hence available to be analysed in research.

The sample for this thesis consisted of 102 individual terrorists, some of whom conducted more than one attack. Each separate attack was counted individually, which resulted in a total sample size of 111 perpetrators. Two-thirds of the sample consisted of IEs while one-third was RWEs. Although other studies have generally found a higher proportion of attacks conducted by IEs versus RWEs, this number is usually only slightly higher. For example, Gill and colleagues (2014) found $43 \%$ of their sample of lone-actors ${ }^{24}$ adhered to an IE ideology and 38\% adhered to a right-wing ideology, while Ellis and colleagues (2016) found that IEs accounted for $38 \%$ of the sample while right-wing accounted for $33 \%$. Both samples included individuals who had undertaken an attack as well as individuals who had only plotted to undertake an attack, whereas the sample in this research was limited to individuals who had undertaken an attack. It is unlikely that the inclusion criteria can entirely explain the discrepancy, as the findings on individuals being able to successfully undertake an attack is mixed, with some finding a higher proportion of IE plots leading to a successful attack (Ellis et al., 2016), while others find that a higher proportion of RWE plots would lead to a successful attack (Gill et al., 2014). However, the more recent time period examined in this thesis compared to either Ellis and colleagues (2016) or Gill and colleagues (2014) may account for the higher proportion of attacks conducted by IEs versus RWEs in this sample.

\section{Background Characteristics}

The current study found that IEs were significantly younger than RWEs, with the mean age for IEs found to be 27.58, while the mean age for RWEs was higher at 37.16. This is in line with what was found for other studies on lone actors. Those that studied populations of IES found a mean age between 24 and 27.3 (Bakker, 2006; Gill et al., 2014; Roy Van Zuijdewijn \& Bakker, 2016; Weenink, 2015) and those that studied RWE found a mean between 32.3 and 36.9 (Gill et al., 2014; Gruenewald et al., 2013a, 2013b; Roy Van Zuijdewijn \& Bakker, 2016). Those that studied lone-actors overall found a mean age between 31 and 35.4 (Eby, 2012; Gill

\footnotetext{
${ }^{24}$ This definition of lone-actors included only individual terrorists and isolated dyads
} 
et al., 2014; Meloy et al., 2015) ${ }^{25}$, which is between the mean ages found in this study for IE and RWE.

This sample was disproportionately male for both ideologies, with only four women in the sample overall, and there were no significant differences between the two ideologies. This is in line with prior studies on terrorism, who have all found that most (if not all) of their sample of terrorists are male (Bakker, 2006; Eby, 2012; Gill et al., 2014; Gruenewald et al., 2013a, 2013b; Meloy et al., 2015; Weenink, 2015). Prior research that compared the two ideological groups also found no gender differences (Chermak \& Gruenewald, 2015; Gill et al., 2014).

When looking at instances where information on education level could be found, this study found that IEs were significantly more likely to have attended tertiary level education or higher compared to RWEs, with over half of the sample (52.9\%) having their highest level of education as attending tertiary level compared with RWEs, the majority of whom $(70.8 \%)$ had attending high school as their highest level of education. Prior studies have found mixed results when looking at education levels for IEs. Weenink (2015) did not find even one person who had completed higher education, and Bakker (2006) found that only $31.3 \%$ of the sample had completed college, although these studies were looking at completion of education whereas this study looked at attending education levels without necessarily having to complete them. Other past studies that have examined education have found that the majority of IEs have at least attended college (Gill et al., 2014; Sageman, 2004) ${ }^{26}$. Not many studies have examined education levels for RWE populations, but Gill et al. (2014) did and found that only $15 \%$ had experienced a tertiary level education, which is similar to what was found in this study. For those studies that compared the two ideological groups, those on extremists in the United States overall found that RWEs were less likely to have attended some college, and more likely to have a high school diploma as their only education attainment than both AI Qaeda related or far left extremists (Chermak \& Gruenewald, 2015), and research on lone-actor terrorists have found that Al Qaeda related were significantly

\footnotetext{
${ }^{25}$ Meloy and Gill's and Gruenewald's sample included only individual terrorists, while Gill et al.'s expanded this definition to include isolated dyads. Weenink's sample consisted of Jihadis who had travelled to Syria/Iraq to join ISIL or had aspirations to do so. Bakker sample of Jihadis included those that operated within a group, as well as individual actors.

${ }^{26}$ Sageman's sample of IEs included those who had participated in group terrorism.
} 
more likely to have attended university and have a university degree compared to right-wing or single issue lone actor terrorists (Gill et al., 2014).

When all cases where the information was unavailable were excluded, the current study found that IEs (37.5\%) were significantly more likely to be to separated or divorced or widowed than RWEs (13.6\%), while RWEs were significantly more likely to be single $(50 \%)$ than IEs (7.5\%). The latter finding is interesting considering that the current study also found that RWEs were significantly older than IEs, with the average age being 37.16. For example, Gianluca Casseri was 50 when he perpetrated the two Florence Market shootings in 2011, and not only was he single at the time of the attack but sources noted that he had experienced issues forming relationships with women over his life (cases 201103 and 201104). Although more IEs (55\%) were married or in relationship at the time of the attack compared to RWEs (36.4\%), there was no significant difference. Prior research that has compared the two groups have found mixed results. For example, Chermak and Gruenewald (2015) found that Al Qaeda related extremists were more likely to be separated or divorced and also more likely to be married than far-right extremists, but that far-left were more likely to be single than Al Qaeda related or far-right extremists, and far-right were more likely to be in a relationship than Al Qaeda related. Other research that has studied failure of sexual-intimate pair bonding (which is similar to the separated category within this research) found no significant differences between the ideological groups (Gill et al., 2014; Meloy \& Gill, 2016) ${ }^{27}$. Studies that did not compare the ideological groups found similar proportions to the current study, finding that the majority of IEs were in a relationship at the time of the attack (Bakker, 2006; Sageman, 2004), and a significant number (42.9\%) of RWE were single at the time of the attack (Gruenewald et al., 2013a). It is possible that IEs and RWEs have experiences with relationships based on the ideologies they adhere to. As Islam is a religion that strongly encourages marriage, and only after marriage are couples permitted to be sexually intimate (Huda, 2019), this may result in IEs being more likely to get married and at a younger age. Right-wing extremism is a wide category that consists of many different sub-groups, some of which endorse misogynistic views. Although misogyny is not one of the five sub-groups of RWE that is of interest to this study, as individuals who believe in RWE can often take ideas

\footnotetext{
${ }^{27}$ Meloy and Gill's sample included on individual terrorists, while Gill et al.'s expanded this definition to include isolated dyads
} 
stemming from different sub-groups (Heitmeyer, 2005) it is likely that a number of those of interest to this study also held misogynistic views. It is possible that either the misogynistic views were a barrier to forming an enduring sexual relationship with women, or their inability to form an enduring sexual relationship with women caused them to have misogynistic beliefs. This has likely contributed to the majority of RWEs being single at the time of the attack, even though the sample is significantly older than IEs.

The current study found that IEs were significantly more likely to have children $36.5 \%$ compared to RWEs (12.9\%), which is in line with prior research that found that RWEs were significantly less likely to have children when compared to Al Qaeda related or single issue terrorists (Gill et al., 2014). Prior studies which excluded cases where no information was available found that $37.9 \%$ of IEs had children (Bakker, 2006) and $25.5 \%$ of RWEs had children (Gruenewald et al., 2013a), the latter which is higher than what was found in this study. However, the current study did not exclude cases which were unknown which likely accounts for the discrepancy. Overall, prior studies and the current study found that more IEs had children than RWEs, which is likely due to similar reasons discussed above for the difference between the groups for marital status. Although sexual experiences (and the consequences of those, such as children) can exist outside of enduring intimate relationships, the higher proportion of RWEs who are single versus IEs likely accounts for the lower levels of children found in the RWE sample.

When cases where information was not available were excluded, the current study found a significant association found between nationality, with IEs being more likely to be an immigrant than RWEs, and RWEs more likely to be born in the country of the attack compared to IEs. Prior studies that examined the immigration status of their sample are rare, and no study undertook a comparative analysis for the ideologies. Weenink (2015) did find that for Jihadis who had travelled to Syria, or were suspected of doing so, only $38.4 \%$ were born in Europe. As well as being rarely explored by other researchers, this variable is not recorded in all cases of terrorism: this study found that although only $8.1 \%$ of IEs had an unknown nationality status, over half $(54.1 \%)$ of RWEs had no indication of where they were born in open source accounts, likely due to widespread assumptions that perpetrators of RWE attacks are more likely to be born in the country of the attack, and perpetrators of IE attacks are more likely to be born overseas. 
Once cases where there was no information were excluded, this study found for employment status that the biggest group were those who were unemployed or retired at the time of the attack, for both IEs (49.0\%) and RWEs (53.6\%); however, there was no significant difference found between the two groups, which is not in line with other research. For example, Gill and colleagues (2014) found that IEs were more likely to be a student at the time of the attack, and that RWE were more likely to be unemployed (the latter at a $10 \%$ significance level). The difference in results for unemployment may be explained by Gill and colleagues utilising a lower significance level than what was used in the current study. Other studies that examined proportion overall have found mixed results for those who adhere to an IE ideology. Although Weenink (2015) was unable to find a subject who was permanently employed, as those who were employed were in temporary jobs, the opposite was found by Bakker (2006), as the majority of his sample were employed at the time of the attack occurring. Yet Gill et al. (2014) found similar results to this study, with $30.8 \%$ of the entire sample being coded as unemployed. Prior research has found similar results to what was found in this study for RWEs, with the majority of the sample being unemployed (Gill et al., 2014; Gruenewald et al., 2013a). Unemployment is a common feature of individuals undertaking lone-actor terrorism, with studies finding the majority of lone-actors are unemployed at the time of the attack (Eby, 2012; Meloy et al., 2015) ${ }^{28}$.

The current study found that the majority of the variables in the attack planning section had results that were in line with what has been found for prior research. In addition, most of the variables had significant differences between the two ideological groups, indicating that for the background characteristics IEs and RWEs have more differences than similarities.

\section{Behavioural Characteristics}

In this study, no significant differences were found between the two ideological groups for mental health issues, with the majority of both IEs and RWEs coded as having some issues with mental health difficulties. Formal diagnoses of a mental health issues were more prevalent in the RWE population (37.8\%) than the IE population (18.9\%), and IEs (32.4\%) had a higher proportion of mentions of mental health difficulties by friends, family or authorities

\footnotetext{
${ }^{28}$ Meloy and Gill's sample included only individual terrorists
} 
than RWE (21.6\%). Prior research also found no significant difference in the prevalence of mental health issues between IEs and RWEs (Gill et al., 2014; Meloy \& Gill, 2016) ${ }^{29}$. However, the proportion of mental health issues in the IE population does not match with what was found in prior studies: those that investigated mental health diagnoses or disorders in samples of IEs (including groups) found a much lower proportion, between $1.7 \%-6 \%$ of the sample (Bakker, 2006; Sageman, 2004; Weenink, 2015) ${ }^{30}$. However, studies that were limited to lone-actors found a higher prevalence, with approximately one-quarter to one-third of the sample of IEs having a mental disorder or mental illness (Gill et al., 2014; Meloy \& Gill, 2016; Roy Van Zuijdewijn \& Bakker, 2016) ${ }^{31}$. The results for this study were similar to previous studies on RWEs, with a number finding the prevalence of mental illness or diagnosis in loneactors between 30\% - 41\% (Gill et al., 2014; Gruenewald et al., 2013a, 2013b; Meloy \& Gill, 2016).

The current study found no significant difference in the presence of social isolation, with similar proportions of IEs (31.1\%) and RWEs (37.8\%) having sources mention them being socially isolated, alone, or a loner. Prior research that has compared the two ideological groups have also found no significant difference (Gill et al., 2014); however, the proportions of lone-actors who were socially isolated in the current study does not match what has been found in prior research. Only one study found similar results to this one for RWEs as one-third $(33 \%)$ of the sample was socially isolated, but found that only $9 \%$ of IEs were in some way socially isolated (Roy Van Zuijdewijn \& Bakker, 2016). Other studies on single individuals undertaking terrorism found much higher proportions of social isolation: Jasparro (2010) found that $64.3 \%$ of his sample of Jihadist 'lone-wolves' were categorised as loners by others while, in his analysis of five case studies of lone-actor terrorism, Spaaij (2010) concluded that all five 'lone wolves'32 were loners. Gill et al. (2014) employed a more liberal definition on lone-actor terrorism, which included individuals and isolated dyads and found that a smaller proportion of the sample (56.8\%) were categorised by sources as socially isolated. Although this study found an even smaller proportion of mention of social isolation across both samples

\footnotetext{
${ }^{29}$ Both studies definitions of lone-actors only included individual terrorists and isolated dyads

${ }^{30}$ Weenink's sample consisted of Jihadis who had travelled to Syria/Iraq to join ISIL or had aspirations to do so. Bakker sample of Jihadis included those that operated within a group, as well as individual actors. Sageman's sample of IEs included those who had participated in group terrorism.

${ }^{31}$ Roy Van Zuijdewijn and Bakker's definition of lone-actors includes individuals, isolated dyads and isolated triads

32 Jasparro's and Spaaij's definition of 'lone wolves' is limited to individuals who have operated alone
} 
than what was found by Gill and colleagues, that may be in part explained by the wider definition of terrorism employed to include attacks undertaken by isolated triads. It is possible there is a correlation between number of attackers and mention of social isolation, with individuals who undertake attacks by themselves being more likely to be viewed by friends, family, or authorities as a loner or socially isolated. The current study found that of the 22 individuals who perpetrated an attack as part of an isolated dyad or triad, only two perpetrators (9.1\%) had sources mentioning that they had experienced social isolation prior to undertaking a terror attack (Syed Farook, case 201512 and Youssef Zaghba, case 201715). As this proportion is lower than what was found for attacks perpetrated by one individual, this lends support to idea that attacks perpetrated by dyads or triads may be less likely to have sources mention that the attackers were socially isolated. Future research may want to further explore this idea further.

The current study found no significant difference in stressful events experienced, with a total of $56.7 \%$ of IEs and $43.2 \%$ of RWE experiencing at least one stressful event over the 12 months prior to the attack occurring. Only one study has compared stressful events between the two ideologies and found that there was no significant difference in experiences of unemployment, financial problems or experiencing an elevated level of stress in the 12 months before the attack (Gill et al., 2014). Other research has found mixed results when counting the number of stressful events in a perpetrator's life. Jasparro (2010) found a much higher proportion at $71 \%$ of his sample of Jihadi lone-actors, however he was investigating stressful events over a perpetrator's life, rather than limiting the occurrences to the 12 months prior to an attack taking place. Gill and colleagues (2014) found that a quarter of their sample (24.4\%) was under an elevated level of stress due to something that occurred in the 12 months prior to an attack taking place, which is much lower than what was found for either ideologies in this study.

This study found no significant association between ideology and criminal history, with almost half of IEs (43.2\%) and RWEs (45.9\%) having a criminal conviction prior to undertaking the terror attack. Prior research has found significant differences between the two ideologies: IEs were significantly less likely to have a previous criminal conviction, (Gill et al., 2014) while research on terrorist actors (including those not meeting the definition of lone-actors) found that the far-right were significantly more likely to have an arrest than IEs (Chermak \& Gruenewald, 2015). The difference for criminal history for the latter study may be partially 
explained by Chermak and Gruenewald counting arrests, which would return more positive results than counting convictions, as the current study has. However, this does not fully explain the difference in significance results found between the current study and past studies. With the current study showing changes in terrorism over time (e.g. the increase in terrorism found between 2010-2017), it is possible that the different results found in this for employment and criminal history are a result of the profile of those who undertake terrorism changing as time goes on, resulting in no significant difference between the ideological groups for these two variables. Exploring this change utilising a longitudinal analysis could be something that future studies could explore. When looking at prevalence rates for IEs, prior research has found mixed results, with Weenink (2015) finding than nearly half of his sample had records in the police database, while Sageman (2004) found only one-quarter of his sample being involved in petty criminal activities. However, studies that look at criminal records or convictions have found approximately one-quarter of IEs have a criminal record (Bakker, 2006; Gill et al., 2014), which is considerably less than what was found in this study. For RWEs, other research did not measure convictions, but did find between $61-64 \%$ of the sample has been previously arrested (Gruenewald et al., 2013a, 2013b). Although it was not measured, it is highly likely that the proportion of those who were convicted was lower in those studies as not every arrest ends in a conviction.

The current study found that in the majority of cases there was no mention of violence in open source reporting, and there was no significant difference between the ideologies, despite the finding that more IEs (31.1\%) had a formal record of violence than RWE (16.2\%). Prior research has also found no significant difference between the two ideological groups for history of engaging in violent criminal activity (Gill et al., 2014; Meloy \& Gill, 2016). When looking at proportions of the population that have undertaken violence, Meloy and Gill (2016) found similar results for IEs, with $29 \%$ of their sample having a history of criminal violence, but they found higher results for RWEs with $33 \%$ of the sample having a history of criminal violence. Another study found a lower proportion, with $22.8 \%$ of RWEs having a history of an arrest for violence (Gruenewald et al., 2013a), which is similar to what was found in this study. Prior studies that examine lone-actors overall have found a higher incidence of violence in the perpetrators' backgrounds: Meloy et al. (2015) found that $42.5 \%$ of their sample had a history of violent crimes, and Schuurman, Bakker, et al. (2018) found that $46 \%$ of their sample had a 
history of violent behaviour ${ }^{33}$. Overall, a history of criminal or formal violence is lower in this study than what has been found in other similar studies.

The current study found that there was no significant difference found between IEs and RWEs for all of the variables in the behavioural characteristics section. To further explore this association, a logistic regression was undertaken on variables that are likely to be indicators of strain (mental health, social isolation) and some personal characteristics but the model did not significantly predict ideology type. Further, as outlined earlier in this section, the current research has supported prior research that there are no significant differences between the ideological groups for the strain variables, which indicates that IEs and RWE have similar experiences of strain.

\section{Attack Planning}

The current study found a significant association between ideology and relationship with terror groups, finding that significantly more IEs $(31.1 \%)$ had previous ties or links to designated terror groups (or had previously tried to join a terror group) compared to no RWES $(0 \%)$. Some prior research has studied variables similar to the ones in the current research, such as failure to affiliate with an extremist group but they did not find any significant differences between the ideological groups (Gill et al., 2014; Meloy \& Gill, 2016) ${ }^{34}$. The discrepancy with prior research may be explained by the requirement of this variable to have a link to a terror group that has been designated officially by the United Nations or a foreign government. Upon reflection, these designations appear to lean towards designating groups associated with IE more than RWE: for example, the UN has two sub-committee that designate entities that are associated with IE organisations, one of which is focused solely on those associated with Al-Qaeda or ISIL (United Nations Security Council, 2019). No such committee exists in the United Nations for designating entities that are associated with RWE groups. Limiting the positive coding of this variable to groups that have been designated has created an unintended bias towards IE, and therefore results for this variable should be interpreted with caution. Prior research has found mixed results when looking at relationship with a terror group or wider extremist movement, as this relationship has been measured in

\footnotetext{
${ }^{33}$ Meloy et al.'s sample included individual actors and autonomous cells of two and three individuals

${ }^{34}$ Meloy and Gill's definition of lone-actors included only while individual actors, while Gill et al.'s definition of lone-actors expanded this to include isolated dyads.
} 
different ways by researchers. For example, Gill et al. (2014) found that $28.1 \%$ of IEs and $47.5 \%$ of RWEs had joined a wider group or movement prior to undertaking or attempting to undertake the terror attack, while Meloy and Gill (2016) found that $18 \%$ of IEs and $33 \%$ of RWEs had experienced failure when attempting to affiliate with a wider extremist movement ${ }^{35}$. Some studies that looked at lone-actor populations as a whole found that the majority of lone actors had either never been a member of a terror group (93\%; Eby, 2012) ${ }^{36}$ or had never been active in an extremist group (two-thirds; Ellis et al., 2016) ${ }^{37}$, while others found that a minority of the sample were members of a terror group (31\%; Schuurman, Bakker, et al., 2018) or had failed to affiliate with an extremist group (13.5\%; Meloy et al., $2015)^{38}$. Overall, most prior research has found similar findings to this study, in that loneactors are more likely to not have been a member of a terror group or wider extremist organisation. However, one study is an exception, with Lindekilde, O'connor, et al. (2019) finding that the vast majority of their sample of autonomous and volatile lone actors had ties to extremist groups; however, they employed a smaller sample than the current study, so comparisons should be made with caution.

This study found that the majority of IEs had some contact with others in the five years before the attack, with $48.6 \%$ having face-to face contact and $14.9 \%$ having virtual contact only. The opposite was true for RWEs as for the majority of the sample there was no evidence of contact, with just under one-third (32.4\%) having face-to-face contact and $16.2 \%$ having virtual contact only. However, no significant differences were found between contact with extremists and ideology type. Prior research has found mixed results for variables that are similar to 'contact with extremists': Gill and colleagues (2014) found no significant differences for interacting with a wider network either face-to-face, or virtually, while Meloy and Gill (2016) found that IEs were more likely to display dependence on the virtual community. When looking at prevalence rates, prior research on samples of IEs have found the majority of the sample having at least attempted to interact with extremist others, with Meloy and Gill (2016) finding that just under two-thirds of their sample had dependence on the virtual community

\footnotetext{
${ }^{35}$ Meloy and Gill's sample included on individual terrorists, while Gill et al.'s expanded this definition to include isolated dyads

${ }^{36}$ Eby's definition of lone wolves is limited to individuals who have operated alone

${ }^{37}$ This definition of lone-actors includes individuals, isolated dyads and isolated triads

${ }^{38}$ Meloy et al.'s sample included individual actors and autonomous cells of two and three individuals
} 
(including discussing extreme beliefs with others) and Jasparro (2010) ${ }^{39}$ reporting that $57.1 \%$ of his sample of 'lone-wolves' had made contact (or attempted to make contact) with others to obtain support for their plans or undertake training for the attack. Prior research on RWEs have found different results to this study, with Meloy and Gill (2016) finding that $51 \%$ of their sample had dependence on the virtual community. Research that studied lone-actors overall found mixed results, with some finding the majority had contact with other extremists (Schuurman, Bakker, et al., 2018) and others finding that only a small minority had contact (Eby, 2012; Meloy et al., 2015). Overall, prior research has found a variety of results when studying this variable, likely due to different definitions employed. Future research that explored the varying levels of contact that lone-actors can have with other extremists, and compared this to definitions used in prior research may be able to provide some further insight into this variable.

The current study found no significant differences between the ideologies for training, despite the majority of RWEs in this study had undertaken training, with $48.6 \%$ having had participated in formal training (including prior military service) and $8.1 \%$ had consumed training material or terrorist propaganda only, compared with $31.1 \%$ of IEs who had undertaken formal training and $13.5 \%$ who consumed training material only. This was opposite to what was found by Gill and colleagues (2014) who found that more IEs (65.4\%) had learned through virtual sources compared with RWEs (37.5\%), and what was found by Grunewald and associates (2013a) who found that a quarter (25.5\%) of RWEs had prior military background and $29.8 \%$ were in possession of extremist materials. Studies that looked at lone-actor populations overall found that while a significant proportion of the sample would undertake some form of training, it was usually not more than half. For example, Schuurman and colleagues (2018) counted three individual ways that their sample could have hands-on experience or formal training, and found that $15 \%$ had prior military experience, $35 \%$ had undertaken training with firearms and one-third had practiced shooting by themselves. In terms of consuming training material, Ellis et al. (2016) found that one-third of the sample used the internet to discover tactical knowledge for the attack and Eby (2012) found that $37 \%$ of his sample of lone actors used the internet to learn about or disseminate information about their extreme ideology. Studies that compared the two ideological groups

${ }^{39}$ This definition of 'lone-wolves' was limited to individuals acting alone. 
found mixed results, with some finding that for group terrorists Al Qaeda related were more likely to have prior military experience than far-right terrorists (Chermak \& Gruenewald, 2015) but for lone-actors there were no significant differences in military experience but Al Qaeda were significantly more likely to learn through virtual sources (Gill et al., 2014). The difference between the current research and prior research may be partially explained by the fact that some prior research was using variables that are a part of the training variable in the current research, such as prior military experiences. Although the prevalence of RWEs undertaking training was a little higher, overall the results of this study for prevalence rates are similar to what was found in other studies on lone-actor samples as a whole.

The current study found no significant association between target reconnaissance and ideology, with similar proportions for both IEs (23.0\%) and RWEs (24.3\%) when visiting a target, although a lower proportion of IEs (13.5\%) researched the target (without visiting) compared to RWEs (29.7\%). For example, Dylan Roof who perpetrated the Charleston church shooting undertook physical reconnaissance of the church approximately six times before he undertook the attack (case 201505). Target reconnaissance has not been widely investigated by other researchers, with no studies undertaking a statistical analysis between the two ideologies and only a few studies looking at the prevalence of this in the lone-actor sample. For example, Schuurman and colleagues (2018) found that $38 \%$ of their sample of lone-actors had visited the target while only $11 \%$ had used the internet to research their target. Similar results were found by Lindekilde and associates (2019) who found that $40 \%$ of autonomous actors and $44 \%$ of volatile actors had visited the target, and a smaller proportion of both autonomous (13\%) and volatile (20\%) actors had used the internet to research their target. Although the proportions were slightly different, both studies found a higher proportion of the sample was undertaking target reconnaissance via visiting the target versus researching the target. This was similar to what was found in this study for the IEs, while RWEs had a higher proportion of the sample undertaking target reconnaissance via researching the target or the attack location.

This study found that both ideologies displayed some form of leakage, with leakage of extreme beliefs only being more common for both IEs (33.8\%) and RWEs (48.6\%) than leakage of plans $(25.7 \%$ and $16.2 \%$ respectively). However, there was no significant difference between the two groups for any of the levels of leakage. Leakage is a concept that has been thoroughly explored in previous studies of lone-actor terrorism, and prior research has found 
mixed results when looking at leakage between the ideological groups. Some found no significant difference in leakage (Meloy \& Gill, 2016) while other research found that IEs were more likely to have others aware of their planning, RWEs were less likely to make verbal statements about their beliefs, and no significant differences found for providing a pre-event warning or having others aware of their extreme beliefs (Gill et al., 2014). Studies that examine prevalence of leakage overall have found similar results to this study, with the vast majority (between 62.5-79\%) of IEs showing evidence of leakage (Gill et al., 2014; Jasparro, 2010; Meloy \& Gill, 2016) and the majority of RWEs (52.5\% - 88\%) showing some sign of leakage (Gill et al., 2014; Meloy \& Gill, 2016). Studies that looked into leakage of extreme beliefs versus leakage of plans found mixed results. Ellis and colleagues (2016) found results similar to this study, with a higher proportion of their sample of lone-actors being likely to leak their intent to act (44\%) versus their extreme beliefs (35\%). However, Schuurman, Bakker, et al. (2018) found opposite results, with the vast majority of their sample of loneactors leaking extreme beliefs ( $86 \%)$, followed by $58 \%$ who indicated to close associates they were involved in violent activities and $26 \%$ that leaked specific details of committing an attack. However, the difference in the results can likely be explained as that study measured individuals' leakage of beliefs and intent individually, whereas the categories in this study were mutually exclusive: in this study, if an individual had leaked their plans then they were not able to be counted in the extreme beliefs category, which may have resulted in an underrepresentation of leakage of beliefs.

The current study found a significant association between 'authorities aware' and ideology, finding that IEs (32.4\%) were more likely to have the authorities aware of their plans than RWEs (2.7\%), while RWEs (64.9\%) were more likely to have no evidence that the authorities were aware of their plans or activities than IEs (35.1\%). For a number of IEs, the authorities were aware of their intentions to travel to Iraq and Syria to join ISIL and had made attempts to stop them. For example, the authorities were aware of Martin Couture-Rouleau's intentions to travel to Syria and had seized his passport in the months leading up to the attack, but did not have enough evidence to charge him and eventually had to return his passport back to him (case 201412). The variable of 'authorities aware' as defined in this study has not been widely studied in other research, or has been studied in part by variables that are similar to, but not exactly the same. For example, directly communicated threat has been a variable that has been studied in past research, and measured if the suspect has communicated their 
intentions with either the authorities or the target. Meloy and Gill (2016) found no significant differences between the two ideologies, with $21 \%$ of IEs and $16 \%$ of RWEs having directly communicated a threat, while Meloy et al. (2015) found that $13.6 \%$ of their sample of loneactor terrorists had directly communicated a threat. The prevalence for directly communicated threat found in these studies is in between the proportions found for authorities aware of plans for both ideologies in this sample. Two other studies looked at whether the perpetrator was known to authorities: Lindekilde, O'connor, et al. (2019) found that $80 \%$ of volatile actors and $48 \%$ of autonomous actors were known to the authorities during the planning or preparation of a terror attack, but this wasn't necessarily limited to knowledge about the attack plans or extreme beliefs, and Schuurman and colleagues (2018) found that $49 \%$ came into contact with authorities during the attack planning or preparation phase, but only $27 \%$ were suspected of involvement in terror activities. Prior studies have mixed results when compared to this study, as although the proportions found by Lindekilde and colleagues was high for the volatile actors, the results found by Schuurman and colleagues was similar to what was found in this study for the IE sample.

This study found a low proportion of the sample had received assistance from others during the attack planning stage, but no significant differences between the ideologies despite IEs having nearly double the proportion (21.9\%) than RWEs (11.4\%). Assistance from a third party while planning has only been explored by a small number of other studies looking at lone actors. For third party assistance when planning the attack, Gill and associates (2014) found that while IEs were more likely to have assistance in obtaining weapons (32.7\%) than RWEs (10\%), there was no significant difference, which follows the general pattern of IEs receiving more help than RWEs. Schuurman, Bakker, et al. (2018) found that $16 \%$ of their sample had third party assistance during the planning stage and $29 \%$ had assistance during the preparation stage. As both of these stages are comparable to the third party planning category in this study, this means that Schuurman and colleagues found a slightly higher prevalence of assistance in their study than what was found in this study. Another study investigating assistance during the attack planning stage found that no volatile actors but over one-quarter of autonomous actors received assistance (Lindekilde, O'connor, et al., 2019), which is similar to the proportions found in this study.

Level of planning was the final variable coded for in this section, and varying results were found with $40.5 \%$ of IEs being coded as high level of planning compared to $29.7 \%$ of 
RWEs, but $43.2 \%$ of RWEs being coded as low level of planning compared to $25.7 \%$ of IEs. However, no significant differences were found between the two ideological groups. Prior research has explored if planning has existed, rather than determining the level of planning. For example, one variable that has been studied by others is presence of a pathway warning behaviour, which measures if an individual has undertaken any planning or preparation to undertake an attack. Meloy and Gill (2016) found no significant association with ideology, with similar proportions of IEs (76\%) and RWEs (81\%) having exhibited pathway warning behaviour, while Meloy and colleagues (2015) found that their entire sample of lone-actors had exhibited at least one sign of pathway warning behaviour. Another study looked into the presence of planning and found that nearly three-quarters (71\%) of the sample had undertaken some planning for the attack (Schuurman, Bakker, et al., 2018). The extremely high levels of planning that have existed in these other studies are a result of the researchers being able to find at least one indication of planning for the attack. This study has a significant minority of individuals being coded as low level of planning across both ideologies, but as low level of planning can include up to two indications of planning, its results are not comparable to other studies who have coded for presence of planning when viewing only one indicator.

For the majority of the variables in the attack planning category there were no significant differences between the ideological groups, meaning that IEs and RWEs were more alike on those variables than some of the other variables in the research. The current study had mixed results when comparing with past research, which was partially explained by the different methods employed to measure those variables.

\section{Attack Perpetration}

This study found no significant difference between ideology and number of attackers, with the majority of attacks being undertaken by a single perpetrator, with only $9.4 \%$ of IE and $5.7 \%$ of RWE attacks being undertaken by isolated dyads, and only $3.1 \%$ of IE and no RWE attacks being undertaken by isolated triads. These results conform with what has been found by other research that employs a definition of lone-actor terrorism that can include more than one individual if they are operating independently of a wider terror group. For example, Gill and associates (2014) found in their sample that $73.1 \%$ were single actors without command and control links (while 17.6\% were individuals with those links) and $9.2 \%$ were 
individuals operated in an isolated dyad. Similar results were found by Ellis and associates (2016), who found that while the majority (83.3\%) of successful attacks were undertaken by individuals, isolated dyads and isolated triads accounted for $8.3 \%$ of attacks each. Although prior research has looked at the numbers of perpetrators across the ideological groups (e.g. Ellis et al., 2016) no statistical analysis between the ideological groups was undertaken or published. Therefore, no comparison to previous studies can be made at this point in time, but this is a direction that future research may look into.

When looking at number of deaths caused by each attack, this study found no significant difference in the number of deaths, with the same number of individuals killed on average by IEs (3.48) and RWEs (3.54). This number is higher than what has been found in previous research on lone-actors. For example, Eby $(2012)^{40}$ found an average number of deaths at 0.64 , while the Institute for Economics and Peace (2017) found an average rate of one death per attack and Ellis and colleagues (2016) found a higher rate at 1.99 deaths per attack. When looking at average number of injuries, this study also found no significant difference in the number of injuries, even though IEs (17.36) had a higher number of average injuries per attack than RWEs (10.0). However, both averages are much higher than what has been found in other studies on lone-actors, such as Eby (2012) who found an average of 1.79 injuries per attack, and Ellis and colleagues Ellis et al. (2016) who found an average of 4.58 injuries per attack. The higher average of deaths and injuries found in this study compared to others is likely due to two factors. The first, being that one inclusion criteria for this study was that the attack had to cause at least one injury or death to someone other than the perpetrator, which resulted in the vast majority (79.6\%) of attacks that occurred in the countries of interest between 2010-2017 were excluded as they either did not cause a death or injury at all, or only caused a death or injury to the perpetrator. Ellis and colleagues (2016) found that over half (58\%) of the attacks in their study did not result in a death or injury to someone other than the perpetrator, which would account for their lower average compared to this study. Secondly, there are a number of outliers in this research that have skewed the data, as a small number (6.1\%) of attacks have accounted for the majority of the deaths and injuries $(62.8 \%$ and $62.1 \%$ respectively). For example, the Nice truck attack killed 86 individuals and injured 434 more (201610) and the Oslo bombing killed 8 individuals and

\footnotetext{
${ }^{40}$ Eby's definition of lone wolves is limited to individuals who have operated alone
} 
injured a further 209 (201101) While the other studies mentioned in this section may have included some of these cases, due to time period or location studied not one has included all of them.

The current study also found a significant difference between target type and ideology, finding IEs (40.6\%) were more likely to target civilians than RWEs (0\%), while RWEs (62.9\%) were more likely to target social minorities that IEs (15.6\%). Prior research that has explored the differences between the two ideologies did not find any significant differences for target type (Gill et al., 2014); however, this is likely due to the different categories used, as Gill and colleagues (2014) classified their categories as either people or property categories, whereas this study did not make that distinction. Overall, IEs in this study were most likely to target civilians followed by government places or figures (32.8\%) and social minorities whereas RWEs were most likely to target social minorities followed by government places of figures $(22.9 \%)$ and political figures or events (14.3\%). This is in line with other research that has examined target type by ideology. For example, Gruenewald and colleagues (2013a) found that RWEs were most likely to target social minorities (53.2\%) followed by government or military targets $(21.3 \%)$, abortion providers $(17.0 \%)$ and civilians $(8.5 \%)$. In their study on lone-actors in Europe, Ellis and colleagues found that civilians were the biggest group targeted, and $37 \%$ of the perpetrators who targeted civilians were IEs compared to $25 \%$ of RWEs. Their study had a higher representation RWEs as their definition of civilian seemed to include targets that would fall under the social minority category within this research (e.g. Muslims). Most other research that has studied lone-actor populations overall has found that the top two targets were civilians or social minorities, followed by government targets (e.g. Gill \& Corner, 2016; Gill et al., 2014; Spaaij, 2010) ${ }^{41}$, which supports the findings of this study.

The current study found no significant association between ideology and weapon type, finding that firearms were the most popular choice for attacks undertaken by IEs (32.8\%) and RWE (45.7\%), followed by knives or other sharp objects ( $31.3 \%$ and $25.7 \%$ respectively), and vehicles (17.2\% and $11.4 \%$ respectively). Prior studies have not undertaken a statistical analysis to determine the statistical association between weapon type and ideologies. Studies that have examined individual ideologies and their choice of weapons have found similar

\footnotetext{
${ }^{41}$ Spaaij's definition of lone wolf terrorism is limited to individuals who have operated alone
} 
results. For example, Jasparro (2010) found that six out of eight of the successful 'lone-wolf'42 attacks undertaken by IEs utilised a firearm, while the other two utilised a vehicle. Gruenewald and colleagues (2013a) found that $84.8 \%$ used a firearm, while a later study undertaken by Gruenewald and colleagues (2013b) found that the majority of the lone wolves used a firearm (81.6\%) followed by bodily weapon and blunt object, and bomb (all at 5.3\% each). A number of other studies that looked at weapon type used by lone-actor terrorist found that firearms were the most common single weapon used, followed by explosives (Ellis et al., 2016; Institute for Economics and Peace, 2017; Schuurman, Bakker, et al., 2018; Spaaij, 2010). This study found that only a small proportion of attacks undertaken by IEs (10.9\%) and RWEs (5.7\%) utilised explosives as the primary weapon, which is not in line with prior research; however, this is likely explained by this study being limited to those attacks which had actually occurred, whereas some studies listed above included plots as well as attacks (e.g. Ellis et al., 2016; Schuurman, Bakker, et al., 2018). Plots with explosives are far less likely to lead to an attack compared to those with firearms, as plots with explosives involve utilising controlled substances, and are less likely to be undertaken without detection from law enforcement agencies (Ellis et al., 2016).

This study measured what happened to the perpetrators at the end of the attack and found that the most common ending for IEs is that the perpetrator was placed in custody (42.2\%) whereas for RWEs it was that the perpetrator escaped (45.7\%). Nearly one-third of IEs (31.3\%) were killed by authorities compared to a smaller number of RWEs (14.3\%), while both IEs and RWEs had a small proportion of individuals who killed themselves $(3.1 \%$ and 8.6\%). There was no significant association found between ideology type and 'end of attack'. It should be noted that for all attacks the perpetrator was either eventually caught by authorities or died; this variable was capturing what happened in the immediate aftermath of an attack. Only a few studies have captured how the attack has ended for lone-actor populations, and none have undertaken a statistical analysis between the two ideologies. In their study of RWE single actors, Gruenewald and associates (2013a) found that $10.6 \%$ of their sample were killed by police, while $4.3 \%$ committed suicide. Although he did not specifically study death by authorities, Eby (2012) did find that $9 \%$ of his sample of lone wolves had attempted to commit suicide, and approximately $6 \%$ were successful. Overall, prior research

\footnotetext{
${ }^{42}$ This definition of 'lone-wolf' was limited to individuals acting alone.
} 
has found that only small proportion of the sample of lone-actors have committed suicide which is in line with what was found in this study, and that rates for RWEs who were killed by the authorities is similar to what has been found in prior research. For IEs, it's possible that the higher proportion of those that were killed by authorities versus killed by their own hands could be indicative of the perpetrators wish to commit suicide, but as it is a forbidden action in Islam (Muslim Public Affairs Council, 2019) death by the authorities in response to an attack may be viewed as a more permissible action.

The final variable in the attack perpetration section is third party assistance, and no significant association was found between ideology type and third party assistance during the attack perpetration phase, with the vast majority of attacks undertaken there was no assistance given by a third party for both IEs (96.9\%) and RWEs (97.1\%). As mentioned earlier, some other authors investigated assistance from a third party, but this was during the planning and preparation phase, rather than the attack perpetration phase. The decision in this thesis to only code an individual as a perpetrator if they were present while the attack was taking place and adhered to the ideology potentially left a gap where another individual may have been present but would have not been counted as an attacker. Two such instances of this occurred in this dataset. The first involved Ali Muhammed Brown, who had two individuals present with him when he attempted to undertake his third attack in the United States in 2014 (case 201409); however, upon investigation, although the individuals were there for the car-jacking and murder of the individual, there was no indication that they adhered to an IE ideology so this case was coded as one perpetrator with third party assistance during the planning and perpetration phases. The second instance was perpetrated by Mohammed Abdul Kadir in the United Kingdom in 2016, who murdered a man that followed a sect of Islam that he believed to be heretical (case 201603). Kadir had an accomplice who helped him undertake surveillance on the victim, and who drove him immediately before and after the attack but was not present at the murder. Therefore, this was coded as one perpetrator with the accomplice providing assistance during the planning and preparation phase. As there were only three instances of third party assistance during planning, it is possible that this variable could have been merged with the third party assistance during planning variable, to count all instances where third party assistance was given to a perpetrator, regardless of if it happened during the planning or perpetration phase. 
Overall, the findings of the variables in the attack perpetration phases were mainly consistent with what has been found in prior research for individuals who are conducting attacks by themselves, or as isolated dyads or triads. For the majority of variables, there was no significant difference between the ideologies, meaning that the shared similar traits with how they perpetrated an attack.

\section{Differences between IEs and RWE}

The second research question was interested in exploring if there were any significant differences in any of the variables between the two ideologies of interest to this research. This research found a number of significant differences between the two groups, which have been discussed below.

The current research found that RWEs were more likely to be single, less likely to have experienced tertiary level education or higher, less likely to have children, and are significantly older than IEs. For example, Anders Breivik, the perpetrator of the 2011 double attack in Norway (cases 201101 and 201102) was single, did not have children, was 32 years old at the time of the attack and had not attended university or relevant tertiary education. As explored above, most of the past research has also found similar results, indicating that they are strong differences between populations of IE and RWE lone-actors, and studies replicating these variables are also likely to find similar results. Compensatory control theory (Kay et al., 2008) may help to understand the key differences between the ideological groups. The theory argues that when an individual has a perceived loss of control in one area of their life, they are likely to increase their trust in a social or ideological control, which compensates for their perceived failure in personal control. Some variables in which RWEs differ significantly from IEs point to circumstances where individuals may have felt a loss of control in their personal life, such as failure to achieve a high educational achievement, failure to have a persistent intimate sexual relationship, failure to reproduce, or failure to gain or keep permanent employment. Added to that, RWEs are significantly older than IEs which means that they at a stage of life where many of their peers have likely achieved the things they themselves have failed to achieve (e.g. finding a partner and having children). The loss of control that RWEs have experienced indicates that they have compensated for that control by increasing their 
belief in RWE, eventually leading these individuals to perpetrate a terror attack. This suggests that compensatory control is more important to explaining RWE than IE.

The current study also found other significant differences between the two ideological groups, namely that IEs were more likely to be an immigrant, more likely to be a member of or have connections to a designated terror group, more likely to have the authorities aware of their plans or activity, and more likely to target civilians than RWEs. Sageman's (2004) Bunch of Guys theory may shed some light on some of the differences between the two ideological groups. The theory argues that individuals who live in Western society but are detached from their cultural origins would seek friendship with similar others. The detachment would breed resentment to the society they live in, and the socialisation would breed extremism, eventually leading them to join an extremist group. Later applications of subculture theory have theorised that IE is a collective solution to the strain this group of individuals is experiencing (Cottee, 2011). The findings of this study support the Bunch of Guys theory, and may explain the drive towards terrorism for some of the individuals in the IE sample. A main finding was that IEs were more likely to be immigrants (i.e. culturally isolated), more likely to be a member of a designated terror group, and more likely to target civilians (i.e. the representation of the Western society they are living in). Another finding is that IEs are more likely to have the authorities aware of their plans or terrorist activity, with some of the sample had been previously arrested or cautioned for their extreme beliefs. The interaction may breed a distrust for the authorities and intensify their belief in IE. For example, two of the three perpetrators of the 2017 London Bridge Attacks (201715) Khuram Shazad Butt and Youssef Zaghba, were not born in the United Kingdom (UK), had links to designated terror groups, had targeted civilians and were both under investigation by the UK authorities for involvement in terrorist activity. In addition, both suspects had interactions with the authorities about their extreme beliefs and had also been arrested prior to undertaking the attack. It can be concluded that the interactions with authorities did not have the desired effect of stopping terrorism. Rather, as both individuals were suspected of attempting to travel to join Islamic State (Zaghba was detained while travelling to Syria) it can be argued that their interactions with authorities steered them towards conducting a terror attack in the UK. This has implications for law enforcement, as in cases that resemble the ones listed above, interactions with IEs may result in the likelihood of a terror attack increasing, rather than preventing one from occurring. 
Although the current study found a number of key differences between IEs and RWEs, for the majority of the variables there were no significant differences found. Agnew's (2010) General Strain Theory of Terrorism may help to explain why some of the sample has chosen to undertake terrorism. The theory outlines that terrorism is more likely when individuals experience collective strain that is persistent, inflicted unjustly and by others that are viewed by the strained collective as more powerful. Strains can take many forms depending on the groups that the individual belongs or relates to, but three variables can be viewed as potential strains on individuals who undertake lone-actor terrorism: mental health, social isolation and stressors. These three variables can be experienced independently, but also the experience of one may increase the likelihood of the other (e.g. experience of social isolation may increase the risk of mental health difficulties); the current study found that approximately one in nine lone-actors suffered high strain, as they had experienced all three variables prior to undertaking the attack. Further, there were no significant differences found for these variables between the ideological groups, signifying that both groups had similar experiences of strain. These experiences may have driven the individuals towards their extreme beliefs, and down the path of perpetrating terrorism in the name of their ideology.

The current study also found no significant differences between IE and RWE for contact with extremists, third party assistance during the attack planning and attack perpetration stages, number of perpetrators, history of violence and criminal history. These results may be understood through applying the different radicalisation pathways for lone actor terrorists as theorised by Lindekilde and colleagues (2019). They theorise that loneactor radicalisation does not exist in isolation and that there are two main radicalisation pathways. The first is embedded radicalisation, which argues that radicalisation occurs while the individual is embedded within a terror group or wider extremist movement, while the second is peripheral radicalisation, which argues that radicalisation occurs while the individual is on the edge or periphery of a group, meaning they interact with a group or movement but never become fully integrated. Although both pathways involve to some extent a wider terror group or movement, they differ in the individual's level of involvement in that movement. Both pathways result in the individual deciding to take action alone, due to either internal influences (e.g. inability to integrate fully into extremist group or deciding to move at a faster pace than the group) or external influences (e.g. being ostracised from the group for extreme views or undesirable behaviour). The authors further theorised that there 
exists three sub-categories of peripheral lone-actors and two subcategories of embedded lone actors, and those who belong to different sub-categories will have differences in how they interact in extremist movements and progress towards violence. Some of the variables looked at in the current study involve interaction with others, such as contact with extremists, third party assistance (planning and perpetration), and number of perpetrators, while other variables may point to behaviour that some groups may find undesirable for their members, such as presence of criminal history and history of violence. These variables are indicative of either the internal or external influences that result in an individual deciding to perpetrate a lone-actor attack, and will vary depending on the type of radicalisation pathway that the individual took. Radicalisation pathways are ideology-agnostic, and this likely accounts for no interaction between ideology and these variables. However, if the sample was divided and compared by radicalisation pathways instead, these variables would likely have significant differences. This is an area that future research may want to explore.

The current study found no significant differences between the ideologies for the remaining variables: gender, level of planning, training, leakage, employment level, target reconnaissance, number of deaths and injuries, weapon type, and end of attack. For these variables, it can be concluded that there are more similarities between IE and RWE loneactors than there are differences. As Colvin and Pisoiu (2018) highlighted, sub-cultures endorsing extremist violence can hold beliefs that are in opposition to mainstream views while at the same time adhering to some mainstream ideals. The goal of the sub-culture is for the mainstream to adapt the beliefs of the sub-culture, and by doing so vastly different subcultures can actually be more similar than they are different. This research shows that IEs and RWE lone-actor terrorist have a number of similar experiences and attributes, which suggests that although their ideologies may be quite different from each other, IE and RWE are both proponents of beliefs that are opposite to the mainstream in which they operate, and they utilise violence as a mechanism for spreading awareness of their extreme beliefs.

\section{Attacks Perpetrated by Returning Foreign Fighters}

The final research question is interested exploring the role that returning foreign fighters (RFF) play in undertaking lone-actor terror attacks. The current study found that $10.9 \%$ of attacks perpetrated by IEs were undertaken by a RFF. This is similar to what was 
found in past research, with the Institute for Economics and Peace (2017) finding that approximately $11 \%$ of their sample of attackers who had undertaken a lone-actor terror attack in OECD countries between 2008-2017 had visited Syria prior to undertaking the attack.

When looking at attacks over time, the current research did not find an increase in lone-attacks perpetrated over time. As attacks perpetrated by lone-actors overall has increased in this sample over time yet attacks perpetrated by RFF has decreased, it means there are less lone-actor attacks being perpetrated by RFF at the end of the period of study than there was at the start of the period of study. This is surprising as at the end of 2017 , the United Nations estimated that 5600 foreign fighters (or $14 \%$ of the total number) had returned to their home country, many of whom would be able to undertake attacks in their home country (United Nations, 2017).

There are a number of reasons as to why the number of lone-actor attacks undertaken by RFF may not have increased over the period studied. Firstly, those foreign fighters who return to the West may not be willing to undertake an attack. In their study on individuals who had returned from Islamic State territory, Speckhard, Shajkovci, and Yayla (2018) found that the vast majority were defectors who no longer had support for the group, with only $14.3 \%$ being still aligned with or belonging to the Islamic State. In addition, Hegghammer (2013) estimated that only one in eleven RFF had undertaken a terror attack. Secondly, some RFF may have wanted to undertake an attack but were not able to do so successfully, due to the likelihood that the law enforcement and intelligence agencies in their home countries were monitoring all returning foreign fighters. In their study on attacks by Jihadi returnees to Western countries between 1980 and 2016, Malet and Hayes (2018) found that in the cases where data was available, only $30.1 \%$ of RFF were able to undertake a successful attack, with the rest being apprehended by the authorities before the attack occurred. Thirdly, as loneactor attacks are only one type of terror attack perpetrated by individuals, it's possible that RFF would be more likely to undertake an attack either as part of a larger group, or by direction from a wider terror group or movement. For example, the November 2015 coordinated attacks in Paris were discounted from this research as they were undertaken by more than three attackers, who had direction from a wider terrorist organisation, but the attackers included seven individuals who had previously fought for the Islamic state in Iraq and Syria (Cragin, 2017). 
The number of attacks perpetrated by RFF have not increased over time, and with just under one in nine lone-actor attacks in this study being perpetrated by a foreign fighter, the prevalence of RFF undertaking successful lone-actor attacks remains low overall. Although it is important to monitor RFF to ensure they do not undertake an attack, law enforcement and intelligence agencies in Western Countries would be better focusing resources on finding lone-actors who exist outside of the RFF population.

\section{Limitations, and Suggestions for Future Research}

One limitation of the current research is the reliance on open-source information for obtaining information on the perpetrators. Firstly, the sample was obtained through searches on the Global Terrorism Database and internet search engines, which rely on media reporting or unclassified information about terror attacks. Therefore, not all terror attacks would have been captured, rather only the attacks that either gained media attention or were released to the public by the Government of that country. Secondly, although Government reports on events or prior academic research was preferred, they were not available in all cases; media reports were the basis for most of the information used to code variables in this study. reliance on reputable news sources (such as the $\mathrm{BBC}$ ) were preferred but were not always possible in every case. At times information was only available in local news sources, and in some of the European contexts this meant reliance on online translating services such as Google translate. In cases where local news sources had to be relied on, attempts to verify the facts through other sources were made through internet searches. In addition, opensource information would only be reporting on information that the publisher believed to be relevant at the time. This would not always match up with all of the variables in the codebook which resulted in unknown information for some cases.

Another limitation was the lack of prior studies on the ideological sub-groups for loneactor terrorism. In the last ten years there has been more focus on lone-actor terrorism, with more researchers deciding to focus on studying the different ideologies that undertake it. However, some studies that have looked at the different ideological sub-groups have not conducted a comparative analysis between them (e.g. Ellis et al., 2016; Gruenewald et al., 2013a, 2013b; Roy Van Zuijdewijn \& Bakker, 2016) and those that have conducted a comparative analysis are drawing from the same dataset of lone-actor terrorists (Gill et al., 
2014; Meloy \& Gill, 2016) ${ }^{43}$. This has made it difficult for the results of the current study to be put into context of the wider literature.

The third limitation is that this study only includes successful attacks, which are defined as attacks that occurred and that caused death or injury to someone other than the perpetrator. Although a purpose of this research was to study successful attacks between IEs and RWEs, results of the study should be interpreted with caution as they cannot be generalised to all instances of lone-actor terrorism in Western countries, as this research does not include all attacks that have occurred but were not successful, or plots that were disrupted by law enforcement or intelligence agencies.

The current study undertook a comparative analysis between the two ideological groups using a variety of perpetrator and attack characteristics and found no significant differences for employment status and criminal history. However, as described above, prior research has found two strong differences between the groups for these variables, with RWEs being more likely to be unemployed and have a criminal history when compared to IEs. It is not clear if the discrepancy between prior research and the current study is due to how the variables were coded, or due to the profile of those who undertake lone-actor terrorism changing as time goes on. The later explanation is possible, especially considering that the number of attacks perpetrated by lone-actors increased significantly between 2010-2017, which may indicate a change in how terrorism is perpetrated. Exploring potential reasons for this discrepancy utilising a longitudinal analysis including data collected after 2017 could be something that future studies could explore.

For a number of the variables in the current study, no prior research had undertaken a statistical analysis on the difference between the two ideological groups. This includes target reconnaissance, number of perpetrators, number of deaths and injuries, weapon type, end of attack and third party assistance during the attack perpetration phase (which the current study found no significant difference between the two ideological groups), as well as nationality (which the current study found that IEs were more likely to be immigrants, compared to RWE). Future studies that compared the two ideologies for these variables

\footnotetext{
${ }^{43}$ Meloy and Gill's sample included on individual terrorists, while Gill et al.'s expanded this definition to include isolated dyads. Ellis et al., and Roy Van Zuijdewijn and Bakker's definitions of lone-actors includes individuals, isolated dyads and isolated triads
} 
would allow these findings to be evaluated in context of the wider literature, to assist in determining if they are representative of the wider population overall.

Finally, the current study found that attacks perpetrated by RFF decreased between 2010-2017, despite attacks perpetrated by lone-actors increasing during the same period. There are many explanations for this, including that RFF do not wish to conduct terror attacks (potentially because they no longer adhere to the ideology), or they do wish to perpetrate terror attacks but are stopped by law enforcement before they can do so, or they are perpetrating terror attacks but not as lone-actors. To investigate these options, future studies could examine plots and attacks perpetrated by RFF overall and compare that to the number of RFF that have returned to each country. 


\section{Conclusion}

The current study aimed to explore the perpetration of lone-actor terror attacks by IEs and RWE in North America, Western Europe and Australia. It aimed to do so through examining the nature and extent of lone actor terrorism, and by undertaking a comparative analysis between the two ideological groups. It also aimed to explore the impact that the dispersion of foreign fighters from Syria and Iraq had on the perpetration of lone-actor terrorism in foreign countries. In total there were 99 terror attacks perpetrated by 102 loneactors, and the number of attacks across both ideologies has increased significantly between 2010-2017. This likely lends support to the idea of contagion, that individuals are likely to imitate violence perpetrated by other individuals, including from those that share similar beliefs as them, as well as those who adhere to an extremely different ideology.

There were a number of key significant differences found between the two ideological groups, which have provided clear profiles for some of the variables of interest to this study. IEs were more likely to be an immigrant to the country of attack they were born in, were more likely to target civilians, and their plots or extremist activity was more visible to law enforcement and intelligence agencies than RWE. Further, for those who were perpetrating extremist activity, interactions with law enforcement or intelligence agencies (i.e. through deradicalisation programmes or arrests for terrorist activity) did not have the desired impact of stopping the extremist activity, and in some cases might even increase the likelihood of terrorism occurring. This is something for law enforcement and intelligence agencies to consider when determining decradicalisation options for those suspected of a desire to perpetrate an IE attack. Other key findings include that RWE are more likely to be single, less likely to have experienced tertiary level education or higher, less likely to have children, and are significantly older than IEs. This provides a profile of individuals who have failed to achieve attainments that can be important indicators of status in Western society such as experiencing tertiary-level education, an enduring intimate-sexual relationship, and having the opportunity to procreate. This may have driven them towards intensifying their beliefs in RWE as a way to compensate for failures, and can explain why these individuals have perpetrated terrorism. This may assist law enforcement and intelligence agencies in identifying what right-wing suspects may be more likely to perpetrate a terror attack. 
Although there were a number of key differences, for the majority of the variables no significant differences were found between the two ideological groups. Variables which indicate high levels of strain, such as mental health, social isolation, and experience of stressful events preceding the attack are experienced by both IEs and RWE. These variables are shared between the ideological groups, which helps provide a picture on the profile of lone-actors overall. As the two ideological groups had more similarities than differences, this indicates that those who adhere to an IE and RWE ideology may be one and the same, despite believing in quite different ideologies.

The current research also found that although attacks perpetrated by lone-actors increased between 2010-2017, the number of the attacks perpetrated by RFF decreased over the same time period. This does not necessarily mean that RFF are not attempting to undertake attacks, as they may be prevented by detection from law enforcement, or the perpetrators may choose to undertake group terrorism. However, the low proportion and decrease of attacks perpetrated by RFF overtime has highlighted the importance for prevention resources for lone-actor terrorism to not be entirely focused on RFF, as the vast majority of IE attacks are perpetrated by individuals who have not previously been foreign fighters.

Past research has explored the difference in personal and attack characteristics of IES and RWE who perpetrate terrorism, including both foiled plots and unsuccessful attacks, but only for attacks perpetrated up to the end of 2015. By focusing on successful attacks only (those that caused an injury or death to someone other than the perpetrator) the current research has provided the characteristics of individuals who perpetrate terrorism, which may help assist law enforcement and intelligence agencies in identifying those who seek to cause harm to their communities. As the current research found, attacks perpetrated by IE and RWE lone-actors has increased significantly between 2010 and 2017, and 60\% of attacks were perpetrated after 2015, which means that lone-actor terrorism is increasingly becoming more common in Western Countries. The current study has been the first to provide a comparative analysis of IE and RWE lone-actor attacks including 2016 and 2017, and has provide a comprehensive dataset on a number of personal and attack variables of these perpetrators which has enabled important distinctions, as well as shared commonalities to be concluded between the two groups. However, as lone-actor terrorism is increasing significantly, more 
research will be needed to determine what is motivating individuals to perpetrate terrorism, and how might we identify those individuals to stop them from perpetrating attacks. 


\section{Bibliography}

Agnew, R. (2010). A general strain theory of terrorism. Theoretical Criminology, 14(2), 131-153. doi:10.1177/1362480609350163

Agresti, A. (2007). An introduction to categorical data analysis (2nd ed. ed.). Hoboken, NJ: WileyInterscience.

Appleton, C. (2014). Lone wolf terrorism in Norway. The International Journal of Human Rights, 18(2), 127-142. doi:10.1080/13642987.2014.889390

Bakker, E. (2006). Jihadi terrorists in Europe: Their characteristics and the circumstances in which they joined the jihad: an explorator study. . The Hague: Netherlands Institute of Interanational Relations Clingendael.

Bandura, A., Barbaranelli, C., Caprara, G. V., \& Pastorelli, C. (1996). Mechanisms of Moral Disengagement in the Exercise of Moral Agency. Journal of Personality and Social Psychology, 71(2), 364-374. doi:10.1037/0022-3514.71.2.364

Barriga, A. Q., \& Gibbs, J. C. (1996). Measuring cognitive distortion in antisocial youth: Development and preliminary validation of the "how I think" questionnaire. Aggressive Behavior, 22(5), 333343. doi:10.1002/(SICI)1098-2337(1996)22:5<333::AID-AB2>3.0.CO

$2-K$

Beam, L. (1992). Leaderless Resistance. The Seditionist, 12. Retrieved from http://www.louisbeam.com/leaderless.htm

Berntzen, L. E., \& Sandberg, S. (2014). The Collective Nature of Lone Wolf Terrorism: Anders Behring Breivik and the Anti-Islamic Social Movement. Terrorism and Political Violence, 26(5), 1-21. doi:10.1080/09546553.2013.767245

Bjelopera, J. P. (2013). American Jihadist Terrorism: Combating a Complex Threat. Library of Congress. $\begin{array}{llll}\text { Congressional } & \text { Research } & \text { Service. } & \text { Retrieved }\end{array}$ https://digital.library.unt.edu/ark:/67531/metadc83950/m1/1/high res d/R41416 2011No v15.pdf

Bouhana, N., Corner, E., Gill, P., \& Schuurman, B. W. (2018). Background and preparatory behaviours of right-wing extremist lone actors: a comparative study. Perspectives on Terrorism, 12(6), 150-163.

Chermak, S., \& Gruenewald, J. A. (2015). Laying a Foundation for the Criminological Examination of Right-Wing, Left-Wing, and Al Qaeda-Inspired Extremism in the United States. Terrorism and Political Violence: Criminological Theory and Terrorism, 27(1), 133-159. doi:10.1080/09546553.2014.975646 
Colvin, S., \& Pisoiu, D. (2018). When Being Bad is Good? Bringing Neutralization Theory to Subcultural Narratives of Right-Wing Violence. Studies in Conflict \& Terrorism, 1-16. doi:10.1080/1057610X.2018.1452754

Corner, E., \& Gill, P. (2015). A False Dichotomy? Mental Illness and Lone-Actor Terrorism. Law and Human Behavior, 39(1), 23-34. doi:10.1037//hb0000102

Cottee, S. (2011). Jihadism as a Subcultural Response to Social Strain: Extending Marc Sageman's "Bunch of Guys" Thesis. Terrorism and Political Violence, 23(5), 730-751. doi:10.1080/09546553.2011.611840

Cragin, R. K. (2017). The November 2015 Paris Attacks: The Impact of Foreign Fighter Returnees. Orbis, 61(2), 212-226. doi:10.1016/j.orbis.2017.02.005

Eby, C. A. (2012). The Nation that Cried Lone Wolf: A Data-Driven Anlysis of Indivudal Terrorists in the United States Since 9/11. (Master's Thesis). Naval Postgraduate School, Montrery, California. Retrieved from https://apps.dtic.mil/dtic/tr/fulltext/u2/a560635.pdf

Ellis, C., Pantucci, R., de Roy van Zuijdewijn, J., Bakker, E., Smith, M., Gomis, B., \& Palombi, S. (2016). Analysing the Processes of Lone-Actor Terrorism: Research Findings. Perspectives on Terrorism, 10(2), 33-41.

Europol. (2012). Annual Terrorism Situation and Trend Report. Retrieved from The Hague: https://www.europol.europa.eu/sites/default/files/publications/europoltsat.pdf

Gill, P., \& Corner, E. (2016). Lone-Actor Terrorist Target Choice. Behavioral Sciences \& the Law, 34(5), 693-705. doi:10.1002/bsl.2268

Gill, P., Horgan, J., \& Deckert, P. (2014). Bombing Alone: Tracing the Motivations and Antecedent Behaviors of Lone-Actor Terrorists. Journal of Forensic Sciences, 59(2), 425-435. doi:10.1111/1556-4029.12312

Gruenewald, J., Chermak, S., \& Freilich, J. D. (2013a). Distinguishing "Loner" Attacks from Other Domestic Extremist Violence. Criminology \& Public Policy, 12(1), 65-91. doi:10.1111/17459133.12008

Gruenewald, J., Chermak, S., \& Freilich, J. D. (2013b). Far-Right Lone Wolf Homicides in the United States. Studies in Conflict \& Terrorism, 36(12), 1-42. doi:10.1080/1057610X.2013.842123

Hegghammer, T. (2013). Should I stay or should I go? Explaining variation in Western jihadists' choice between domestic and foreign fighting.(Report)(Author abstract). American Political Science Review, 107(1), 1. doi:10.1017/\$0003055412000615

Hegghammer, T., \& Nesser, P. (2015). Assessing the Islamic State's commitment to attacking the West. Perspectives on Terrorism, 9(4), 14-30. 
Heitmeyer, W. (2005). Right-wing terrorism. In T. Bjorgo (Ed.), Root Causes of Terrorism: Myths, Reality and Ways Forward (pp. 141-153). Retrieved from https://ebookcentral.proquest.com/lib/vuw/reader.action?doclD=199597\&query

Huda. (2019). Islamic Marriage and Involvement of Friends and Family. Retrieved from https://www.learnreligions.com/islamic-marriage-2004443

Institute for Economics and Peace. (2015). Global Terrorism Index: Measuring and Understanding the Impact of Terrorism. Retrieved from http://economicsandpeace.org/wpcontent/uploads/2015/11/Global-Terrorism-Index-2015.pdf

Institute for Economics and Peace. (2017). Global Terrorism Index: Measuring and Understanding the $\begin{array}{llll}\text { Impact of Terrorism. } & \text { Retrieved }\end{array}$ http://visionofhumanity.org/app/uploads/2017/11/Global-Terrorism-Index-2017.pdf

Islamic State and the crisis in Iraq and Syria in maps. (2018). BBC News. Retrieved from https://www.bbc.com/news/world-middle-east-27838034

Jasparro, C. (2010). Lone wolf: The threat from independent jihadists. 23(1), 14-19.

Kaplan, J., Lööw, H., \& Malkki, L. (2014). Introduction to the Special Issue on Lone Wolf and Autonomous Cell Terrorism. Terrorism and Political Violence, 26(1), 1-12. doi:10.1080/09546553.2014.854032

Kay, A. C., \& Eibach, R. P. (2013). Compensatory Control and Its Implications for Ideological Extremism. Journal of Social Issues, 69(3), 564-585. doi:10.1111/josi.12029

Kay, A. C., Gaucher, D., Napier, J. L., Callan, M. J., \& Laurin, K. (2008). God and the Government: Testing a Compensatory Control Mechanism for the Support of External Systems. Journal of Personality and Social Psychology, 95(1), 18-35. doi:10.1037/0022-3514.95.1.18

Landis, J. R., \& Koch, G. G. (1977). The measurement of observer agreement for categorical data. Biometrics, 33(1), 159-174. doi:10.2307/2529310

Lindekilde, L., Malthaner, S., \& O'connor, F. (2019). Peripheral and embedded: relational patterns of lone-actor terrorist radicalization. Dynamics of Asymmetric Conflict, 1-22. doi:10.1080/17467586.2018.1551557

Lindekilde, L., O'connor, F., \& Schuurman, B. (2019). Radicalization patterns and modes of attack planning and preparation among lone-actor terrorists: an exploratory analysis. Behavioral Sciences of Terrorism and Political Aggression, 1-21. doi:10.1080/19434472.2017.1407814

Malet, D., \& Hayes, R. (2018). Foreign Fighter Returnees: An Indefinite Threat? Terrorism and Political Violence, 1-19. doi:10.1080/09546553.2018.1497987

Malthaner, S., \& Lindekilde, L. (2017). Analyzing Pathways of Lone-Actor Radicalization:: A Relational Approach. Oakland, California: University of California Press. 
Meloy, J. R., \& Gill, P. (2016). The Lone-Actor Terrorist and the TRAP-18. Journal of Threat Assessment and Management, 3(1), 37-52. doi:10.1037/tam0000061

Meloy, J. R., \& O' Toole, M. E. (2011). The Concept of Leakage in Threat Assessment. Behavioral Sciences \& the Law, 29(4), 513-527. doi:10.1002/bsl.986

Meloy, J. R., Roshdi, K., Glaz-Ocik, J., \& Hoffmann, J. (2015). Investigating the Individual Terrorist in Europe. Journal of Threat Assessment and Management, 2(3-4), 140-152. doi:10.1037/tam0000036

Muslim Public Affairs Council. (2019). Religious views on suicide Retrieved from https://www.mpac.org/programs/anti-terrorism-campaign/islamic-views-regardingterrorism-and-suicidem/religious-views-on-suicide.php

Nacos, B. L. (2009). Revisiting the Contagion Hypothesis: Terrorism, News Coverage, and Copycat Attacks. Perspectives on Terrorism, 3(3).

National Consortium for the Study of Terrorism and Responses to Terrorism. (2018). Global Terrorism Database. Retrieved from https://www.start.umd.edu/gtd/. Retrieved 6 October 2018 https://www.start.umd.edu/gtd/

Nesser, P. (2012). Research Note: Single Actor Terrorism: Scope, Characteristics and Explanations. Perspectives on Terrorism, 6(6), 61-73.

Pantucci, R., Ellis, C., \& Chaplais, L. (2015). Lone Actor Terrorism: Literature Review. Retrieved from London:

https://www.chathamhouse.org/sites/default/files/publications/research/20160105LoneAct orTerrorismLiteratureReviewRUSI.pdf

Perry, S., Hasisi, B. J. T., \& Violence, P. (2015). Rational choice rewards and the jihadist suicide bomber. 27(1), 53-80.

Ribeaud, D., \& Eisner, M. (2010). Are Moral Disengagement, Neutralization Techniques, and SelfServing Cognitive Distortions the Same? Developing a Unified Scale of Moral Neutralization of Aggression. International Journal of Conflict and Violence, 4(2), 299-315. doi:10.4119/UNIBI/ijcv.92

Roy Van Zuijdewijn, J., \& Bakker, E. (2016). Analysing Personal Characteristics of Lone-Actor Terrorists: Research Findings and Recommendations. Perspectives on Terrorism.

Sageman, M. (2004). Understanding Terror Networks. Philadelphia: University of Pennsylvania Press. Schuurman, B., Bakker, E., Gill, P., \& Bouhana, N. (2018). Lone Actor Terrorist Attack Planning and Preparation: A Data-Driven Analysis. Journal of Forensic Sciences, 63(4), 1191-1200. doi:10.1111/1556-4029.13676 
Schuurman, B., Lindekilde, L., Malthaner, S., O'Connor, F., Gill, P., \& Bouhana, N. (2018). End of the Lone Wolf: The Typology that Should Not Have Been. Studies in Conflict \& Terrorism, 1-8. doi:10.1080/1057610X.2017.1419554

Spaaij, R. (2010). The Enigma of Lone Wolf Terrorism: An Assessment. Studies in Conflict \& Terrorism, 33(9), 854-870. doi:10.1080/1057610X.2010.501426

Speckhard, A., Shajkovci, A., \& Yayla, A. (2018). Defected from ISIS or Simply Returned, and for How Long?-Challenges for the West in Dealing with Returning Foreign Fighters. Homeland Security Affairs, xiv.

Sykes, G. M., \& Matza, D. (1957). Techniques of Neutralization: A Theory of Delinquency. American Sociological Review, 22(6), 664-670. doi:10.2307/2089195

Tajfel, H., Billig, M. G., Bundy, R. P., \& Flament, C. (1971). Social categorization and intergroup behaviour. European Journal of Social Psychology, 1(2), 149-178. doi:10.1002/ejsp.2420010202

United Nations. (2017, 29 November 2017). Returning foreign terrorist fighters pose 'enormous challenge with no easy solution,' Security Council told. Retrieved from https://news.un.org/en/story/2017/11/637592-returning-foreign-terrorist-fighters-poseenormous-challenge-no-easy-solution

United Nations Security Council. (2019, 5/11/2019). ISIL (Da'esh) \& Al-Qaida Sanctions List. Retrieved from https://www.un.org/securitycouncil/sanctions/1267/aq sanctions list

van Ginkel, B., Entenmann, E., Chauzal, G., Dorsey, J., Jegerings, M., Paulussen, C., . . Zavagli, S. (2016). The Foreign Fighters Phenomenon in the European Union. Profiles, Threats \& Policies. Terrorism and Counter-Terrorism Studies. doi:10.19165/2016.1.02

Victoroff, J. I., \& Kruglanski, A. W. (2009). Psychology of terrorism : classic and contemporary insights / edited by Jeff Victoroff and Arie W. Kruglanski. Hove: Psychology Press.

Webber, D., \& Kruglanski, A. W. (2018). The social psychological makings of a terrorist. Current Opinion in Psychology, 19, 131-134. doi:10.1016/j.copsyc.2017.03.024

Weenink, A. W. J. P. o. t. (2015). Behavioral problems and disorders among radicals in police files. 9(2), 17-33.

Wikström, P. O. H. (2014). Why crime happens: A situational action theory: Wiley Blackwell.

Wikström, P. O. H., \& Bouhana, N. (2017). Analyzing Radicalization and Terrorism: A Situational Action Theory: wiley. 


\section{Appendix}

Table 14

List of 99 Cases Included in the Current Study

\begin{tabular}{|c|c|c|c|c|c|}
\hline Case ID & Date & Attack description & Perpetrator(s) & Deaths & Injuries \\
\hline 201001 & $18 / 02 / 2010$ & $\begin{array}{l}\text { IRD building plane } \\
\text { crash }\end{array}$ & $\begin{array}{c}\text { Andrew Joseph Stack } \\
\text { III }\end{array}$ & 1 & 13 \\
\hline 201002 & $4 / 03 / 2010$ & Pentagon shooting & John Bedell & 0 & 2 \\
\hline 201003 & $14 / 05 / 2010$ & $\begin{array}{l}\text { MP Stephen Timms } \\
\text { stabbing }\end{array}$ & Roshonara Choudhry & 0 & 1 \\
\hline 201004 & $11 / 12 / 2010$ & Stockholm bombing & Taimour al-Abdaly & 0 & 2 \\
\hline 201101 & $22 / 07 / 2011$ & Oslo bombing & Anders Breivik & 8 & 209 \\
\hline 201102 & $22 / 07 / 2011$ & $\begin{array}{l}\text { Utøya rampage } \\
\text { shooting }\end{array}$ & Anders Breivik & 69 & 33 \\
\hline 201103 & $13 / 12 / 2011$ & $\begin{array}{l}\text { First Florence market } \\
\text { shooting }\end{array}$ & Gianluca Casseri & 2 & 1 \\
\hline 201104 & $13 / 12 / 2011$ & $\begin{array}{l}\text { Second Florence } \\
\text { market shooting }\end{array}$ & Gianluca Casseri & 0 & 2 \\
\hline 201201 & $11 / 01 / 2012$ & $\begin{array}{l}\text { New Jersey } \\
\text { firebombing }\end{array}$ & Anthony Graziano & 0 & 1 \\
\hline 201202 & $11 / 03 / 2012$ & $\begin{array}{c}\text { Toulouse soldier } \\
\text { shooting }\end{array}$ & Mohamed Merah & 1 & 0 \\
\hline 201203 & $12 / 03 / 2012$ & $\begin{array}{l}\text { Brussels mosque arson } \\
\text { attack }\end{array}$ & Rachid El-Boukhari & 1 & 2 \\
\hline 201204 & $15 / 03 / 2012$ & $\begin{array}{c}\text { Montauban soldier } \\
\text { shooting }\end{array}$ & Mohamed Merah & 2 & 1 \\
\hline 201205 & $19 / 03 / 2012$ & $\begin{array}{l}\text { Toulouse Jewish } \\
\text { school shooting }\end{array}$ & Mohamed Merah & 4 & 1 \\
\hline 201206 & 6/08/2012 & $\begin{array}{l}\text { Wisconsin Sikh temple } \\
\text { shooting }\end{array}$ & Wade Michael Page & 6 & 4 \\
\hline
\end{tabular}




\begin{tabular}{|c|c|c|c|c|c|}
\hline 201301 & $15 / 04 / 2013$ & Boston bombing & $\begin{array}{c}\text { Tamerlan Tsarnaev } \\
\text { and } \\
\text { Dzhokhar Tsarnaev }\end{array}$ & 3 & 264 \\
\hline 201302 & 29/04/2013 & Birmingham stabbing & Pavlo Lapshyn & 1 & 0 \\
\hline 201303 & $22 / 05 / 2013$ & Lee Rigby attack & $\begin{array}{l}\text { Michael Adebolajo } \\
\text { and } \\
\text { Michale Adebowale }\end{array}$ & 1 & 0 \\
\hline 201304 & $26 / 05 / 2013$ & $\begin{array}{l}\text { HM prison Full Sutton } \\
\text { hostage attack }\end{array}$ & $\begin{array}{c}\text { Feroz Khan, Fuad } \\
\text { Awale and David } \\
\text { Watson }\end{array}$ & 0 & 2 \\
\hline 201305 & $1 / 11 / 2013$ & LAX shooting & Paul Ciancia & 1 & 3 \\
\hline 201401 & $13 / 04 / 2014$ & $\begin{array}{l}\text { Kansas Jewish } \\
\text { community centre } \\
\text { shooting }\end{array}$ & Frazier Glenn Cross & 2 & 0 \\
\hline 201402 & $13 / 04 / 2014$ & $\begin{array}{l}\text { Kansas Jewish } \\
\text { retirement village } \\
\text { shooting }\end{array}$ & Frazier Glenn Cross & 1 & 0 \\
\hline 201403 & $27 / 04 / 2014$ & Seattle shooting & $\begin{array}{c}\text { Ali Muhammed } \\
\text { Brown }\end{array}$ & 1 & 0 \\
\hline 201404 & $24 / 05 / 2014$ & $\begin{array}{l}\text { Brussels Jewish } \\
\text { museum shooting }\end{array}$ & Mehdi Nemmouche & 4 & 0 \\
\hline 201405 & $1 / 06 / 2014$ & Seattle shooting & $\begin{array}{c}\text { Ali Muhammed } \\
\text { Brown }\end{array}$ & 2 & 0 \\
\hline 201406 & $4 / 06 / 2014$ & RCMP shooting & Justin Bourque & 3 & 2 \\
\hline 201407 & $6 / 06 / 2014$ & $\begin{array}{c}\text { Georgia county } \\
\text { courthouse shooting }\end{array}$ & Dennis Marx & 0 & 1 \\
\hline 201408 & $8 / 06 / 2014$ & Las Vegas shootings & $\begin{array}{l}\text { Jerad Miller and } \\
\text { Amanda Miller }\end{array}$ & 3 & 0 \\
\hline 201409 & $25 / 06 / 2014$ & New Jersey shooting & $\begin{array}{c}\text { Ali Muhammed } \\
\text { Brown }\end{array}$ & 1 & 0 \\
\hline 201410 & $12 / 09 / 2014$ & $\begin{array}{l}\text { Pennsylvania state } \\
\text { trooper shooting }\end{array}$ & Eric Frein & 1 & 1 \\
\hline
\end{tabular}




\begin{tabular}{|c|c|c|c|c|c|}
\hline 201411 & 23/09/2014 & Melbourne stabbing & Abdul Numan Haider & 0 & 2 \\
\hline 201412 & 20/10/2014 & Quebec vehicle attack & $\begin{array}{l}\text { Martin Couture- } \\
\text { Rouleau }\end{array}$ & 1 & 1 \\
\hline 201413 & $22 / 10 / 2014$ & $\begin{array}{c}\text { Canada National War } \\
\text { Memorial shooting }\end{array}$ & Michael Zehaf-Bibeau & 1 & 3 \\
\hline 201414 & $23 / 10 / 2014$ & $\begin{array}{c}\text { New York hatchet } \\
\text { attack }\end{array}$ & Zale H. Thompson & 0 & 3 \\
\hline 201415 & $15 / 12 / 2014$ & $\begin{array}{c}\text { Sydney Lindt café } \\
\text { siege }\end{array}$ & Man Haron Monis & 2 & 4 \\
\hline 201416 & $20 / 12 / 2014$ & $\begin{array}{c}\text { France police station } \\
\text { stabbing }\end{array}$ & $\begin{array}{c}\text { Bertrand } \\
\text { Nzohabonayo }\end{array}$ & 0 & 3 \\
\hline 201501 & $3 / 02 / 2015$ & $\begin{array}{l}\text { Nice Jewish cultural } \\
\text { centre attack }\end{array}$ & Moussa Coulibaly & 0 & 2 \\
\hline 201502 & $14 / 02 / 2015$ & $\begin{array}{l}\text { Copenhagen cultural } \\
\text { centre shooting }\end{array}$ & Omar el-Hussein & 1 & 3 \\
\hline 201503 & $14 / 02 / 2015$ & $\begin{array}{l}\text { Copenhagen } \\
\text { synagogue shooting }\end{array}$ & Omar el-Hussein & 1 & 2 \\
\hline 201504 & $3 / 05 / 2015$ & $\begin{array}{l}\text { Prophet Mohammed } \\
\text { cartoon exhibit } \\
\text { shooting }\end{array}$ & $\begin{array}{c}\text { Elton Simpson and } \\
\text { Nadir Soofi }\end{array}$ & 0 & 1 \\
\hline 201505 & $17 / 06 / 2015$ & $\begin{array}{l}\text { Charleston church } \\
\text { shooting }\end{array}$ & Dylann Roof & 9 & 0 \\
\hline 201506 & $26 / 06 / 2015$ & $\begin{array}{c}\text { France beheading } \\
\text { attack }\end{array}$ & Yassin Salhi & 1 & 2 \\
\hline 201507 & $16 / 07 / 2015$ & $\begin{array}{l}\text { Tennessee Navy } \\
\text { recruiting centre } \\
\text { shooting }\end{array}$ & $\begin{array}{c}\text { Mohammad Youssef } \\
\text { Abdulazeez }\end{array}$ & 5 & 2 \\
\hline 201508 & $17 / 10 / 2015$ & $\begin{array}{l}\text { Henriette Reker } \\
\text { stabbing }\end{array}$ & Frank S. & 0 & 5 \\
\hline 201509 & $22 / 10 / 2015$ & $\begin{array}{c}\text { Sweden school sword } \\
\text { attack }\end{array}$ & $\begin{array}{l}\text { Anton Lundin } \\
\text { Pettersson }\end{array}$ & 3 & 1 \\
\hline
\end{tabular}




\begin{tabular}{|c|c|c|c|c|c|}
\hline 201510 & $4 / 11 / 2015$ & $\begin{array}{l}\text { University of California } \\
\text { stabbing }\end{array}$ & Faisal Mohammad & 0 & 4 \\
\hline 201511 & $6 / 11 / 2015$ & $\begin{array}{c}\text { Los Angeles bus driver } \\
\text { attack }\end{array}$ & K.C. Tard Jr. & 0 & 1 \\
\hline 201512 & $2 / 12 / 2015$ & $\begin{array}{l}\text { San Bernadino } \\
\text { shooting }\end{array}$ & $\begin{array}{l}\text { Syed Rizwan Farook } \\
\text { and Tashfeen Malik }\end{array}$ & 14 & 22 \\
\hline 201513 & $5 / 12 / 2015$ & $\begin{array}{l}\text { Queens convenience } \\
\text { store attack }\end{array}$ & Piro Kolvani & 0 & 1 \\
\hline 201514 & $5 / 12 / 2015$ & London tube stabbing & Muhaydin Mire & 0 & 3 \\
\hline 201601 & $7 / 01 / 2016$ & $\begin{array}{l}\text { Philadelphia police } \\
\text { officer shooting }\end{array}$ & Edward Archer & 0 & 1 \\
\hline 201602 & $11 / 02 / 2016$ & $\begin{array}{l}\text { Ohio restaurant } \\
\text { machete attack }\end{array}$ & Mohamed Barry & 0 & 4 \\
\hline 201603 & $18 / 02 / 2016$ & $\begin{array}{l}\text { Rochdale Imam } \\
\text { hammer attack }\end{array}$ & $\begin{array}{l}\text { Mohammed Abdul } \\
\text { Kadir }\end{array}$ & 1 & 0 \\
\hline 201604 & $18 / 02 / 2016$ & Indiana hatchet attack & Dana Ericson & 0 & 1 \\
\hline 201605 & $24 / 03 / 2016$ & $\begin{array}{c}\text { Glasgow shopkeeper } \\
\text { attack }\end{array}$ & Tanveer Ahmed & 1 & 1 \\
\hline 201606 & $16 / 04 / 2016$ & $\begin{array}{l}\text { Essen Sikh temple } \\
\text { bombing }\end{array}$ & $\begin{array}{l}\text { Yusuf T. and } \\
\text { Mohamed B. }\end{array}$ & 0 & 3 \\
\hline 201607 & $12 / 06 / 2016$ & $\begin{array}{l}\text { Florida nightclub } \\
\text { shooting }\end{array}$ & Omar Mateen & 49 & 53 \\
\hline 201608 & $13 / 06 / 2016$ & $\begin{array}{c}\text { France Police } \\
\text { Commander attack }\end{array}$ & Larossi Abballa & 2 & 0 \\
\hline 201609 & $16 / 06 / 2016$ & Jo Cox shooting & Thomas Mair & 1 & 1 \\
\hline 201610 & $14 / 07 / 2016$ & Nice truck attack & $\begin{array}{c}\text { Mohamed Lahouaiej } \\
\text { Bouhlel }\end{array}$ & 86 & 434 \\
\hline 201611 & 26/07/2016 & $\begin{array}{c}\text { Normandy church } \\
\text { attack }\end{array}$ & $\begin{array}{c}\text { Adel Kermiche and } \\
\text { Abdel Malik Petitjean }\end{array}$ & 1 & 1 \\
\hline
\end{tabular}




\begin{tabular}{|c|c|c|c|c|c|}
\hline 201612 & $10 / 08 / 2016$ & $\begin{array}{c}\text { Ontario explosive } \\
\text { attack }\end{array}$ & Aaron Driver & 0 & 1 \\
\hline 201613 & $10 / 09 / 2016$ & Sydney stabbing & Ihsas Khan & 0 & 1 \\
\hline 201614 & $17 / 09 / 2016$ & Minnesota mall attack & Dahir Ahmed Adan & 0 & 10 \\
\hline 201615 & $17 / 09 / 2016$ & $\begin{array}{l}\text { New York City } \\
\text { bombing }\end{array}$ & Ahmad Khan Rahimi & 0 & 30 \\
\hline 201616 & $28 / 11 / 2016$ & $\begin{array}{c}\text { Ohio State University } \\
\text { attack }\end{array}$ & Abdul Razak Ali Artan & 0 & 11 \\
\hline 201617 & $15 / 12 / 2016$ & $\begin{array}{c}\text { Tweet sent to } \\
\text { deliberately cause an } \\
\text { epileptic fit }\end{array}$ & John Rayne Rivello & 0 & 1 \\
\hline 201701 & $5 / 01 / 2017$ & $\begin{array}{c}\text { Explosion near } \\
\text { Gothenburg asylum } \\
\text { centre }\end{array}$ & Viktor Melin & 0 & 1 \\
\hline 201702 & 29/01/2017 & $\begin{array}{l}\text { Islamic Cultural Centre } \\
\text { of Quebec shooting }\end{array}$ & $\begin{array}{l}\text { Alexandre } \\
\text { Bissonnette }\end{array}$ & 6 & 19 \\
\hline 201703 & $31 / 01 / 2017$ & $\begin{array}{c}\text { Union Station } \\
\text { Colorado shooting }\end{array}$ & Joshua Cummings & 1 & 0 \\
\hline 201704 & $22 / 02 / 2017$ & Kansas bar shooting & Adam Purinton & 1 & 2 \\
\hline 201705 & $18 / 03 / 2017$ & $\begin{array}{l}\text { Paris traffic-stop } \\
\text { shooting }\end{array}$ & Ziyed Ben Belgacem & 0 & 1 \\
\hline 201706 & $20 / 03 / 2017$ & New York City stabbing & James Harris Jackson & 1 & 0 \\
\hline 201707 & $22 / 03 / 2017$ & $\begin{array}{c}\text { Westminster Bridge } \\
\text { attack }\end{array}$ & Khalid Masood & 5 & 50 \\
\hline 201708 & $7 / 04 / 2017$ & Stockholm truck attack & Rakhmat Akilov & 5 & 14 \\
\hline 201709 & $20 / 04 / 2017$ & $\begin{array}{c}\text { Champs-Elysees } \\
\text { shooting }\end{array}$ & Karim Cheurfi & 1 & 3 \\
\hline 201710 & $18 / 05 / 2017$ & $\begin{array}{l}\text { Milan train station } \\
\text { stabbing }\end{array}$ & $\begin{array}{c}\text { Ismail Tommaso } \\
\text { Hosni }\end{array}$ & 0 & 3 \\
\hline 201711 & 19/05/2017 & Tampa shooting & Devon Arthurs & 2 & 0 \\
\hline
\end{tabular}




\begin{tabular}{|c|c|c|c|c|c|}
\hline 201712 & $20 / 05 / 2017$ & $\begin{array}{l}\text { University of Maryland } \\
\text { stabbing }\end{array}$ & Sean Urbanski & 1 & 0 \\
\hline 201713 & $26 / 05 / 2017$ & Portland train stabbing & $\begin{array}{l}\text { Jeremy Joseph } \\
\text { Christian }\end{array}$ & 2 & 1 \\
\hline 201714 & $3 / 06 / 2017$ & $\begin{array}{c}\text { Canadian Tire store } \\
\text { attack }\end{array}$ & Rehab Dughmosh & 0 & 1 \\
\hline 201715 & $3 / 06 / 2017$ & London bridge attack & $\begin{array}{c}\text { Khuram Shazad Butt, } \\
\text { Rachid Redouane and } \\
\text { Youssef Zaghba }\end{array}$ & 8 & 48 \\
\hline 201716 & $5 / 06 / 2017$ & $\begin{array}{c}\text { Melbourne hostage } \\
\text { attack }\end{array}$ & Yacqub Khayre & 1 & 3 \\
\hline 201717 & $6 / 06 / 2017$ & $\begin{array}{c}\text { Notre Dame hammer } \\
\text { attack }\end{array}$ & Farid Ikken & 0 & 1 \\
\hline 201718 & $19 / 06 / 2017$ & $\begin{array}{c}\text { Finsbury Park car } \\
\text { attack }\end{array}$ & Darren Osborne & 1 & 12 \\
\hline 201719 & $21 / 06 / 2017$ & $\begin{array}{c}\text { Michigan airport knife } \\
\text { attack }\end{array}$ & Amor Ftouhi & 0 & 2 \\
\hline 201720 & $28 / 07 / 2017$ & $\begin{array}{l}\text { Hamburg supermarket } \\
\text { attack }\end{array}$ & Ahmad Alhaw & 1 & 6 \\
\hline 201721 & $12 / 08 / 2017$ & $\begin{array}{c}\text { Charlottesville car } \\
\text { attack }\end{array}$ & James Alex Fields Jr. & 1 & 28 \\
\hline 201722 & $18 / 08 / 2017$ & $\begin{array}{c}\text { Turku market square } \\
\text { attack }\end{array}$ & $\begin{array}{l}\text { Abderrahman } \\
\text { Bouanane }\end{array}$ & 2 & 8 \\
\hline 201723 & $25 / 08 / 2017$ & $\begin{array}{l}\text { Buckingham palace } \\
\text { sword attack }\end{array}$ & $\begin{array}{l}\text { Mohiussunnath } \\
\text { Choudhury }\end{array}$ & 0 & 2 \\
\hline 201724 & $15 / 09 / 2017$ & $\begin{array}{l}\text { London tube station } \\
\text { explosive attack }\end{array}$ & Ahmed Hassan & 0 & 51 \\
\hline 201725 & $20 / 09 / 2017$ & Leister car attack & Paul Moore & 0 & 1 \\
\hline 201726 & $30 / 09 / 2017$ & Alberta van attack & Abdulahi Hasan Sharif & 0 & 1 \\
\hline 201727 & $30 / 09 / 2017$ & $\begin{array}{l}\text { Commonwealth } \\
\text { stadium attack }\end{array}$ & Abdulahi Hasan Sharif & 0 & 4 \\
\hline
\end{tabular}




\begin{tabular}{cccccc}
201728 & $1 / 10 / 2017$ & $\begin{array}{c}\text { Marseille train station } \\
\text { stabbing }\end{array}$ & Ahmed Hanachi & 2 & 0 \\
201729 & $8 / 10 / 2017$ & Washington shooting & $\begin{array}{c}\text { Jason Cooper and } \\
\text { Donald Prichard }\end{array}$ & 0 & 1 \\
201730 & $31 / 10 / 2017$ & $\begin{array}{c}\text { New York City truck } \\
\text { attack }\end{array}$ & Sayfullo Saipov & 8 & 12 \\
201731 & $27 / 11 / 2017$ & $\begin{array}{c}\text { Andreas Hollstein } \\
\text { stabbing }\end{array}$ & Werner S. & 0 & 2 \\
201732 & $11 / 12 / 2017$ & $\begin{array}{c}\text { New York City bus } \\
\text { station explosion }\end{array}$ & Akayed Ullah & 0 & 3 \\
\hline & $21 / 12 / 2017$ & Melbourne car attack & Saeed Noori & 1 & 18 \\
\hline
\end{tabular}

